
French Feebate on the Automobile Market"

\author{
Isis Durrmeyer
}




\title{
Winners and Losers: The Distributional Effects of the French Feebate on the Automobile Market*
}

\author{
Short title: Winners \& losers from the French feebate \\ Isis Durrmeyer
}

October 19, 2021

\begin{abstract}
I quantify the welfare and environmental gains and losses from a policy establishing an environmental tax/subsidy for new cars in France in 2008. I estimate a structural model of demand and supply that features heterogeneity in consumer preferences to go beyond the average policy effects and analyse distributional aspects. The policy reduces average carbon emissions by $1.6 \%$ at the cost of additional emissions of local pollutants. The regulation favours middle-income individuals but has redistributive effects when combined with a tax that is proportional to income. Moreover, local pollutant emissions increase least in poor and rural areas, suggesting another redistribution channel.
\end{abstract}

JEL codes: L51, Q51, D12

Keywords: policy evaluation, structural model, distributional effects

\section{Introduction}

Policy evaluation tends to focus on the average or overall impact, often neglecting the importance of distributional effects. For instance, the long-lasting "yellow vests" protests in France, which began in October 2018 and destabilised the government, illustrate the crucial

*Toulouse School of Economics, Université Toulouse Capitole. 1 Esplanade de l'Université, 31080 Toulouse, France. Email: isis.durrmeyer@tse-fr.eu.

I would like to thank Estelle Cantillon, Rob Clark, Allan Collard-Wexler, Pierre Dubois, Xavier D'Haultfœuille, Philippe Février, Gautam Gowrisankaran, Nezih Guner, Nina Leheyda, Laurent Linnemer, Nicolas Martinez, Andrea Pozzi, Mathias Reynaert, Alex Sanz Fernandez, Philipp Schmidt-Dengler, Monika Schnitzer, Giulia Tani, Andre Trindade and Frank Verboven for their helpful comments and suggestions. I would also like to thank the participants of various seminars and conferences. I acknowledge financial support from the Deutsche Forschungsgemeinschaft through SFB-TR 15, the Agence Nationale de Recherche under grants ANR-CAREGUL and ANR-17-EUR-0010 (Investissements d'Avenir program). I would like to thank Pierre-Louis Debar and Julien Mollet from the Comité des Constructeurs Français d'Automobiles for providing me with the data. 
role of distributional effects for public policy acceptance. The movement started with an increase in the diesel tax, a measure with a low expected impact on the overall population that severely penalises suburban and rural households that rely heavily on cars for work and social activities. Another example is the strong reaction of the Chilean population to a small subway fare price increase in October 2019 in the capital city Santiago. Understanding a policy's distributional effects is especially relevant when it favours some individuals at the expense of others. This the case with the 2008 French environmental feebate ("bonus/malus"). This environmental policy introduces a combination of purchase taxes and subsidies for new cars based on their carbon emission levels $\left(\mathrm{CO}_{2}\right)$. The purchase of low-emission vehicles is encouraged through a rebate ("bonus") that reaches up to $€ 1,000$, while the purchase of high-emission cars is discouraged through a tax ("malus") up to $€ 2,600$.

This paper evaluates the 2008 French feebate policy and analyses its distributional effects. There are two types of gains and losses for French households from the feebate policy: a direct effect through the amount spent by individuals and the characteristics of their car purchases and an indirect effect from the air quality. By targeting $\mathrm{CO}_{2}$ emissions, the feebate policy favours diesel cars, which, relative to gasoline cars, are associated with higher emissions of nitrogen oxide $\left(\mathrm{NO}_{\mathrm{X}}\right)$ and particulate matter $(\mathrm{PM})$. These are the most hazardous air pollutants and directly affect the respiratory system. ${ }^{1}$ The increase in emissions of these pollutants caused by the feebate policy is a hidden cost that my policy evaluation takes into account. $\mathrm{NO}_{\mathrm{X}}, \mathrm{PM}$ and other local pollutants downgrade the air quality near their origin, so the question of where they are emitted is relevant. This is, however, not the case of $\mathrm{CO}_{2}$ emissions that generate global pollution. The policy effect on the emissions of local pollutants is heterogeneous across regions and constitutes another source of redistribution across individuals, which I quantify.

I use a structural model for the demand and supply of new automobiles to simulate the market equilibrium (car prices and market shares of the different car models) without the feebate regulation. My model predicts which car models individuals would have purchased and their prices, absent of the feebate policy in 2008, allowing me to identify the causal effect of the feebate regulation from the comparison between the market equilibria with and without the policy. I specify and estimate a demand model that incorporates a high level of heterogeneity in preferences for car attributes and price sensitivities. I leverage granular data on car sales at the local level to identify the heterogeneity parameters: I exploit the correlation between car purchases' characteristics and consumers' demographic characteristics across municipalities. Standard models fail to characterise the winners and losers because they do not specify preference heterogeneity as a function of individual characteristics. In contrast, I link gains or losses from the feebate to households' demographic characteristics. On the supply side, I model the pricing strategies of car manufacturers when they are subject to the feebate regulation and estimate the marginal costs of all the cars proposed on the market.

Finally, I investigate the performance of the actual feebate scheme in redistributing benefits across individuals and car manufacturers and limiting the diesel car share and emissions of

\footnotetext{
${ }^{1}$ The World Health Organization estimates that ambient air pollution caused 4.2 million premature deaths worldwide in 2016.
} 
local pollutants. I measure the potential gains associated with alternative feebate schemes that reach the same $\mathrm{CO}_{2}$ emissions reduction at the same budget cost as the 2008 feebate scheme. Among the set of possible feebate schemes that achieve these two objectives, I identify those that maximise each of the following outcomes: consumer surplus, national manufacturers' profits, reduction of emissions of local pollutants and diesel car share reduction. I consider different weights for each municipality's outcome in the global objective: weights that are simply proportional to the population size; weights that are proportional to the population size and inversely proportional to income; a Rawlsian weighting scheme that puts all weight on the most disadvantaged municipality and a weighting system that takes into account only the difference between the best and the worst outcomes. I focus on three classes of feebate schemes: one that taxes and subsidises equally gasoline and diesel cars and two that penalise diesel cars (with different levels of penalisation).

The identification of the policy effect relies on the assumption that the feebate has a price effect. I do not model and estimate any potential side effects that the regulation could generate. The introduction of taxes and rebates based on $\mathrm{CO}_{2}$ emissions may transmit some information on how society values the environment. It is also plausible that this new policy makes environmental friendliness a more salient car characteristic. D'Haultfœuille et al. (2016) provide evidence of a shift in preferences towards low-emission cars in 2008, suggesting a potential additional policy effect on top of the pecuniary incentives. Because there is no direct evidence that the feebate policy is responsible for the shift in preferences except for the time coincidence, I prefer to focus my analysis on the pure pecuniary incentive effect of the policy.

I adopt a structural approach rather than a reduced-form approach because most of the outcomes of interest, such as consumer surplus and car manufacturer profits, are not directly observable but can be expressed as functions of the model parameters. My model flexibly represents consumers' car choice and converts the policy's impact into monetary terms. Finally, with such a structural approach, it is possible to quantify the impacts of hypothetical feebates used to evaluate the performance of the 2008 feebate.

I find that the policy increases annual welfare by $€ 115$ to $€ 119$ million. This overall welfare effect balance the consumer surplus, car manufacturer profits with the budget cost of the policy for the government and the value of emissions generated or avoided. In addition to $\mathrm{CO}_{2}, \mathrm{NO}_{\mathrm{X}}$ and PM emissions, I account for carbon monoxide (CO) and hydrocarbon (HC) emissions. I find that the French households overall gain from the policy, but if the policy cost is financed by taxing them, their overall surplus decreases by $€ 39$ million. The budget cost of the policy reaches $€ 210$ million that necessitates an average household tax of $€ 23.9$ to be financed. French car manufacturers considerably benefit from the feebate policy, with an increase of $€ 158$ million in their profits. Average $\mathrm{CO}_{2}$ emissions from car purchases decrease by $1.6 \%$ but overall annual new car emissions increase. Once converted in monetary terms, the change in annual $\mathrm{CO}_{2}$ emissions generates a loss of $€ 0.49$ million. This cost can turn into a benefit when taking into account that extra new car sales are old car replacements. Lastly, average emissions of $\mathrm{NO}_{\mathrm{X}}$ and $\mathrm{PM}$ increase, while those of $\mathrm{CO}$ and $\mathrm{HC}$ decrease. Overall, the annual cost of local pollutant emissions increases under all assumptions on the origin of extra new car sales, reducing welfare by $€ 0.015$ to $€ 1.31$ million. 
Beyond the overall policy effect, I find heterogeneous impacts across households and car manufacturers. On the consumer side, the distributional consequences depend on the tax system used to finance the feebate budget cost. Under a uniform tax (identical for all individuals), the feebate scheme favours middle-income individuals. In contrast, if the tax is proportional to income, the feebate achieves some redistribution from the richest to the poorest households. The 2008 feebate performance is high in terms of maximising consumer surplus, with potential gains below 0.5\%. Consumer surplus inequalities could potentially be further reduced by more than $10 \%$. However, this reduction would come at the cost of a decrease in total consumer surplus. On the car manufacturer side, the feebate heavily stimulates French manufacturers at the expense of most German manufacturers and some Asian and American manufacturers. There is little room to improve French car manufacturers' profits; the current feebate scheme achieves more than $99.5 \%$ of the maximum profits obtainable with alternative feebates, depending on the weights assigned to each car manufacturer and the feebate class.

A side effect of the feebate policy is that it pushes individuals to buy cars that, on average, emit $0.5 \%$ more $\mathrm{NO}_{\mathrm{X}}$ emissions and $0.3 \%$ more $\mathrm{PM}$ emissions indicating potential consequences for local air quality. Emissions increase the most in municipalities where they are initially the lowest, implying another type of redistribution in favour of high-emissions municipalities. The municipalities where $\mathrm{NO}_{\mathrm{X}}$ and $\mathrm{PM}$ emissions increase most are rich and dense municipalities, where the diesel car share is initially moderate. However, these municipalities are associated with larger decreases in the average emissions of $\mathrm{CO}$ and $\mathrm{HC}$, reflecting the trade-off between pollutants. The municipalities where emissions increase most are also those where pollution is typically a critical issue. I find that $\mathrm{NO}_{\mathrm{X}}$ emissions increase most in municipalities where nitrogen dioxides in the ambient air are the highest. My assessment of the feebate performance indicates that local pollutants' rise could be lower under alternative feebate schemes. I find that moderate increases in $\mathrm{NO}_{\mathrm{X}}$ and $\mathrm{PM}$ emissions are possible, especially with diesel-penalizing feebates. However, this comes at the cost of higher $\mathrm{CO}$ and $\mathrm{HC}$ emissions, indicating that it is impossible to improve emissions rates for all pollutants simultaneously.

This paper complements two other studies on the effects of the French feebate policy. The first study, by D'Haultfouille et al. (2014), quantifies the short- and long-term impacts of the feebate on $\mathrm{CO}_{2}$ emissions. A second study, by D'Haultfœuille et al. (2016), disentangles the sources of $\mathrm{CO}_{2}$ emissions reduction in the automobile market over the period 2003-2008 and quantifies the role of the feebate policy. These two papers focus on aggregate outcomes only and do not consider the heterogeneity in the feebate's impacts or its distributional consequences. Nor they do consider its collateral effects on the emissions of local air pollutants. The two papers estimate the full policy impact, including its side effect, while my analysis is bounded to the pecuniary effect of the policy. D'Haultfouille et al. (2016) rely, as I do here, on a structural model of demand and supply to describe the car market. In contrast, D'Haultfœuille et al. (2014) identify the feebate's effects on car market shares directly, without relying on an equilibrium model for the automobile market. The identification strategy relies on comparing market shares between 2007 and 2008, controlling for differences in observables. The paper by D'Haultfœuille et al. (2014) also investigates the feebate's effect on total $\mathrm{CO}_{2}$ emissions through the car replacement rate and car production, which 
my analysis neglects. However, the authors cannot balance the environmental policy effects with local pollution and the welfare gains and losses from households and car manufacturers, which I can do.

Other related papers evaluate the impacts of hypothetical and actual environmental policies on the automobile market using structural models. Goldberg (1998) is the first to model and analyse the effects of fuel economy standards in the U.S. Huse (2012) examines the effect of an asymmetric regulation in the Swedish car market: the "green car rebate", which is awarded under different standards depending on whether the car uses fossil fuel or renewable energy. Adamou et al. (2014) evaluate the welfare effects of a hypothetical feebate policy in the German automobile market. Durrmeyer and Samano (2018) compare the efficiency of hypothetical feebate-type policies with fuel economy standards. These studies focus on aggregate effects and do not investigate the distributional consequences of the regulations or their impacts on air quality.

The externalities of $\mathrm{CO}_{2}$-based regulation on local pollution have been theoretically investigated by Ambec and Coria (2013) and empirically by Linn (2019). The latter compares the effects of hypothetical fuel taxes and vehicle taxes on the level of $\mathrm{NO}_{\mathrm{X}}$. He does not rely on the level of car $\mathrm{NO}_{\mathrm{X}}$ emissions as I do here, and the only heterogeneity in $\mathrm{NO}_{\mathrm{X}}$ emissions comes from the fuel type in his model.

The first papers studying the distributional consequences of automobile market regulations focus on gas and carbon taxes. Bento et al. (2009) study the distributional effects of an increase in the gas tax using a model that represents car purchases and car usage, while West (2004) investigates alternative regulations to gas taxes such as vehicle subsidies. A few papers evaluate whether other types of environmental regulations on the automobile market are progressive or regressive. For instance, Jacobsen (2013) estimates the welfare effects of an increase in fuel economy standards by income class. My paper is close to three recent articles that focus on the distributional aspects of different environmental regulations. Davis and Knittel (2019) quantify the distributional effects of fuel economy standards in the U.S. and find that the standards are mildly progressive. Their study differs from mine since they do not rely on an equilibrium model for the car market. Instead, they calculate the implicit subsidy or tax implied by the standard for all cars purchased and use this to measure consumers' gains or losses. Holland et al. (2019) investigate the distributional effects of the introduction of electric vehicles and the consequences of the displacement of emissions from the road to power plants. Finally, Levinson (2019) provides theoretical and empirical evidence that fuel economy standards are more regressive than fuel taxes using household transportation survey data. This study, like Davis and Knittel (2019), does not use a demand and supply model and assumes that agents do not reoptimise their vehicle choice under different tax schemes.

Several recent papers quantify the distributional effects of environmental regulation in contexts other than the automobile market: Bento et al. (2015) use a hedonic regression approach on housing prices to study the distribution of gains and costs related to the Clean Air Act Amendments; Borenstein and Davis (2016) evaluate the effects of tax credits on clean energy in the U.S.; Reguant (2019) analyses the distributional consequences of alternative subsidy schemes for renewable electricity generation; Feger et al. (2020) focus on the distribution of the gains and losses associated with subsidies for solar panels in 
Switzerland.

This paper evaluates the performance of the 2008 feebate setup by comparing its outcomes to those of optimal schemes associated with given objective functions and outcomes. This study contributes to the literature on optimal environmental regulation in line with the recent papers by Holland et al. (2016) and Allcott and Kessler (2019). The former computes the optimal electric vehicle purchase taxes or subsidies when they can be geographically differentiated. The latter paper derives the optimal targeting of individuals in an energy conservation information programme.

From a methodological point of view, this paper uses a combination of aggregate and individual data to estimate demand and supply. Unlike Berry et al. (2004) and Petrin (2002), I do not observe individual car purchases with direct links between individual choices and demographic characteristics. Instead, I exploit the correlation between the average characteristics of cars purchased and the average demographic characteristics of the local municipality. The way I use local-level data, and the estimation method closely follow Nurski and Verboven (2016).

The remainder of the paper proceeds as follows. The next section presents the feebate policy, describes the data and provides some descriptive evidence. In Section 3, I describe the structural model of the market equilibrium and the estimation method. Section 4 presents the model specification and the estimation results. In Section 5, I analyse the aggregate and distributional effects of the feebate policy and evaluate the performance of the feebate scheme. Finally, Section 6 concludes.

\section{Institutional details and data}

\subsection{The feebate policy}

The environmental feebate policy was announced at the end of November 2007 and was applied on January $1^{\text {st }}, 2008$. This policy was one of several measures taken by the government following the Grenelle Environnement roundtables addressing environmental issues. The main objective of this policy was to reduce $\mathrm{CO}_{2}$ emissions related to automobiles. The policy was announced as permanent and was supposed to be neutral for the state budget. Its actual cost reached $€ 294$ million in 2008 and $€ 626$ million in 2009, according to the official figures provided in the report of the CGDD (2013), the former French ministry of ecology. The report notes that two factors were not well accounted for in the model prediction: an increase in fuel prices and the high popularity of low-emission cars. The feebate scheme includes rebates and taxes associated with nine classes of $\mathrm{CO}_{2}$ emissions (see Table 1 below). The amounts of the rebates and taxes were supposed to remain constant, whereas the thresholds were to be reduced by five grams per kilometre (g/km hereafter) each year from 2010 onwards to take into account technical progress. I focus only on the feebate effects for the year 2008 because car manufacturers were not able to react to the policy by modifying their car characteristics and car assortment between November 2007 and 2008 but rather reacted to the policy by changing their car prices, a change that is possible to credibly model. The quantification of 
the welfare effects after 2008 is more challenging since it requires a model with endogenous product characteristics (see Klier and Linn, 2012).

As Table 1 shows, the amounts of the rebates and fees represent a non-negligible percentage of the purchase prices and reach $8 \%$ of the gross price for class A. They are also rather heterogeneous across classes, indicating that the feebate scheme affected the market equilibrium in a non-symmetric way.

Table 1: Feebate scheme in 2008

\begin{tabular}{lccc}
\hline \hline $\begin{array}{l}\text { Class of } \\
\text { emissions }\end{array}$ & $\begin{array}{c}\text { Emissions } \\
(\text { in } \mathrm{g} / \mathrm{km})\end{array}$ & $\begin{array}{c}\text { Feebate } \\
(\text { in } € \text { ) }\end{array}$ & $\begin{array}{c}\text { Percentage of } \\
2007 \text { prices }\end{array}$ \\
\hline $\mathrm{A}$ & $(60-100]$ & $-1,000$ & $8.0 \%$ \\
$\mathrm{~B}$ & $(100-120]$ & -700 & $4.6 \%$ \\
$\mathrm{C}+$ & $(120-130]$ & -200 & $1.1 \%$ \\
$\mathrm{C}-$ & $(130-140]$ & 0 & $0.0 \%$ \\
$\mathrm{D}$ & $(140-160]$ & 0 & $0.0 \%$ \\
$\mathrm{E}+$ & $(160-165]$ & +200 & $-0.93 \%$ \\
$\mathrm{E}-$ & $(165-200]$ & +750 & $-3.1 \%$ \\
$\mathrm{~F}$ & $(200-250]$ & $+1,600$ & $-4.2 \%$ \\
$\mathrm{G}$ & $>250$ & $+2,600$ & $-5.2 \%$ \\
\hline \hline
\end{tabular}

Note: the feebate is positive for a fee and negative for a rebate.

\subsection{Data}

In this analysis, I combine two main datasets. The first one was obtained from the French Syndicate of Car Manufacturers ("Comité des Constructeurs Français d'Automobiles", CCFA) and contains information about new car characteristics and sales from 2003 to 2008 at the municipality level. This database is constructed from the records of all registrations of new cars purchased by French households. I observe the main car characteristics (horsepower, weight, cylinder, type of fuel, and body style), including the level of $\mathrm{CO}_{2}$ emissions (from driving cycle tests) and the catalogue price. The level of $\mathrm{CO}_{2}$ emissions from tests is likely to underestimate true $\mathrm{CO}_{2}$ emissions, as pointed out by Reynaert and Sallee (2021). However, this is not problematic for estimates of the changes in $\mathrm{CO}_{2}$ emissions in percentage terms as long as the bias reflects a constant factor proportional to the true emissions and is uniform across cars and car manufacturers, an assumption adopted by Reynaert and Sallee (2021).

I constructed the second dataset that contains the demographic characteristics of the households for 31,588 of the 36,569 municipalities in France; these data were obtained from several publicly available datasets provided by the French National Survey Institute (see INSEE). ${ }^{2}$ The dataset combines information on the median income level and the number of households for each year between 2003 and 2008 with data from the 2008 census on household size and socio-professional activities.

\footnotetext{
${ }^{2}$ Some municipalities are dropped from my sample because some of their statistics are missing; these are very small municipalities. Note that the three largest cities (Paris, Marseille and Lyon) are split into smaller units, "arrondissement".
} 


\subsection{Assumptions on emissions}

Emissions of local pollutants. Because the CCFA data do not provide information on emissions of local pollutants for each car model, I estimate these emissions from observable car characteristics using a reduced-form equation. To do so, I rely on two datasets from the French Energy Agency (ADEME) and the UK Vehicle Certification Agency that provide information on the emissions levels of all car models. Details on the data, the reduced-form model and the results are provided in Appendix A. I find that the predicted emissions are in line with the observed emissions for 2008 in the UK data. $\mathrm{NO}_{\mathrm{X}}$ and $\mathrm{PM}$ are much higher for diesel engines than for gasoline engines. In contrast, emissions of $\mathrm{CO}$ and $\mathrm{HC}$ are lower for diesel engines than for gasoline engines. This pattern is consistent with differences in the emissions technology of the different engines and the observed emissions in the ADEME and UK data. ${ }^{3}$ I also estimate the same reduced-form equation for $\mathrm{CO}_{2}$ emissions and use the comparison between the observed and predicted values to test the external validity of the prediction model. I find a high correlation coefficient of 0.88 between true $\mathrm{CO}_{2}$ emissions and predicted emissions across car models, indicating that the prediction model is able to capture the heterogeneity in emissions of different car models.

To understand how the feebate, which is based on $\mathrm{CO}_{2}$ emissions, may affect the emissions of other pollutants, I analyse the correlations between the different pollutants (see Table 12 in Appendix A.2). $\mathrm{CO}_{2}$ emissions are positively correlated with those of $\mathrm{CO}(0.17)$ and $\mathrm{HC}(0.26)$ and negatively correlated with those of $\mathrm{NO}_{\mathrm{X}}(-0.23)$ and $\mathrm{PM}(-0.18)$. The high negative correlations between $\mathrm{CO}_{2}$ and $\mathrm{NO}_{\mathrm{X}}$ and $\mathrm{PM}$ emissions are, however, almost entirely driven by the differences between diesel and gasoline cars since the correlation between $\mathrm{CO}_{2}$ and $\mathrm{NO}_{\mathrm{X}}$ becomes positive within fuel types, while the within-fuel-type correlation between $\mathrm{CO}_{2}$ and PM is almost zero. The effect of the feebate on $\mathrm{NO}_{\mathrm{X}}$ and PM emissions, therefore, depends crucially on whether individuals mostly substitute towards lower $\mathrm{CO}_{2}$-emitting cars within the same fuel type or switch fuels.

The demand model includes an outside option, which is the choice not to buy a new car. Since the feebate policy is likely to modify the fraction of households choosing the outside option, it is important to estimate the level of emissions generated by the outside option. The main assumptions and the estimates are presented in Appendix A.3. Because the outside option includes a fraction of non-drivers, the emissions from the outside option are lower than those of an average new car in 2008 for $\mathrm{CO}_{2}$ and $\mathrm{NO}_{\mathrm{X}}$. This is not the case for PM, CO and HC. The emissions from the outside option are $60 \%$ higher than those from new cars in 2008. This indicates that, by stimulating sales and replacement of old, polluting vehicles with new vehicles associated with low emissions levels, the feebate is likely to affect total emission non-uniformly across pollutants.

Cost of emissions. To perform a cost-benefit analysis of the feebate regulation, I need estimates of the social costs of $\mathrm{CO}_{2}$ emissions and air pollutant emissions. For $\mathrm{CO}_{2}$ emissions,

\footnotetext{
${ }^{3}$ The exception is PM, for which I predict higher emissions for diesel than gasoline cars in 2008, whereas, in 2012-2015, the average PM emissions are higher for gasoline than diesel cars. This ranking difference is explained by a change in emissions standards between the two periods. Indeed, between Euro 4 and Euro 5 standards, diesel cars' maximum PM emissions level was divided by five.
} 
I use the uniform value of $€ 40$ per ton, which is close to the value estimated by the U.S. Environmental Protection Agency. ${ }^{4}$ It also corresponds to the lowest value suggested by the European Commission (see the report of the DG MOVE, 2014). For the cost of air pollution, I include only the damage cost estimates for $\mathrm{NO}_{\mathrm{X}}, \mathrm{PM}$ and $\mathrm{HC}$, following the literature (there is not enough evidence of a causal direct adverse effect of $\mathrm{CO}$ on health); I use the estimates for France provided in the report of the DG MOVE (2014) which are displayed in the first row of Table 16 in Appendix C. The air pollution cost of PM depends on the density of the municipality: it costs almost twice as much in suburban areas as in rural areas and more than six times more in urban areas.

The annual car emissions are computed assuming gasoline cars are driven 10,000 kilometres, while diesel cars are driven 17,000 kilometres. ${ }^{5}$ Combined with the pollution cost estimates, I estimate the annual average local air pollution cost per car to be $€ 38$ in 2008 , and the average annual carbon cost of a car to be $€ 95$. For a diesel car, the average local pollution cost is between $€ 50$ (in rural areas) and $€ 77$ (in urban areas), and the $\mathrm{CO}_{2}$ cost is $€ 111$. In contrast, the average local pollution cost for a gasoline car is between $€ 5$ and $€ 9$, and its $\mathrm{CO}_{2}$ emissions cost is $€ 74$. The difference between diesel and gasoline comes from two factors. First, diesel cars are assumed to be driven 7,000 more kilometres, mechanically inflating the annual emissions and their costs. Second, diesel cars emit more $\mathrm{NO}_{\mathrm{X}}$ and PM, the costliest pollutants.

An emissions increase may be more costly in areas where emissions are initially high than in areas where they are low. To approximate such heterogeneity in emissions costs, I estimate an emission cost for each pollutant and municipality based on the pollution levels of the municipality. More precisely, I suppose a municipality emissions cost is a simple function of the emissions level of the municipality and calibrate this function such that the average national emissions cost is equal to the uniform value suggested by the report of the DG MOVE (2014). I consider four different functions: linear, quadratic, discontinuous-uniform and discontinuous-linear. For the discontinuous functions, the cost is null for emissions below the median emissions level and uniform or linear above this median level. I consider three proxies for the initial emissions levels of the municipalities. The first is the municipality's average new car emissions in 2008 in the absence of the feebate. The second proxy is local estimates of annual average air emissions concentrations. I rely on emissions concentrations of nitrogen dioxide $\left(\mathrm{NO}_{2}\right)$, atmospheric particles with a diameter of 10 micrometres or less (PM10) and benzene (as a proxy for HC) estimated using data from air pollution measurement stations in France. The data (from ATMO and EEA), model and results for the prediction of the air emissions concentrations are presented in Appendix B. The third proxy is simply the population density, measured by the number of households divided by the municipality surface area, reflecting that pollution constitutes a critical issue in the most densely populated areas. $^{6}$ I provide the details on the calibration and statistics about the distribution of estimated costs across municipalities in Appendix C.

\footnotetext{
${ }^{4}$ See https://19january2017snapshot.epa.gov/climatechange/social-cost-carbon_.html, last accessed: 1 July 2021.

${ }^{5}$ These figures represent the average kilometres driven by diesel and gasoline cars in France in 2007 (see D'Haultfœuille et al., 2014).

${ }^{6}$ See Opendatasoft for the municipality surface area data.
} 


\subsection{Descriptive evidence}

I correlate car purchase characteristics with demographic characteristics across French municipalities through descriptive regressions. The estimated parameters provide information about correlations and are not interpreted as causal effects. I regress the average car price (gross of feebate in 2008), rebate, diesel car share, $\mathrm{CO}_{2}$ emissions and emissions of local pollutants on income, income squared, the share of households according to different sizes within the municipality, the share of households reporting different professional activities within the municipality, and municipality size (rural, with less than 20,000 inhabitants; urban, with between 20,000 and 200,000 inhabitants; and very urban, with more than 200,000 inhabitants). I also include year interacted with the county ("departement") fixed effects to flexibly control for the general evolution of car purchases over time. ${ }^{7}$ The percentage of households in each category is multiplied by 10 , so the parameters are interpreted as the effects of a $10 \%$ increase in the percentage of households in the category.

Heterogeneity of purchases. The first three columns of Table 2 show that the demographic characteristics are significantly correlated with the average price, the average rebate and the fuel type of the cars purchased. Not surprisingly, I observe that higher incomes and high socio-professional categories (entrepreneurs and executives) are associated with higher prices, lower rebates and lower shares of diesel cars. Individuals living in rural areas tend to buy more diesel cars and receive more rebates, but they also tend to spend more. Finally, cars are slightly cheaper in 2005-2007 than in 2003, while the average price paid decreases considerably in 2008 (-€1,720). This price change in 2008 may be the consequence of both demand and supply effects. Consumers likely choose more fuel-efficient cars to obtain rebates, which are also cheaper cars. On the supply side, car manufacturers probably decrease the gross prices of polluting vehicles in response to the feebate. Finally, there is an increasing trend in the diesel car share, with a structural break in $2008(+5.5 \%$ in 2008 versus an average trend of 2.1\% over 2003-2007). In addition to providing evidence on the heterogeneity of purchase patterns, the significant correlations support the identification strategy for the heterogeneity parameters, which leverages the covariance between the demographic characteristics and the car purchase characteristics across municipalities.

Heterogeneity of emissions. The correlations between the average emissions of cars purchased and the demographic characteristics across municipalities reveal interesting patterns. First, the patterns for $\mathrm{NO}_{\mathrm{X}}$ and $\mathrm{PM}$ emissions are closely related and share many similarities with the correlations between demographics and the share of diesel cars. Second, the signs of the correlations between demographic characteristics and $\mathrm{HC}$ and $\mathrm{CO}$ emissions are identical most of the time and are in line with the correlations between demographic characteristics and $\mathrm{CO}_{2}$ emissions. This is not surprising given the positive correlation between $\mathrm{CO}_{2}$ and $\mathrm{CO}$ and $\mathrm{HC}$ emissions. These results suggest that it is crucial to know whether car buyers are willing to switch fuel to take advantage of rebates and avoid taxes to determine the feebate's impact on local pollutant emissions. High incomes and urban areas are associated with

${ }^{7}$ The county unit is the second smallest level of aggregation after the municipality, with 96 different counties in mainland France. 
high $\mathrm{CO}_{2}, \mathrm{CO}$ and $\mathrm{HC}$ emissions but low $\mathrm{NO}_{\mathrm{X}}$ and $\mathrm{PM}$ emissions. High socio-professional categories tend to buy cars with high $\mathrm{CO}_{2}, \mathrm{NO}_{\mathrm{X}}$ and $\mathrm{PM}$ emissions. There is a negative time trend for $\mathrm{CO}_{2}$ emissions, with notable reductions in 2006 and 2008 (this is consistent with the findings of D'Haultfœuille et al., 2016, who analyse the different sources of the decrease in $\mathrm{CO}_{2}$ emissions from 2003-2008 and observe a sharp reduction in average $\mathrm{CO}_{2}$ emissions in 2006 as a reaction to the introduction of car energy labels). The time trends in emissions of local pollutants are heterogeneous across pollutants. Average $\mathrm{NO}_{\mathrm{X}}$ emissions increase between 2007 and 2008, suggesting an effect of the feebate policy. PM emissions decrease between 2007 and 2008 but by much less than the annual decrease between 2004 and 2007, indicating a possible feebate impact. In contrast, $\mathrm{CO}$ and $\mathrm{HC}$ emissions consistently decrease between 2003 and 2008, with more significant declines in 2008 than in the previous years. All these correlations indicate that the year of the feebate introduction is peculiar, revealing that the feebate probably affects all emissions.

Reaction of car manufacturers. To obtain a sense of whether and how car manufacturers have reacted to the feebate regulation instituted in 2008, I first provide a simple regression of the net prices on the amount of the rebate/fee and use the car characteristics, car models and year fixed effects as controls. This regression is not weighted by car market shares to eliminate the demand effect. The coefficient of the rebate reflects the percentage of the rebate or fee that is passed through to the final price paid by consumers. I find that approximately $58 \%$ of the rebate or fee is passed through to the final price, which indicates a probable reaction of car manufacturers. The regression also indicates that in 2008, the average price of cars decreases more than in previous years: the average price decreases by $€ 137$ in 2008 , compared to only $€ 88$ in 2007 . This stronger reduction in price may be the consequence of strategic interactions between car manufacturers: the feebate modifies the entire price equilibrium, including the prices of cars not directly affected. The structural model below describes the manufacturers' optimal pricing strategies and the optimal responses to the feebate.

To check for signs of policy anticipation by French car manufacturers in the data, I use a difference-in-differences approach to compare the $\mathrm{CO}_{2}$ emissions of French manufacturers with those of other car manufacturers after the policy's introduction. If the design of the feebate policy were the consequence of lobbying, we could expect French lobbyists to be more active than lobbyists for foreign car manufacturers. I regress the $\mathrm{CO}_{2}$ emissions of all cars (not weighted by their market shares) on year dummies, a dummy for French car manufacturers and an interaction term between the French dummy and the year 2008. The results suggest no sign of anticipation by French manufacturers, and this is robust across specifications. The details of the regressions investigating the supply-side reactions are provided in Tables 17 and 18 in Appendix D.1.

\section{Model}

In this section, I present a model of demand and supply for new automobiles both under and in the absence of the feebate regulation. The model allows for heterogeneous preferences 
Table 2: Regression of the average characteristics of car purchases on the demographic characteristics of the municipality

\begin{tabular}{|c|c|c|c|c|c|c|c|c|}
\hline & Price & Rebate & $\%$ Diesel & $\mathrm{CO}_{2}$ & $\mathrm{NO}_{\mathrm{X}}$ & $\mathrm{PM}$ & $\mathrm{CO}$ & $\mathrm{HC}$ \\
\hline Income & $\begin{array}{l}6.29^{* *} \\
(1.16)\end{array}$ & $\begin{array}{l}-1.81 \\
(1.54)\end{array}$ & $\begin{array}{l}-1.35 \\
(0.853)\end{array}$ & $\begin{array}{l}3.26 \\
(0.432)\end{array}$ & $\begin{array}{l}2.6 \\
(1.32)\end{array}$ & $\begin{array}{c}-0.638 \\
(0.691)\end{array}$ & $\begin{array}{l}5.93^{* *} \\
(2.04)\end{array}$ & $\begin{array}{l}3.96 \\
(0.482)\end{array}$ \\
\hline Income $^{2}$ & $\begin{array}{c}-0.287 \\
(0.256)\end{array}$ & $\begin{array}{c}-0.554^{\dagger} \\
(0.283)\end{array}$ & $\begin{array}{l}-1.52^{* *} \\
(0.185)\end{array}$ & $\begin{array}{c}0.006 \\
(0.1)\end{array}$ & $\begin{array}{l}-3.28^{* *} \\
(0.297)\end{array}$ & $\begin{array}{l}-1.1^{* *} \\
(0.15)\end{array}$ & ${ }_{(0.429)}^{2.32}$ & $\begin{array}{c}-0.154 \\
(0.11)\end{array}$ \\
\hline \%Couple & $\begin{array}{l}3.15 \\
(0.154)\end{array}$ & $\begin{array}{c}-0.161 \\
(0.241)\end{array}$ & $\begin{array}{l}3.77^{* *} \\
(0.101)\end{array}$ & $\begin{array}{c}-0.171^{* *} \\
(0.054)\end{array}$ & $\begin{array}{l}5.43 \\
(0.158)\end{array}$ & $\begin{array}{l}2.5^{* *} \\
(0.09)\end{array}$ & $\begin{array}{c}-8.24^{* *} \\
(0.26)\end{array}$ & $\begin{array}{l}-1.55^{* *} \\
(0.055)\end{array}$ \\
\hline$\%$ Family & $\begin{array}{l}1.42 \\
(0.108)\end{array}$ & $\begin{array}{l}0.783^{* *} \\
(0.156)\end{array}$ & $\underbrace{}_{(0.078)}$ & $\begin{array}{c}-0.359^{* *} \\
(0.042)\end{array}$ & $\begin{array}{l}4.25 \\
(0.122)\end{array}$ & $\begin{array}{l}1.97 \\
(0.063)\end{array}$ & $\begin{array}{l}-6.37^{* *} \\
(0.188)\end{array}$ & $\frac{-1.12^{* *}}{(0.044)}$ \\
\hline$\%$ Farmer & $\begin{array}{l}3.09 \\
(0.295)\end{array}$ ** & $\begin{array}{l}-0.08 \\
(0.541)\end{array}$ & $\begin{array}{l}5.32 \\
(0.198)\end{array}$ ** & $\begin{array}{c}-0.094 \\
(0.111)\end{array}$ & $\begin{array}{l}8.18 \text { ** } \\
(0.309)\end{array}$ & $\begin{array}{l}3.47^{* *} \\
(0.18)\end{array}$ & ${ }_{(0.511)}^{-13^{* *}}$ & $\begin{array}{l}-2.1^{* *} \\
(0.1)\end{array}$ \\
\hline$\%$ Entrepreneur & $\begin{array}{l}9.377^{* *} \\
(0.459)\end{array}$ & $\begin{array}{l}-4.21^{* *} \\
(0.588)\end{array}$ & $\begin{array}{l}1.82 \\
(0.331)\end{array}$ & $\begin{array}{l}3.02 \\
(0.183)\end{array}$ & $\begin{array}{l}2.63 \\
(0.482)\end{array}$ & $\begin{array}{l}1.93 \\
(0.259)\end{array}$ & $\begin{array}{l}-7.7^{* *} \\
(0.791)\end{array}$ & $\begin{array}{l}-1.17^{* *} \\
(0.172)\end{array}$ \\
\hline$\%$ Executive & $\begin{array}{l}3.69 \\
(0.281)\end{array}$ & $\begin{array}{l}-1.02^{* *} \\
(0.376)\end{array}$ & $\begin{array}{l}0.762^{* *} \\
(0.184)\end{array}$ & $\begin{array}{l}0.775^{* *} \\
(0.097)\end{array}$ & $\begin{array}{l}0.898^{* *} \\
(0.285)\end{array}$ & $\begin{array}{c}0.089 \\
(0.16)\end{array}$ & $\begin{array}{c}-3.39^{* *} \\
(0.46)\end{array}$ & $\begin{array}{c}-0.524^{* *} \\
(0.111)\end{array}$ \\
\hline$\%$ Intermediate & $\begin{array}{c}-0.305 \\
(0.226)\end{array}$ & $\begin{array}{l}0.996^{* *} \\
(0.345)\end{array}$ & $\begin{array}{l}2.06 \\
(0.139)\end{array}$ & $\begin{array}{c}-0.679^{* *} \\
(0.08)\end{array}$ & $\begin{array}{l}2.72 \\
(0.222)\end{array}$ & $\begin{array}{l}1.633^{* *} \\
(0.128)\end{array}$ & $\begin{array}{l}-6.1^{* *} \\
(0.358)\end{array}$ & $\begin{array}{l}-1.21^{* *} \\
(0.074)\end{array}$ \\
\hline \%Employee & $\begin{array}{l}0.072 \\
(0.243)\end{array}$ & $\begin{array}{c}-0.367 \\
(0.346)\end{array}$ & $\begin{array}{c}-0.105 \\
(0.175)\end{array}$ & $\begin{array}{l}0.206^{*} \\
(0.098)\end{array}$ & $\begin{array}{l}-0.24 \\
(0.256)\end{array}$ & $\begin{array}{l}0.567^{* *} \\
(0.142)\end{array}$ & $\begin{array}{l}-1.66^{* *} \\
(0.417)\end{array}$ & $\begin{array}{c}-0.179^{*} \\
(0.091)\end{array}$ \\
\hline \%Manual labourer & $\begin{array}{l}1.12 \\
(0.209)\end{array}$ & $\begin{array}{l}0.52 \\
(0.347)\end{array}$ & $\begin{array}{l}2.73 \\
(0.159)\end{array}$ & $\begin{array}{c}-0.585^{* *} \\
(0.085)\end{array}$ & $\begin{array}{l}4.17 \\
(0.238)\end{array}$ & $\begin{array}{l}1.65^{* *} \\
(0.126)\end{array}$ & $\begin{array}{l}-7.27^{* *} \\
(0.382)\end{array}$ & $\begin{array}{l}-1.11^{* *} \\
(0.082)\end{array}$ \\
\hline$\%$ Other & $\begin{array}{l}0.861^{* *} \\
(0.203)\end{array}$ & $\begin{array}{l}0.08 \\
(0.276)\end{array}$ & $\begin{array}{l}0.465^{* *} \\
(0.147)\end{array}$ & $\begin{array}{l}0.175^{*} \\
(0.07)\end{array}$ & $\begin{array}{l}0.914^{* *} \\
(0.237)\end{array}$ & $\begin{array}{l}0.291 \\
(0.121)\end{array}$ & $\begin{array}{l}-2.45^{* *} \\
(0.367)\end{array}$ & $\begin{array}{c}-0.162^{*} \\
(0.08)\end{array}$ \\
\hline Urban & $\begin{array}{l}-2.15^{* *} \\
(0.165)\end{array}$ & $\begin{array}{c}-0.902^{* *} \\
(0.237)\end{array}$ & $\begin{array}{l}-4.35^{* *} \\
(0.116)\end{array}$ & $\begin{array}{l}0.524^{* *} \\
(0.057)\end{array}$ & $\begin{array}{l}-6.63^{* *} \\
(0.186)\end{array}$ & $\begin{array}{l}-2.5^{* *} \\
(0.102)\end{array}$ & $\begin{array}{l}9.35 \\
(0.295)\end{array}$ & $\begin{array}{l}1.66 \\
(0.06)\end{array}$ \\
\hline Very urban & $\begin{array}{l}-3.26^{* *} \\
(0.205)\end{array}$ & $\begin{array}{c}-0.501^{\dagger} \\
(0.301)\end{array}$ & $\begin{array}{l}-5.4 \\
(0.135)\end{array}$ & $\begin{array}{l}0.4311^{* *} \\
(0.069)\end{array}$ & $\begin{array}{l}-8.33^{* *} \\
(0.213)\end{array}$ & $\begin{array}{l}-4.03^{* *} \\
(0.116)\end{array}$ & $1_{(0.347)}^{12.7}$ & $\begin{array}{l}2.18^{* *} \\
(0.07)\end{array}$ \\
\hline 2004 & $\begin{array}{l}0.392 \\
(0.189)\end{array}$ & & $\begin{array}{l}0.469^{* *} \\
(0.139)\end{array}$ & $\begin{array}{c}-0.839^{* *} \\
(0.074)\end{array}$ & $\begin{array}{c}-0.563^{* *} \\
(0.185)\end{array}$ & $\begin{array}{l}4.81 \\
(0.126)\end{array}$ & $\begin{array}{l}-5.2^{* *} \\
(0.356)\end{array}$ & $\begin{array}{c}-0.011 \\
(0.11)\end{array}$ \\
\hline 2005 & $\begin{array}{l}-1.38^{* *} \\
(0.178)\end{array}$ & & $\begin{array}{l}0.154 \\
(0.127)\end{array}$ & ${ }_{(0.067)}^{-2.1}$ & $\begin{array}{l}-26.1^{* *} \\
(0.186)\end{array}$ & $\begin{array}{c}-13.42^{* *} \\
(0.11)\end{array}$ & $\begin{array}{l}-16.2^{* *} \\
(0.322)\end{array}$ & $\begin{array}{l}-13.3^{\text {** }} \\
(0.086)\end{array}$ \\
\hline 2006 & $\begin{array}{l}-4.6^{* *} \\
(0.21)\end{array}$ & & $\begin{array}{l}3.099^{* *} \\
(0.146)\end{array}$ & $\begin{array}{l}-6.19^{* *} \\
(0.077)\end{array}$ & $\begin{array}{l}-16.9^{* *} \\
(0.226)\end{array}$ & $\begin{array}{l}-16.22^{* *} \\
(0.128)\end{array}$ & $\begin{array}{l}-17.5^{* *} \\
(0.371)\end{array}$ & $\begin{array}{l}-15.2^{* *} \\
(0.092)\end{array}$ \\
\hline 2007 & $\begin{array}{l}-1.55^{* *} \\
(0.218)\end{array}$ & & $\begin{array}{l}4.555^{* *} \\
(0.145)\end{array}$ & $\begin{array}{l}-5.95^{* *} \\
(0.078)\end{array}$ & $\begin{array}{l}-15.4^{* *} \\
(0.223)\end{array}$ & $\begin{array}{c}-32.18^{* *} \\
(0.124)\end{array}$ & $\begin{array}{l}-25.5^{* *} \\
(0.369)\end{array}$ & $\begin{array}{l}-15.7^{* *} \\
(0.096)\end{array}$ \\
\hline 2008 & $\begin{array}{l}-17.2^{* *} \\
(0.212)\end{array}$ & & ${ }_{(0.152)}{ }^{* *}$ & $\begin{array}{l}-15.7^{\text {** }} \\
(0.083)\end{array}$ & $\begin{array}{l}-7.85^{* *} \\
(0.222)\end{array}$ & $\begin{array}{c}-35.58^{* *} \\
(0.129)\end{array}$ & $\begin{array}{l}-47.9^{* *} \\
(0.377)\end{array}$ & $\begin{array}{l}-17.6^{* *} \\
(0.104)\end{array}$ \\
\hline Intercept & $\begin{array}{l}175.7^{* *} \\
(1.57)\end{array}$ & $\begin{array}{l}27.2^{* *} \\
(2.22)\end{array}$ & $\begin{array}{l}40.8^{* *} \\
(1.26)\end{array}$ & $\begin{array}{l}146.4^{* *} \\
(0.624)\end{array}$ & $\begin{array}{l}120.6^{* *} \\
(1.88)\end{array}$ & $\begin{array}{l}88.6 \\
(0.979)\end{array}$ & $\begin{array}{l}351.1^{* *} \\
(3.01)\end{array}$ & $\begin{array}{l}55.7^{* *} \\
(0.669)\end{array}$ \\
\hline $\mathrm{R}^{2}$ & 0.262 & 0.208 & 0.518 & 0.562 & 0.576 & 0.781 & 0.515 & 0.776 \\
\hline
\end{tabular}

Note: The average price is in $€ 100$, rebate is in $€ 10$, and income is in $€ 10,000$. "\%" stands for the percentage of households in each category. The household sizes and professional activities are in 10\%. \%Diesel is the share of diesel cars (in \%). $\mathrm{CO}_{2}$ emissions are in $\mathrm{g} / \mathrm{km} ; \mathrm{CO}, \mathrm{NO}_{X}$ and $\mathrm{HC}$ emissions are in $\mathrm{mg} / \mathrm{km}$, and PM emissions are in $\mathrm{mg} / 10 \mathrm{~km}$. The reference categories are singles, retired and rural cities. All specifications include year $\times$ county fixed effects and are estimated using 180,045 observations, except the regression with the rebate as the dependent variable, which includes only county fixed effects and uses 30,848 observations from 2008. The reported year fixed effects are the averages of the year $\times$ county fixed effects, weighted by the number of households. The regressions are weighted by the number of households. Significance levels: $\dagger: 10 \%, *: 5 \%, * *: 1 \%$.

related to demographic characteristics. The demand is represented by a random coefficients logit model that is similar to the model used in Nurski and Verboven (2016). The supply model formalises the pricing strategies of car manufacturers, which are multi-product firms that compete with each other as in the standard model of Berry et al. (1995).

\subsection{Demand}

I consider $n_{m}$ potential buyers from municipality $m$ choosing either to purchase or not one of the $J$ cars offered (the latter is the outside option and is denoted by 0 ). Consumers do 
not have preferences for the cars themselves but for car attributes. Each consumer, denoted by $i$, maximises her utility, which is a linear function of the car characteristics and the price. The index $j$ stands for the car. I omit the year index to keep the number of indexes small.

$$
u_{i m j}=\mathbf{x}_{\mathbf{j}} \boldsymbol{\beta}_{\boldsymbol{m}}+\alpha_{m} p_{j}+\xi_{j}+\epsilon_{i m j}
$$

$\mathbf{x}_{j}$ and $\xi_{j}$ represent observed and unobserved car characteristics, respectively, and $p_{j}$ is the price. $\epsilon_{i m j}$ is an individual and car-specific preference term, which is assumed to be identically and independently distributed according to an extreme value. $\boldsymbol{\beta}_{\boldsymbol{m}}$ and $\alpha_{m}$ are the parameters for preferences for car attributes and price sensitivity, respectively. These parameters are common to all individuals within a municipality. I further assume that these parameters are deterministic functions of demographic characteristics:

$$
\boldsymbol{\beta}_{\boldsymbol{m}}=\overline{\boldsymbol{\beta}}+\boldsymbol{\Sigma}^{\boldsymbol{X}} \mathbf{d}_{\mathbf{m}}^{\prime} \quad \text { and } \quad \alpha_{m}=\bar{\alpha}+\mathbf{d}_{\mathbf{m}} \boldsymbol{\sigma}_{\boldsymbol{p}}
$$

where $\mathbf{d}_{\mathbf{m}}$ is the vector of demographic characteristics of the consumers in municipality $m$. $\boldsymbol{\Sigma}^{\boldsymbol{X}}$ is the matrix of heterogeneity parameters that link individual preference for car attributes to the vector of demographic characteristics. $\boldsymbol{\sigma}_{\boldsymbol{p}}$ is, similarly, the vector of heterogeneity parameters for price sensitivity. The mean utility of the outside option is normalised to 0 so that $u_{i m 0}=\epsilon_{i m 0}$. The utility function can be expressed as the sum of the mean utility $\left(\delta_{j}\right)$, a deviation from this mean related to the demographic characteristics of the municipality $\left(\mu_{m j}\right)$ and an individual error term:

$$
u_{i m j}=\delta_{j}+\mu_{m j}+\epsilon_{i m j} .
$$

Because of the distribution of $\epsilon_{i m j}$, the probability that consumer $i$ from municipality $m$ chooses car $j$, which is also equal to the market share of car $j$ in the municipality, is expressed as:

$$
s_{i m j}=s_{m j}=\frac{\exp \left(\delta_{j}+\mu_{m j}\right)}{1+\sum_{k=1}^{J} \exp \left(\delta_{k}+\mu_{m k}\right)} .
$$

The market share of car $j$ at the national level is:

$$
s_{j}=\sum_{m} \phi_{m} \frac{\exp \left(\delta_{j}+\mu_{m j}\right)}{1+\sum_{k=1}^{J} \exp \left(\delta_{k}+\mu_{m k}\right)},
$$

where $\phi_{m}$ is the percentage of consumers in each municipality: $\phi_{m}=\frac{n_{m}}{\sum_{m} n_{m}}$.

\subsection{Supply}

I assume that the car market is an oligopolistic market with $F$ firms selling differentiated cars. Car manufacturers have market power and set their prices, taking into account demand and the prices of competitors. ${ }^{8}$ I assume that car manufacturers set their prices nationally,

\footnotetext{
${ }^{8}$ I abstract here from modelling the vertical relations between car manufacturers and dealers and assume perfect integration, such that the manufacturers set the final prices paid by the consumers.
} 
so there is no price discrimination across municipalities. This assumption is consistent with the use of catalogue prices as optimal prices since I do not observe transaction prices. ${ }^{9}$ The profit of manufacturer $f$ selling the set of cars $\mathcal{F}$ is:

$$
\pi_{f}=\sum_{j \in \mathcal{F}} \sum_{m} n_{m} s_{m j}(\mathbf{p}) \times\left(p_{j}-c_{j}\right),
$$

where $c_{j}$ is the marginal cost. $s_{m j}(\mathbf{p})$ is the market share of product $j$ that depends on the prices of all the cars, which are represented by the vector $\mathbf{p}$. The optimal price $p_{j}$ is derived from profit maximisation such that:

$$
\sum_{m} \phi_{m}\left(s_{m j}(\mathbf{p})+\sum_{k \in \mathcal{F}}\left(p_{k}-c_{k}\right) \frac{\partial s_{m k}}{\partial p_{j}}(\mathbf{p})\right)=0, \quad \forall j \in \mathcal{F}
$$

\subsection{Market equilibrium under the feebate regulation}

The feebate regulation modifies consumers' optimal choices and firms' pricing strategies. Let $\lambda_{j}$ be the rebate or fee associated with the level of $\mathrm{CO}_{2}$ emissions of car model $j$. I adopt the convention that $\lambda_{j}$ is positive for a fee and negative for a rebate. For this analysis, $\tilde{\mathbf{p}}$ denotes the vector of the prices set by car manufacturers under the feebate regulation. Consumer $i$ 's utility is modified as follows:

$$
\tilde{u}_{i m j}=\mathbf{x}_{\mathbf{j}} \boldsymbol{\beta}_{\boldsymbol{m}}+\alpha_{m}\left(\tilde{p}_{j}+\lambda_{j}\right)+\xi_{j}+\epsilon_{i m j} .
$$

The market shares under the feebate policy are:

$$
\tilde{s}_{j}=\sum_{m} \phi_{m} \frac{\exp \left(\tilde{\delta}_{j}+\tilde{\mu}_{m j}\right)}{1+\sum_{k=1}^{J} \exp \left(\tilde{\delta}_{k}+\tilde{\mu}_{m k}\right)}
$$

where $\tilde{\delta}_{j}=\mathbf{x}_{\mathbf{j}} \overline{\boldsymbol{\beta}}+\bar{\alpha}\left(\tilde{p}_{j}+\lambda_{j}\right)+\xi_{j}$ and $\tilde{\mu}_{m j}=\mathbf{x}_{\mathbf{j}} \boldsymbol{\Sigma}^{\boldsymbol{X}} \mathbf{d}_{\mathbf{m}}^{\prime}+\left(\tilde{p}_{j}+\lambda_{j}\right) \mathbf{d}_{\mathbf{m}} \boldsymbol{\sigma}_{\boldsymbol{p}}$. Car manufacturers set their prices taking into account the potential rebates and taxes that consumers are subject to. The profit function of firm $f$ is now:

$$
\tilde{\pi}_{f}=\sum_{m} n_{m} \sum_{j \in \mathcal{F}} \tilde{s}_{m j}(\tilde{\mathbf{p}}+\boldsymbol{\lambda}) \times\left(\tilde{p}_{j}-c_{j}\right) .
$$

The optimal prices satisfy:

$$
\sum_{m} \phi_{m}\left(\tilde{s}_{m j}(\tilde{\mathbf{p}}+\boldsymbol{\lambda})+\sum_{k \in \mathcal{F}}\left(\tilde{p}_{k}-c_{k}\right) \frac{\partial \tilde{s}_{m k}}{\partial \tilde{p}_{j}}(\tilde{\mathbf{p}}+\boldsymbol{\lambda})\right)=0, \quad \forall j \in \mathcal{F}
$$

\footnotetext{
${ }^{9}$ I could apply the methodology developed by D'Haultfœuille et al. (2019) to allow for unobserved price discrimination across municipalities, but the computation cost would be very high given a large number of municipalities.
} 
Let $\tilde{p}_{j}^{n}=\tilde{p}_{j}+\lambda_{j}$ denote the price net of rebate or fee and $\tilde{\mathbf{p}}^{\mathbf{n}}$ the vector of net prices. I can rewrite the previous equation as:

$$
\sum_{m} \phi_{m}\left(\tilde{s}_{m j}\left(\tilde{\mathbf{p}}^{\mathbf{n}}\right)+\sum_{k \in \mathcal{F}}\left(\tilde{p}_{k}^{n}-\lambda_{k}-c_{k}\right) \frac{\partial \tilde{s}_{m k}}{\partial \tilde{p}_{j}^{n}}\left(\tilde{\mathbf{p}}^{\mathbf{n}}\right)\right)=0, \quad \forall j \in \mathcal{F} .
$$

The effect of the feebate on pricing strategies is identical to a marginal cost increase (for a fee) or reduction (for a rebate). Because of market power and strategic interactions, not all of the fee or rebate is passed through to the consumer; instead, car manufacturers adapt their margins. Car manufacturers are able to extract part of the rebate by increasing the prices of cars with rebates. In the case of a fee, car manufacturers lower their price and decrease their margins to avoid large reductions in sales.

\subsection{Estimation}

I estimate the parameters of utility using the generalised method of moments. I use the standard aggregate demand and supply moments, as in Berry et al. (1995), complemented with micro-moments in the spirit of Berry et al. (2004) and Petrin (2002). The micromoments leverage the information on car sales at the municipality level and ensure the identification of the heterogeneity parameters. Specifically, I use the covariance between the characteristics of car purchases and the demographic characteristics across municipalities, as in Nurski and Verboven (2016). I do not directly use sales at the municipality level for two related reasons. First, there are many null market shares, which the logit model cannot rationalise given the assumption that the error term is extreme value distributed. Second, sales at the local level fail to generate precise estimates of the market shares because there are only a few sales in each municipality: the maximum number of car sales is 433, and the average number of sales is 19. The estimates of the local market shares are too sensitive to the presence of outliers and are not reliable for estimating the demand model. I instead rely on annual national aggregate market shares and use local sales in the micro-moments.

Once I estimate the demand parameters, I can back out the marginal costs for all car models and each year by inverting the system of first-order equations associated to firms' profit maximisation problem given by Equation (1) without the feebate policy and Equation (2) under the feebate policy.

Aggregate moments. The aggregate moment conditions are based on the interaction of unobserved product characteristics $\xi_{j}$ with the instruments $\mathbf{z}_{\mathbf{j}}$. The vector $\boldsymbol{\xi}$ is unobserved, but it is such that the theoretical market shares are equal to the observed market shares:

$$
s_{j}^{o b s}=s_{j}(\boldsymbol{\xi}, \boldsymbol{\theta})
$$

$\boldsymbol{\theta}$ represents the vector of the parameters $\left(\overline{\boldsymbol{\beta}}, \bar{\alpha}, \boldsymbol{\Sigma}^{\boldsymbol{X}}, \boldsymbol{\sigma}_{\boldsymbol{p}}\right)$. To invert the market share equation and recover the vector of the unobserved product characteristics $\boldsymbol{\xi}$, I use the contraction mapping suggested by Berry et al. (1995). The price $p_{j}$ is endogenous because it is likely to be correlated with the unobserved product characteristics $\xi_{j}$. The firms have market power, 
and their pricing decisions depend on demand, including its unobserved component. The instruments that I use are functions of other products' characteristics, such as those used in Berry et al., 1995 (more details are provided in the next section). The moment conditions are $\mathbb{E}\left(\xi_{j} \mathbf{z}_{\mathbf{j}}\right)=\mathbf{0}$, and the sample analogues are given by:

$$
\mathbf{g}^{\mathbf{d}}(\boldsymbol{\theta})=\frac{1}{J} \sum_{j=1}^{J} \xi_{j}(\boldsymbol{\theta}) \mathbf{z}_{\mathbf{j}}
$$

In addition to the moment conditions from the demand side, I construct moment conditions using the supply side, starting from the specification of the marginal cost equation:

$$
\begin{aligned}
& \ln c_{j}=\mathbf{x}_{\mathbf{j}}^{\mathbf{s}} \gamma+\omega_{j} \\
& \ln \left(p_{j}-m_{j}(\boldsymbol{\theta})\right)=\mathbf{x}_{\mathbf{j}}^{\mathbf{s}} \gamma+\omega_{j},
\end{aligned}
$$

where $m_{j}(\boldsymbol{\theta})$ is the margin of car $j$ obtained from the price optimality condition, $\mathbf{x}_{\mathbf{j}}^{\mathbf{s}}$ represents the observable cost shifters, and $\omega_{j}$ represents the unobservable cost shocks. The moment conditions are based on the independence between the cost shocks and the instruments $\mathbf{Z}^{\mathbf{s}}$ : $\mathbb{E}\left(\omega_{j} \mathbf{z}_{\mathbf{j}}^{\mathbf{s}}\right)=\mathbf{0}$. I use the sample analogue:

$$
\mathbf{g}^{\mathbf{s}}(\boldsymbol{\theta}, \gamma)=\frac{1}{J} \sum_{j=1}^{J} \omega_{j}(\boldsymbol{\theta}, \gamma) \mathbf{z}_{\mathbf{j}}^{\mathbf{s}}
$$

Micro-moments. The micro-moments exploit the information on demographic characteristics and product market shares of products at the municipality level. The micro-moments match (i) the predicted average demographic characteristics of the car purchasers and (ii) the covariances between the demographic characteristics and the product characteristics with their empirical counterparts. The sets of micro-moments are crucial for identifying the observed heterogeneity, as noted in Berry et al. (2004), Petrin (2002) and Nurski and Verboven (2016). For this analysis $s_{j}, s_{m j}, \overline{\mathbf{d}}$, and $\overline{\mathbf{x}}$ denote the observed aggregate market share, municipality market share, mean demographic characteristics and mean product characteristics, respectively, while $s_{j}(\boldsymbol{\theta}), s_{m j}(\boldsymbol{\theta}), \overline{\mathbf{d}}(\boldsymbol{\theta})$, and $\overline{\mathbf{x}}(\boldsymbol{\theta})$ are the predicted values for a given parameter $\boldsymbol{\theta}$. The third set of moments are :

$$
\left\{\begin{array}{l}
\mathbf{g}^{\text {micro, },(i)}(\boldsymbol{\theta})=\frac{1}{J} \sum_{j=1}^{J}\left[\frac{\sum_{m} \phi_{m} s_{m j} \mathbf{d}_{\mathbf{m}}}{s_{j}}-\frac{\sum_{m} \phi_{m} s_{m j}(\boldsymbol{\theta}) \mathbf{d}_{\mathbf{m}}}{s_{j}(\boldsymbol{\theta})}\right] \\
\mathbf{G}^{\text {micro, },(i i)}(\boldsymbol{\theta})=\frac{1}{J} \sum_{j=1}^{J}\left[\frac{\sum_{m} \phi_{m} s_{m j}\left(\mathbf{d}_{\mathbf{m}}-\overline{\mathbf{d}}\right)^{\prime} \cdot\left(\mathbf{x}_{\mathbf{j}}-\overline{\mathbf{x}}\right)}{s_{j}}-\frac{\sum_{m} \phi_{m} s_{m j}(\boldsymbol{\theta})\left(\mathbf{d}_{\mathbf{m}}-\overline{\mathbf{d}}(\boldsymbol{\theta})\right)^{\prime} \cdot\left(\mathbf{x}_{\mathbf{j}}-\overline{\mathbf{x}}(\boldsymbol{\theta})\right)}{s_{j}(\boldsymbol{\theta})}\right] .
\end{array}\right.
$$

Since I exactly match the aggregate market shares, $s_{j}(\boldsymbol{\theta})=s_{j}$ and $\overline{\mathbf{x}}(\boldsymbol{\theta})=\overline{\mathbf{x}}$, and the moments can be written as:

$$
\left\{\begin{array}{l}
\mathbf{g}^{\text {micro, },(i)}(\boldsymbol{\theta})=\frac{1}{J} \sum_{j=1}^{J} \frac{\sum_{m} \phi_{m} \mathbf{d}_{\mathbf{m}}\left(s_{m j}-s_{m j}(\boldsymbol{\theta})\right)}{s_{j}} \\
\mathbf{G}^{\text {micro },(i i)}(\boldsymbol{\theta})=\frac{1}{J} \sum_{j=1}^{J} \frac{\sum_{m} \phi_{m}\left[s_{m j}\left(\mathbf{d}_{\mathbf{m}}-\overline{\mathbf{d}}\right)-s_{m j}(\boldsymbol{\theta})\left(\mathbf{d}_{\mathbf{m}}-\overline{\mathbf{d}}(\boldsymbol{\theta})\right)\right]^{\prime} \cdot\left(\mathbf{x}_{\mathbf{j}}-\overline{\mathbf{x}}\right)}{s_{j}} .
\end{array}\right.
$$




\subsection{Discussion}

The model is static and abstracts from the dynamic aspects related to the car purchase decision. Because a car is a durable good that is used for several years and can be sold on a second-hand car market, consumer anticipation of future car prices and characteristics and second-hand car market characteristics play a role in the purchase decisions. The dynamic aspects related to the existence of the secondary market have been studied by Gavazza et al. (2014) and Chen et al. (2013). The first paper focuses on the allocative effects of the secondhand car market, while the second focuses on the competition of car manufacturers with themselves through the secondary market. Abstracting from modelling the dynamics and the second-hand car market may lead to bias in price elasticity and mark-up estimates, as shown by Chen et al. (2008). However, these dynamic models cannot account for the heterogeneity in car characteristics and $\mathrm{CO}_{2}$ emissions. The cars are treated as a homogeneous product with a single dimension of heterogeneity, the vintage. Such a dynamic model would not be relevant for the analysis of the feebate policy, the effect of which is precisely to induce substitution from high $\mathrm{CO}_{2}$-emitting cars to low $\mathrm{CO}_{2}$-emitting cars.

In not modelling the decision as dynamic and abstracting from the second-hand car market, I am not able to investigate three aspects of the feebate policy. First, I cannot investigate the policy's impact on the purchase decision through a change in consumers' expectations. The policy may change households' expectations about future fuel efficiency technology, as they anticipate car manufacturers will develop fuel-efficient cars at lower costs. As a consequence, some individuals, in particular those most sensitive to fuel costs, may prefer to wait before buying a new car. Second, my analysis neglects the effects of the policy on the second-hand car market. Since new car prices are modified by the feebate introduction, resale prices are likely to be modified in 2008 and in the years after, implying some additional welfare and distributional effects that my analysis does not take into account. The third effect that I do not evaluate is the impact of the policy on emissions through a change in cars' lifetimes. The policy is likely to increase the lifetimes of cars with taxes that become more expensive and decrease those of rebated cars that are cheaper. This constitutes an adverse effect of the policy since polluting cars end up less frequently renewed. This is the Gruenspecht (1982) effect, and it reduces the environmental benefit of a policy (see Jacobsen and Van Benthem, 2015 for the effects of CAFE standards and Bento et al., 2009 for an analysis of an increase in gasoline taxes).

\section{Estimation results}

\subsection{Model specification}

I estimate the model with heterogeneity relying on the three sets of moments derived in the previous section. I also estimate a simple logit model without heterogeneity in preferences using moments from demand and supply only. The observed product characteristics introduced in the utility function are the price (net of the feebate in 2008), fuel cost, horsepower, cylinder capacity, weight (as a proxy for car size), and type of car body (coupe, wagon or sedan). I use data obtained from the French National Survey Institute on the average fuel prices 
for each year to compute the average cost of driving 100 kilometres. I do not observe cars' fuel consumption levels directly, but I can infer them using the engineering formula that links a car's $\mathrm{CO}_{2}$ emissions to the fuel consumption. ${ }^{10} \mathrm{I}$ also include year fixed effects to capture symmetric shocks to the automobile market and brand fixed effects to control for unobserved heterogeneity of cars at the brand level. I allow for heterogeneity in terms of price sensitivity, fuel cost, weight and cylinder capacity. I assume that price sensitivity is a linear function of income, while I allow fuel cost sensitivity to depend on income and municipality size. I consider that the valuation for car weight can be different in rural (less than 20,000 inhabitants) and urban (more than 20,000 inhabitants) areas. Finally, I allow the valuation of cylinder capacity to depend on household size. Household size is represented by the percentage of households in each of these two categories: households with children and households without children. Finally, I consider the following variables as cost shifters: horsepower, fuel consumption (in litres for 100 kilometres), weight and cylinder capacity. I also introduce brand fixed effects in the cost function.

The estimation method relies on instruments, making the standard assumption that product characteristics other than price are exogenous and using these product characteristics as instruments. I construct additional instruments that are functions of the characteristics of other products. The characteristics of competing products are correlated with the price through strategic interactions across firms: if a car has close substitutes, it has lower market power and, therefore, a lower price. I also use functions of the characteristics of other cars of the same brand. The argument is similar: if the brand offers many close substitutes to a car, then the manufacturer has high market power and is able to set a high price. More precisely, I use three sets of instruments: the sums of the characteristics of all the other brands' cars, the sums of the characteristics of other cars of the same brand and the sums of the characteristics of the other brands' cars in the same segment. I consider eight segments: mini, small family, large family, executive, small minivan, large minivan, sports and all road. I use the same instruments to construct the demand and supply moments but do not use instruments to form the micro-moments.

I estimate the model using a sample of municipalities to reduce the computation cost associated with the calculation of aggregate market shares. The market share inversion uses the contraction mapping proposed by Berry et al. (1995), which involves the computation of the aggregate market shares many times. I randomly draw 3,000 municipalities (approximately $10 \%$ of all municipalities) with a weight that is proportional to the number of households. ${ }^{11}$ For the data to be consistent with the model, I use aggregate market shares, which are computed by summing the sales over the municipalities sampled. Because the feebate policy was announced at the end of November 2007, there was room for arbitrage: households could bring forward or postpone their car purchases by a couple of months to escape the fees or obtain rebates. This could introduce non-stationarity in the car sales of December 2007 and January 2008 and bias the parameter estimates. To limit this effect, I exclude the car registrations from December and January for each year to compute the annual market

\footnotetext{
${ }^{10}$ The fuel consumption (in $\mathrm{L} / \mathrm{km}$ ) $\psi_{j}$ of car $j$ is related to the $\mathrm{CO}_{2}$ emissions (in $\mathrm{g} / \mathrm{km}$ ) through the following formula: $\mathrm{CO}_{2 j}=\psi_{j} \times k_{f(j)}$, where $k_{f(j)}$ reflects the quantity of $\mathrm{CO}_{2}$ emissions in a liter of fuel and is equal to $2,287 \mathrm{~g} / \mathrm{L}$ for gasoline cars and $2,686 \mathrm{~g} / \mathrm{L}$ for diesel cars.

${ }^{11}$ The sample is representative of the full population as Table 19 in Appendix D.1 suggests.
} 
shares. While my model is estimated on aggregate sales calculated over ten months and a sample of 3,000 municipalities, the welfare analysis covers the full year and the full sample of municipalities.

It is necessary to aggregate different versions of products to obtain exploitable variations in market shares across products and to obtain a choice set of a reasonable size. I define a product (car model) as a brand, model name, body style, and class of $\mathrm{CO}_{2}$ emissions. I do not use the fuel type to directly define car models, but it is highly correlated with the class of $\mathrm{CO}_{2}$ emissions, so cars with different fuel types are generally in two different classes of $\mathrm{CO}_{2}$ emissions and are therefore considered to be two different car models. For each car model, I assign the characteristics of the most frequently purchased version of the car model. I finally obtain 5,028 different car models for the six years covered by my dataset. To compute the market shares of the products and an outside option, I assume the potential market is one-fourth of the total number of households. For the estimation, I use one-fourth of the total number of households from the sample of selected municipalities multiplied by a factor of 10/12 to account for the fact that annual market shares are calculated from car sales over ten months.

\subsection{Parameter estimates}

Table 3 displays the estimated parameters for the models both with and without heterogeneity in consumer preferences. Price and fuel cost have significant negative coefficients. The estimates of the model with heterogeneity are in line with those of the simple model. Since the parameters of heterogeneity are significant, I use the model with heterogeneity as the main specification. Weight, horsepower and cylinder capacity are characteristics that consumers appreciate. On average, individuals prefer sedans or convertibles to cars with a wagon body. I find, surprisingly, that price sensitivity increases with income. Crawford et al. (2019) also find such a surprising income effect for demand for cable TV. On the other hand, sensitivity to the fuel cost decreases with income, as expected. This sensitivity is also lower in urban municipalities than in rural areas, but the heterogeneity parameter is small relative to the average fuel cost sensitivity parameter. I find that consumers living in urban municipalities place less value on car weight, reflecting heterogeneity in car usage across municipalities

according to population density. I also observe that households without children value cylinder capacity less than other household types. From the demand parameters and using the full sample of municipalities, I compute the car margins and find significant market power in the car market: the average mark-up rate is $41.7 \%$ in 2008 . I provide in Appendix D.2 some additional estimation results and present the robustness checks to investigate potential issues related to using the year 2008 in the estimation.

\section{Analysis of the policy effects}

\subsection{Aggregate effects of the feebate}

Nature of the counterfactual. The impact of the feebate policy on the car market is inferred from the difference between the market equilibrium under the feebate and the market 
Table 3: Estimation results

\begin{tabular}{|c|c|c|c|c|}
\hline & \multicolumn{2}{|c|}{ Model w/o heterogeneity } & \multicolumn{2}{|c|}{ Model with heterogeneity } \\
\hline & Parameter & Std. err. & Parameter & Std. err. \\
\hline \multicolumn{5}{|l|}{ Utility parameters } \\
\hline Price $(€ 10,000)$ & $-1.56^{* *}$ & 0.013 & $-0.675^{* *}$ & 0.074 \\
\hline Horsepower & $0.296^{* *}$ & 0.018 & $0.29^{* *}$ & 0.018 \\
\hline Fuel cost $(€ / 100 \mathrm{~km})$ & $-0.386^{* *}$ & 0.015 & $-0.797^{* *}$ & 0.022 \\
\hline Weight $(100 \mathrm{~kg})$ & $0.305^{* *}$ & 0.015 & $0.349^{* *}$ & 0.015 \\
\hline Cylinder capacity $\left(1,000 \mathrm{~cm}^{3}\right)$ & 0.005 & 0.011 & $0.292^{* *}$ & 0.012 \\
\hline Convertible & -0.103 & 0.088 & -0.079 & 0.085 \\
\hline Wagon & $-0.866^{* *}$ & 0.063 & $-0.852^{* *}$ & 0.062 \\
\hline Intercept & $-9.05^{* *}$ & 0.236 & $-8.51^{* *}$ & 0.233 \\
\hline Income $\times$ fuel cost & & & $0.227^{* *}$ & 0.01 \\
\hline Income $\times$ price & & & $-0.509^{* *}$ & 0.039 \\
\hline Urban $\times$ fuel cost & & & $0.035^{* *}$ & 0.005 \\
\hline Urban $\times$ weight & & & $-0.034^{* *}$ & 0.003 \\
\hline$\%$ Without children $\times$ cylinder & & & $-0.537^{* *}$ & 0.015 \\
\hline
\end{tabular}

Note: Price and income are in constant $2008 €$; horsepower is the fiscal horsepower. "Urban" is a dummy for municipalities with more than 20,000 inhabitants, and "\% Without children" is the frequency of households without children in the municipality. Both models are estimated using 5,028 car models and include brand and year dummies in the utility and the marginal cost functions. Significance levels: $\dagger: 10 \%, *: 5 \%, * *: 1 \%$.

equilibrium in the absence of the feebate. For consistency, both situations are simulated using the demand parameters, car marginal costs and the full sample of municipalities. The marginal costs are obtained from the system of equations associated with price optimality (Equation 2), assuming the observed prices in 2008 are optimal for the full sample of municipalities under the feebate. This implies that my model perfectly predicts the observed prices but does not necessarily perfectly predict the market shares at the national level. Alternatively, I could rely on the vector of marginal costs obtained by assuming price optimality for the sample of 3,000 municipalities. This alternative approach benefits from being consistent with the estimation approach that relies on the price optimality condition for the same sample. Yet, it seems more appropriate to recover the marginal costs using the full sample of municipalities because it exploits more information. I estimate the marginal costs using the two approaches and find that they are almost identical: the average absolute difference is only $0.43 \%$, and for $97.5 \%$ of the car models, the cost difference is below $2 \%$. As Table 23 in Appendix D.3 reveals, the aggregate outcomes (car sales, profits and budget costs) are very close using the two alternative cost vectors. This table also shows that they are consistent with the observed outcomes, confirming that my model is relevant for describing the car market at the national level.

Gains and losses for consumers are measured through the variation in their surplus, which is the expected utility of their best car choice. So the average variation in consumer surplus due to the feebate is the difference in expected utilities with and without the feebate. Since the only source of heterogeneity within each municipality is the individual and productspecific preference shock $\epsilon_{i k}$, individual surpluses are identical in the same municipality. Given the distributional assumption on this preference shock (see Small and Rosen, 1981), 
the expression for the average surplus variation for municipality $m$ is:

$$
\Delta c s_{m}=-t_{m}+\frac{\ln \left(1+\sum_{k=1}^{J} \exp \left(\tilde{\delta}_{k}+\tilde{\mu}_{m k}\right)\right)-\ln \left(1+\sum_{k=1}^{J} \exp \left(\delta_{k}+\mu_{m k}\right)\right)}{-\alpha_{m}},
$$

where $\delta_{k}$ and $\mu_{m k}$ represent the mean utility and the municipality-specific portion of the utility in the absence of the feebate policy, respectively, while $\tilde{\delta}_{k}$ and $\tilde{\mu}_{m k}$ are those under the feebate policy. $\alpha_{m}$ is the price sensitivity of municipality $m$ and is negative. $t_{m}$ is the tax introduced to finance the cost of the feebate. I first consider a uniform, per consumer tax $t$ to subsidise the deficit. $t$ is such that:

$$
n \times t=b .
$$

$n$ is the total number of potential buyers (one-fourth of the total number of French households), and $b$ is the deficit. I obtain $t=€ 29.3$. I also examine a tax that is proportional to the income to offset the deficit. I solve for the tax rate $\tau$ such that the total tax revenue is equal to the deficit:

$$
\sum_{m}\left(\tau \times i_{m}\right) n_{m}=b
$$

where $i_{m}$ and $n_{m}$ are the median income and the number of potential car buyers of the municipality $m$. I obtain $\tau=\frac{15.7}{10,000}$, implying municipality taxes between $€ 11.6$ and $€ 79.7$ with a median of $€ 27.9$, which is slightly below the uniform tax. Ultimately, the type of tax used to subsidise the deficit generated by the feebate policy does not affect the total consumer surplus or the total welfare effect. This result occurs because I specify a linear utility function that rules out any income effect. However, the type of tax used has important consequences for the distribution of gains and losses across municipalities.

Feebate pass-through. Before the analysis of the welfare and environmental effects of the feebate scheme, I investigate how car prices are modified in response to the policy. I find that prices are not so different without the feebate, indicating a high pass-through of fees and rebates. I find an average pass-through of $101.9 \%$ for cars subject to either a fee or a rebate. In addition, only $5 \%$ of car models have a pass-through below $100 \%$. This suggests that the feebate is overshifted to the car price, which contrasts with the $60 \%$ passthrough I estimate using the reduced-form approach. ${ }^{12}$ Such an overshifting of the feebate is nevertheless consistent with the theoretical framework developed by Anderson et al. (2001). Bonnet and Réquillart (2013), and Griffith et al. (2018) also find an overshifting of taxes in the context of grocery items (soda drinks and margarine products, respectively). The reason for tax overshifting is that the fees soften competition among car manufacturers for cars subject to taxes and increase competition for cars affected by rebates. The average posted price increase due to the feebate policy is modest and is equal to only $€ 13.5$. Even the maximum posted price increase reaches the modest value of $€ 82$. Table 24 in Appendix D.3

\footnotetext{
${ }^{12}$ The reduced-form pass-through estimates could be biased for several reasons: the reduced-form equation may be misspecified, there may be within-car model unobservable characteristics that are correlated to the amount of rebate or fee, or the inference may be invalid because car prices are not independent, which violates the i.i.d. assumption.
} 
presents the absolute values of the pass-through and the pass-through rates (in percentage of the fee or rebate) by $\mathrm{CO}_{2}$ emissions class.

Effects on households and car manufacturers. As Table 4 shows, the feebate stimulates the car market, with an increase in the sales of new cars by approximately 23,000 units. My model does not specify the exact form of the outside option, so I cannot distinguish whether these extra new sales are due to a substitution from a purchase on the second-hand market, early replacement of an old car or new car owners. The origin of new car sales is not relevant for the estimates of welfare effects of the policy on households and car manufacturers but has important consequences for the environmental impacts of the policy.

Using the estimates for marginal costs, I am able to compute the manufacturers' margins for each car and the additional profits generated by the feebate. The feebate increases overall industry profits by $2.1 \%$, but French manufacturers' profits increase by almost twice as much $(3.8 \%)$. The net profit increase for French manufacturers ( $€ € 157.5$ million) is greater than the total industry net profit increase $(+€ 156.9$ million). This suggests that some manufacturers experience losses because of the policy. I precisely identify the winners and losers across car manufacturers in Section 5.2. I further decompose the rise in manufacturer profits to disentangle the gains from extra sales (the extensive margin) from the gains from increased margins (the intensive margin). I find that $€ 8.85$ million can be attributed to the rise of carmakers' margins while $€ 148.1$ million are attributable to extra sales. The extensive margin is, therefore, the most important margin and accounts for $94 \%$ of the profit increase. The profit decomposition is very similar for French manufacturers.

Total consumer surplus increases because of the feebate policy, with a net gain of $€ 172$ million (which corresponds to a rise of $2.1 \%$ ). However, this increase is lower than the cost of the feebate, which reaches $€ 211.6$ million. These figures imply that there is a negative variation of $€ 39$ million in total consumer surplus when the deficit is offset by a tax on individuals. The diesel car share increases by 0.44 percentage points because of the feebate. This seems relatively small, but it is similar in magnitude to the annual trend in the diesel share increase (I estimate the diesel share to increase by 0.94 percentage points per year). ${ }^{13}$ My estimate of the feebate's effect on the diesel share is comparable to almost half of a year's worth of a jump in this share.

Effects on emissions. The change in average emissions reflects the modification of the composition of the car fleet caused by the feebate policy. The variation in total emissions is also affected by the increase in total car sales and substitution towards diesel cars, which are assumed to be driven 7,000 kilometres more than gasoline cars annually. The main objective of the feebate is to reduce $\mathrm{CO}_{2}$ emissions, and indeed the feebate is responsible for a decrease of $2.2 \mathrm{~g} / \mathrm{km}$ in the average $\mathrm{CO}_{2}$ emissions of new cars. This corresponds to a reduction of $1.6 \%$ in average emissions. This figure might appear small, but it is $34 \%$ higher than the annual trend in average $\mathrm{CO}_{2}$ emissions observed over the period 2003-2007 (-1.64 g/km annually). ${ }^{14}$

\footnotetext{
${ }^{13}$ This trend is estimated by regressing a dummy for diesel car purchases on an intercept and a time trend over the period 2003-2007.

${ }^{14}$ This is estimated by regressing $\mathrm{CO}_{2}$ emissions on a time trend using car sales over the period 2003-2007.
} 
Table 4: Welfare and environmental effects of the feebate policy

\begin{tabular}{lccc}
\hline \hline & Feebate & $\begin{array}{c}\text { No } \\
\text { Feebate }\end{array}$ & $\begin{array}{c}\text { Variation } \\
\text { (in \%) }\end{array}$ \\
\hline Total sales (1,000 units) & 1,223 & 1,200 & 1.91 \\
Share of diesel $(\%)$ & 70.97 & 70.53 & 0.62 \\
Profits French (M€) & 4,322 & 4,164 & 3.78 \\
Profits all $(\mathrm{M} €)$ & 7,645 & 7,488 & 2.1 \\
Consumer surplus $(\mathrm{M} €)$ & 8,551 & 8,379 & 2.05 \\
\hline Average emissions & & & \\
$\mathrm{CO}_{2}(\mathrm{~g} / \mathrm{km})$ & 138.56 & 140.82 & -1.6 \\
$\mathrm{NO}(\mathrm{mg} / \mathrm{km})$ & 147.44 & 146.71 & 0.50 \\
$\mathrm{PM}(\mathrm{mg} / 10 \mathrm{~km})$ & 68.94 & 68.71 & 0.33 \\
$\mathrm{CO}(\mathrm{mg} / \mathrm{km})$ & 243.40 & 243.85 & -0.18 \\
$\mathrm{HC}(\mathrm{mg} / \mathrm{km})$ & 32.13 & 32.19 & -0.18 \\
\hline \hline Note: "M€" stands for millions of euros. & &
\end{tabular}

This is consistent with the price effect of the feebate estimated by D'Haultfœuille et al. (2016) but lower than the $4 \%$ reduction in average $\mathrm{CO}_{2}$ emissions estimated by D'Haultfœuille et al. (2014). The difference stems from the fact that I evaluate the pecuniary impact while they assess the total policy effect, including the potential informational and behavioural channels.

This decrease in average $\mathrm{CO}_{2}$ emissions is accompanied by modest declines in average emissions of $\mathrm{CO}$ and $\mathrm{HC}(-0.18 \%$ for both pollutants). In contrast, the average emissions of $\mathrm{PM}$ and $\mathrm{NO}_{\mathrm{X}}$, the most hazardous local pollutants, increase because of the feebate: average $\mathrm{NO}_{\mathrm{X}}$ emissions increase by $0.5 \%$, while average $\mathrm{PM}$ emissions increase by $0.33 \%$. These figures confirm the trade-off between global and local air pollution and that the feebate policy sacrifices local air quality to reduce $\mathrm{CO}_{2}$ emissions. The effects of the feebate on local pollutant emissions are quite significant once the figures are converted into annual emissions. All annual emissions of local pollutants increase between $2.04 \%$ and $2.47 \%$, primarily driven by the increase in new car sales. I also find an increase in annual $\mathrm{CO}_{2}$ emissions even though average emissions decrease. I estimate that the feebate generates 12,284 extra tons of $\mathrm{CO}_{2}$ emissions annually, corresponding to an increase of less than $0.5 \%$.

The increase in emissions of new cars is compensated by a decrease in emissions from the outside good, provided that a share of the extra car sales are early car replacements. I consider three scenarios for the origin of the extra new car sales. In the first and benchmark scenario, I consider the proportions of old car owners and non-motorized households within the share of households choosing the outside option to be identical both in the presence and absence of the feebate. The second scenario is optimistic and assumes that all extra car sales from the feebate are for replacements of old cars. It implies that the share of non-motorized households who choose the outside option remains constant both under and in the absence of the feebate policy. The third scenario makes a pessimistic assumption and considers all extra feebate-induced car sales constitute new drivers or households that acquire additional vehicles and drive more. The distribution of the households according to their car ownership status (new car owner, old car owner or no car) under the different scenarios is presented in 
Table 25 in Appendix D.3.

Under the benchmark and optimistic scenarios, I find that the feebate policy decreases emissions of the outside option by $0.38 \%$ and $0.48 \%$, respectively. These figures, although small, imply large amounts of emissions avoided from the outside option because the number of households choosing the outside option is large. Table 5 shows that under the benchmark scenario, 40,500 tons of $\mathrm{CO}_{2}$ are avoided, which more than compensates for the extra 12,000 tons from new cars. Under the second scenario, which considers all extra new car sales to be early replacements, emissions from the outside option decrease by 51,200 tons. This is because the average $\mathrm{CO}_{2}$ emissions from an average old car are much higher than the new car emissions in 2008. The emissions of PM and HC avoided from households choosing the outside option are greater than the extra emissions from new cars under the two scenarios. For the emissions of $\mathrm{CO}$, compensation between avoided and new emissions occurs only under the optimistic scenario. For $\mathrm{NO}_{\mathrm{X}}$ emissions, however, the increase in new car emissions is not compensated by emissions savings from the households choosing the outside option. This results from the combination of two effects: (i) the average emissions of $\mathrm{NO}_{\mathrm{X}}$ from the outside option are lower than the average car emissions in 2008, and (ii) the average $\mathrm{NO}_{\mathrm{X}}$ emissions of new cars are greater under the feebate than in its absence. The lower bounds of the net feebate effects indicate that the feebate potentially generates a net reduction of all types of emissions except for $\mathrm{NO}_{\mathrm{X}}$.

I use these bounds and the estimates of the social costs of emissions suggested by the report of the DG MOVE (2014) to convert the policy's environmental effects into monetary terms. The increases in emissions of $\mathrm{CO}_{2}$ and $\mathrm{NO}_{\mathrm{X}}$ are the costliest for society. The cost of the net increase in $\mathrm{NO}_{\mathrm{X}}$ emissions is between $€ 185,000$ and $€ 945,000$. The effect of the feebate on the emissions of PM is estimated to be between a cost of $€ 344,000$ and a benefit of $€ 160,000$. Under the optimistic scenario, the gains from the reduction in $\mathrm{CO}_{2}$ emissions reach $€ 1.56$ million. Even though there is a net decrease in the emissions of PM and $\mathrm{HC}$ under the benchmark and optimistic scenarios, once they are converted to monetary terms, they do not compensate the cost from the increase in $\mathrm{NO}_{\mathrm{X}}$ emissions. The total policy cost in terms of emissions of local pollutants is between $€ 15,000$ and $€ 1.31$ million.

Table 5: Effects of the feebate on annual emissions

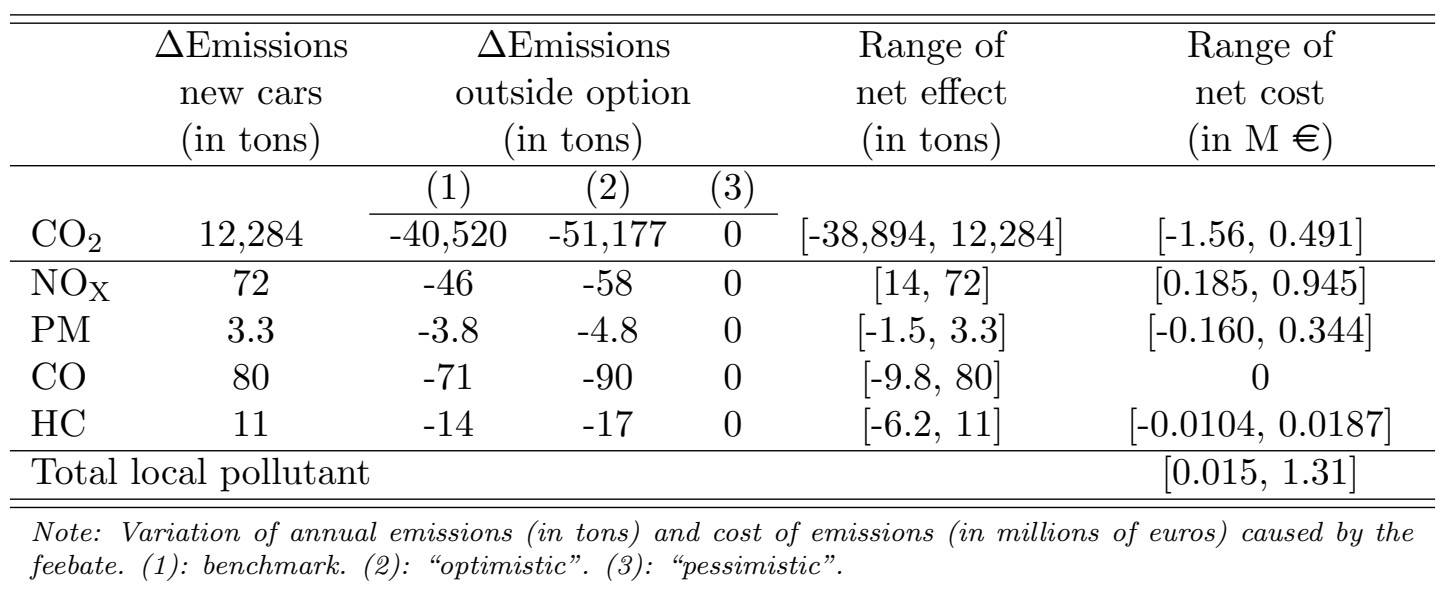


I evaluate the robustness of the net cost from local pollutant emissions to the use of the heterogeneous social costs of emissions calibrated in Appendix C. I rely on the benchmark assumption for the origin of extra new car sales. The results are presented in Table 26 in Appendix D.3. The net feebate cost related to local pollutant emissions is estimated to be between $€ 0.095$ and $€ 0.324$ million, depending on the specification, indicating that my benchmark estimate of $€ 0.284$ million is rather conservative. The overall welfare policy effect is not very sensitive to the estimates of the social cost of local pollutants. The lowest cost is obtained when the emissions cost is a quadratic function of the population density. In this specification, the total costs of $\mathrm{NO}_{\mathrm{X}}$ and $\mathrm{PM}$ emissions are much lower than in the benchmark case, reflecting that the feebate raises emissions where population densities are lowest. In contrast, I estimate a higher policy cost when the social costs are discontinuous functions of average car emissions. Under these two discontinuous cost scenarios, the decrease in the emissions from the outside option generates lower gains than in the scenarios with uniform social costs.

Feebate balance. I determine the net annual feebate value by balancing benefits with costs, including the budget cost and social costs of emissions. I provide here the first evaluation of the feebate policy that accounts for both emissions of global and local pollutants (D'Haultfouille et al., 2014 only evaluate the social cost of $\mathrm{CO}_{2}$ emissions in their shortand long-run analysis of the policy). The gains for car manufacturers ( $€ 157$ million) and households (€172 million) have to be balanced with the budget cost and the cost of the extra emissions. As the previous results suggest, there is a net environmental loss only under the assumption that the new car sales are new drivers (pessimistic scenario). This pessimistic scenario still implies a large positive balance for the feebate policy, with a net welfare gain of $€ 115.6$ million. This gain reaches $€ 119$ million under the optimistic scenario, while it is estimated to be $€ 118.3$ million for the benchmark scenario. These results are provided in Table 6 .

I implicitly assumed away any shadow cost of public funds. A shadow cost of public funds of 1.56 would be necessary to obtain budget neutrality, implying that the government needs to pay $€ 1.56$ to spend one euro under the feebate policy. This value seems higher than typical estimates from the literature (for instance, Ballard et al., 1985 estimate a shadow cost lower than 1.39 for consumer sales tax). The feebate policy is welfare improving under reasonable values for the shadow cost of public funds. The main reason for this net positive gain is the significant increase in carmarkers' profits, which as previously noted, is mainly driven by the stimulation of new car sales. The welfare analysis provided here is partial and neglects any policy effect outside the car market and neglects dynamic effects. Perhaps individuals who buy a car reduce their expenses on other goods, which I do not account for in this partial analysis. The feebate stimulates the car market by generating some car replacements, as my benchmark scenario assumes. Car sales may decrease in the future, but this is not accounted for in my analysis and contributes to this positive balance. 
Table 6: Cost-benefit analysis of the feebate policy

\begin{tabular}{lccc}
\hline \hline & Benchmark & Optimistic & Pessimistic \\
\hline Cost of the policy (-) & 211.6 & 211.6 & 211.6 \\
$\Delta$ Consumer surplus & 172.1 & 172.1 & 172.1 \\
$\Delta$ Profits & 156.9 & 156.9 & 156.9 \\
$\Delta$ Cost $\mathrm{CO}_{2}$ new cars (-) & 0.491 & 0.491 & 0.491 \\
$\Delta$ Cost local pollution new cars $(-)$ & 1.31 & 1.31 & 1.31 \\
$\Delta$ Cost $\mathrm{CO}_{2}$ outside option (-) & -1.62 & -2.05 & 0 \\
$\Delta$ Cost local pollution outside $(-)$ & -1.02 & -1.29 & 0 \\
\hline$\Delta$ Welfare & 118.3 & 119.0 & 115.6 \\
\hline \hline
\end{tabular}

Note: in millions of euros. "(-)" means the value has to be subtracted to obtain the balance.

\subsection{Distributional effects}

Heterogeneity across individuals. I first analyse the heterogeneity of the effects of the feebate across consumers, which is the direct consequence of preference heterogeneity. Intuitively, we expect an individual to gain from the feebate if the cars that this consumer likes become cheaper. I investigate in Appendix D.4 the partial effect of each demographic characteristic on the variations of consumer surplus, both in level and percentage. I find that the income has two effects that work in opposite directions. On the one hand, richer individuals are more sensitive to the price, leaving them more reactive to the policy. On the other hand, they do not value the car's fuel efficiency, so they do not gain by substituting to fuel-efficient cars. This is why the variation of the consumer surplus from the feebate is the largest for middle income individuals. Given the form of the surplus function, the different parameters of heterogeneity interact so the net effect of the feebate on individuals remain an empirical question that I investigate below.

I first analyse the heterogeneity of the effects of the feebate across consumers, which is the direct consequence of preference heterogeneity. Intuitively, we expect an individual to gain from the feebate if the cars that this consumer likes become cheaper. I investigate in Appendix D.4 the partial effect of each demographic characteristic on the variations of consumer surplus, both in level and percentage. I find that income has two effects that work in opposite directions. On the one hand, wealthier individuals are more sensitive to the price, leaving them more reactive to the policy. On the other hand, they do not value the car's fuel efficiency, so they do not gain by substituting to fuel-efficient vehicles. This is why the variation of the consumer surplus from the feebate is the largest for middle-income individuals. Given the form of the surplus function, the different parameters of heterogeneity interact, so the net effect of the feebate on individuals remains an empirical question that I investigate below.

When the deficit is subsidised by a uniform tax, the analysis in levels is identical since the variation in the average individual surplus is shifted by the amount of the tax (€29.3). Under this scenario, all the income categories experience welfare losses except the top two income deciles. The maximum average loss is $€ 10.5$, the figure for the lowest income decile. On average, consumers lose $€ 5.5$, which represents an average of only $1.4 \%$ of their surplus. 
The results from analysing the variations of surplus in percentage terms are different from the scenario without tax because the losses in relative terms are higher for individuals with low baseline surplus, i.e. those in the middle-income category. It might also seem surprising that the average variation in consumer surplus for the two highest income deciles is positive in levels while they are negative in percentage terms. But it comes from the significant remaining heterogeneity within these two income deciles. $36 \%$ of individuals in the ninth income decile (38\% for the tenth decile) have negative surplus variations, while $64 \%$ (62\% for the tenth decile) increase their surplus. Because the winners gain, on average, more than the losers, the feebate has a small but positive effect on average. When analysing the surplus variation in relative terms, the average rise in consumer surplus for the winners is smaller than the average decrease of the losers implying an average negative effect of the feebate in percentage terms.

When the deficit is offset by a tax that is proportional to the income, the distributional effects are quite different since the top income class is associated with larger welfare gains and higher taxes. At the same time, low-income individuals pay lower taxes. The low-income category becomes the biggest winner since the individuals only lose $€ 2.3$ on average. In absolute terms, the effects on the surplus are relatively homogeneous between the second and the ninth income deciles (between -€5.36 and $-€ 4.04$ ), while the average surplus of the tenth income decile decreases by $€ 13.1$. On average, the highest income class pays a tax of $€ 43.5$, which is more than twice the average tax for the first income decile $(€ 21.1)$. In relative terms, the heterogeneity is less pronounced since the average loss for the highest income decile represents only a small percentage of the surplus of the individuals in this decile.

Next, I investigate heterogeneity in the effects of the feebate policy across different municipality sizes. The welfare gains in level terms appear relatively homogeneous, with variations from $€ 19.3$ for cities with between 100,000 and 200,000 inhabitants to $€ 26.9$ for rural municipalities (under the no-tax scenario). In relative terms, the results are different since the cities with 100,000-200,000 inhabitants have the highest relative gains. This is the consequence of the relatively low utility of car ownership, in contrast with small municipalities associated with high utility from holding a car. When the tax is proportional to income, there is significant redistribution from the largest municipalities to the smallest ones. The average individual surplus losses in cities of more than 200,000 inhabitants are between $-€ 10$ and $-€ 7.4$, representing variations in their surplus of $-1.6 \%$ and $-2 \%$, respectively.

I provide additional results on the heterogeneity of the feebate effects across individuals in Appendix D.4. First, I illustrate the relationship between the variation in individual surplus and income in Figure 4 using local polynomial regressions. Under the uniform tax scenario, the curve is bell-shaped. Under a proportional tax, the consumer surplus variation is flat until $€ 25,000$ (a value close to the ninth income decile) and decreases slowly for the surplus variation in percentage and more rapidly for variation in level terms. It suggests that my analysis by income decile hides heterogeneity at the extreme top of the income distribution and reveals that the feebate hurts very high-income individuals. Secondly, I use an alternative method to analyse the role of income that relies on computing the variation in consumer surplus associated with each income decile of the national income distribution (Table 28). The results confirm that the losses are highest for low-income individuals 
Table 7: Average consumer surplus variation and average emissions variation by income decile and population density

\begin{tabular}{|c|c|c|c|c|c|c|c|c|c|c|c|c|c|c|c|}
\hline & & \multicolumn{6}{|c|}{$\Delta$ consumer surplus } & \multicolumn{8}{|c|}{$\Delta$ emissions } \\
\hline & & \multicolumn{2}{|c|}{ No tax } & \multicolumn{2}{|c|}{ Unif. tax } & \multicolumn{2}{|c|}{ Prop. tax } & \multicolumn{2}{|c|}{$\Delta \mathrm{NO}_{\mathrm{X}}$} & \multicolumn{2}{|c|}{$\Delta \mathrm{PM}$} & \multicolumn{2}{|c|}{$\Delta \mathrm{CO}$} & \multicolumn{2}{|c|}{$\Delta \mathrm{HC}$} \\
\hline & & lev. & $\%$ & lev. & $\%$ & lev. & $\%$ & lev. & $\%$ & lev. & $\%$ & lev. & $\%$ & lev. & $\%$ \\
\hline \multicolumn{16}{|c|}{ Income decile } \\
\hline d1 & 14,800 & 18.8 & 2.21 & -10.5 & -1.56 & -2.28 & -0.54 & 0.37 & 0.23 & 0.14 & 0.19 & 0.044 & 0.023 & -0.006 & -0.018 \\
\hline $\mathrm{d} 2$ & 15,767 & 19 & 2.83 & -10.3 & -2.33 & -5.1 & -1.42 & 0.48 & 0.31 & 0.17 & 0.24 & -0.18 & -0.074 & -0.033 & -0.1 \\
\hline d3 & 16,489 & 20.3 & 2.85 & -9.02 & -1.92 & -5.05 & -1.27 & 0.52 & 0.34 & 0.19 & 0.26 & -0.24 & -0.098 & -0.039 & -0.12 \\
\hline $\mathrm{d} 4$ & 17,149 & 21.1 & 2.87 & -8.13 & -2.04 & -5.31 & -1.57 & 0.57 & 0.38 & 0.2 & 0.29 & -0.31 & -0.13 & -0.048 & -0.15 \\
\hline d5 & 17,767 & 22.1 & 2.86 & -7.22 & -1.87 & -5.36 & -1.57 & 0.61 & 0.42 & 0.21 & 0.31 & -0.37 & -0.15 & -0.054 & -0.17 \\
\hline d6 & 18,538 & 23.3 & 2.83 & -5.99 & -1.73 & -5.26 & -1.61 & 0.67 & 0.46 & 0.23 & 0.33 & -0.44 & -0.17 & -0.061 & -0.19 \\
\hline $\mathrm{d} 7$ & 19,588 & 25.5 & 2.69 & -3.82 & -1.37 & -4.47 & -1.45 & 0.72 & 0.5 & 0.24 & 0.36 & -0.49 & -0.2 & -0.066 & -0.2 \\
\hline $\mathrm{d} 8$ & 21,009 & 27.8 & 2.49 & -1.44 & -0.58 & -4.04 & -0.85 & 0.81 & 0.57 & 0.27 & 0.4 & -0.61 & -0.24 & -0.077 & -0.23 \\
\hline d9 & 23,339 & 29.9 & 2.45 & 0.63 & -0.4 & -4.67 & -0.93 & 0.96 & 0.7 & 0.31 & 0.48 & -0.82 & -0.32 & -0.1 & -0.3 \\
\hline d10 & 50,695 & 30.4 & 2.71 & 1.1 & -0.35 & -13.1 & -1.84 & 1.5 & 1.3 & 0.43 & 0.81 & -1.7 & -0.57 & -0.2 & -0.54 \\
\hline \multicolumn{16}{|c|}{ Population density } \\
\hline$<2,0$ & & 26.4 & 2.26 & -2.86 & -0.66 & -1.61 & -0.39 & 0.59 & 0.39 & 0.2 & 0.29 & -0.25 & -0.1 & -0.035 & -0.11 \\
\hline 2,00 & 4,999 & 26.9 & 2.59 & -2.42 & -0.84 & -1.81 & -0.63 & 0.61 & 0.41 & 0.22 & 0.31 & -0.34 & -0.14 & -0.046 & -0.14 \\
\hline 5,00 & 9,999 & 25.9 & 2.63 & -3.36 & -0.98 & -2.4 & -0.7 & 0.61 & 0.41 & 0.21 & 0.31 & -0.33 & -0.14 & -0.046 & -0.14 \\
\hline 10,0 & $-19,999$ & 23.4 & 2.82 & -5.91 & -1.31 & -4.25 & -0.98 & 0.59 & 0.4 & 0.21 & 0.3 & -0.33 & -0.13 & -0.048 & -0.15 \\
\hline 20,0 & $-49,999$ & 19.7 & 3.01 & -9.53 & -2.31 & -7.81 & -1.9 & 0.69 & 0.49 & 0.23 & 0.35 & -0.5 & -0.2 & -0.071 & -0.21 \\
\hline 50,0 & $-99,999$ & 20.2 & 2.98 & -9.04 & -2.2 & -6.79 & -1.72 & 0.65 & 0.45 & 0.22 & 0.33 & -0.45 & -0.18 & -0.065 & -0.2 \\
\hline $100,($ & $0-199,999$ & 19.3 & 3.14 & -9.99 & -2.77 & -8.71 & -2.4 & 0.71 & 0.51 & 0.24 & 0.36 & -0.56 & -0.22 & -0.078 & -0.24 \\
\hline 200, & 0-2 million & 21.5 & 2.94 & -7.77 & -2.19 & -7.38 & -2.04 & 0.75 & 0.54 & 0.25 & 0.38 & -0.59 & -0.22 & -0.081 & -0.24 \\
\hline Pari & area & 25.5 & 2.55 & -3.77 & -0.82 & -10 & -1.64 & 1.1 & 0.95 & 0.33 & 0.58 & -1.1 & -0.36 & -0.13 & -0.36 \\
\hline Aver & & 23.8 & 2.68 & -5.46 & -1.41 & -5.46 & -1.31 & 0.72 & 0.53 & 0.24 & 0.37 & -0.51 & -0.19 & -0.069 & -0.2 \\
\hline
\end{tabular}

and reveal higher welfare losses at the top of the income distribution, implying even more redistribution than my benchmark estimates suggest. Finally, I investigate the role of other demographics (household size and socio-professional activity) to characterise the winners and losers in Table 29. In the demand model, consumer preferences vary by income, type of area (rural or urban) and household size (with or without children). The effect of the policy can nevertheless be heterogeneous along with other demographic characteristics because these are correlated with income, type of area and household size. The results reveal that the feebate generates higher gains, in relative terms, for low and medium socio-professional categories and hurts more families with children.

Heterogeneity across car manufacturers. Figure 1 displays the profit variation for each car manufacturer. Although the feebate policy increases industry profits by $2.1 \%$, the gains are heterogeneous across manufacturers, and some are worse off because of the feebate regulation. As previously noted, the increase in French manufacturers' profits is greater than the increase in profits for the sector overall. The distribution of gains and losses at the car manufacturer level indicates that there are winners and losers. French manufacturers and the Fiat Group (Italian) are the big winners, while the big losers are German manufacturers, except Volkswagen, which is barely affected (its profits increase by only $0.15 \%$ ). There is more heterogeneity among Asian car manufacturers: most of them (Toyota, Nissan, Suzuki, Honda, Mitsubishi, Subaru, Ssangyong) lose, but some improve their situation (Hyundai and Mazda). Among American car manufacturers, Ford and GM are better off, while Chrysler is severely harmed. 
The two French manufacturers gain the most: the PSA Group's profits increase by $€ 97.5$ million, while the gains for the Renault Group amount to $€ 60$ million. The third-largest winner from the feebate policy is Fiat, with $€ 20$ million additional profits. Fiat's profits increase the most in relative terms $(6.3 \%)$. The increase in earnings in relative terms is smaller for PSA (4.1\%) and Renault (3.3\%). Daimler (Mercedes) suffers the most in absolute terms (-€13.5 million, which corresponds to a reduction in its profits of $6.1 \%$.) Porsche is the manufacturer with the most significant profit reduction in relative terms $(-32.1 \%)$. Chrysler, Mitsubishi, Ssangyong and Lada are significantly harmed by the feebate policy, with profit reductions of $18.5 \%, 11.2 \%, 20.6 \%$ and $24.9 \%$, respectively.

Figure 1: Profit variations by car manufacturer

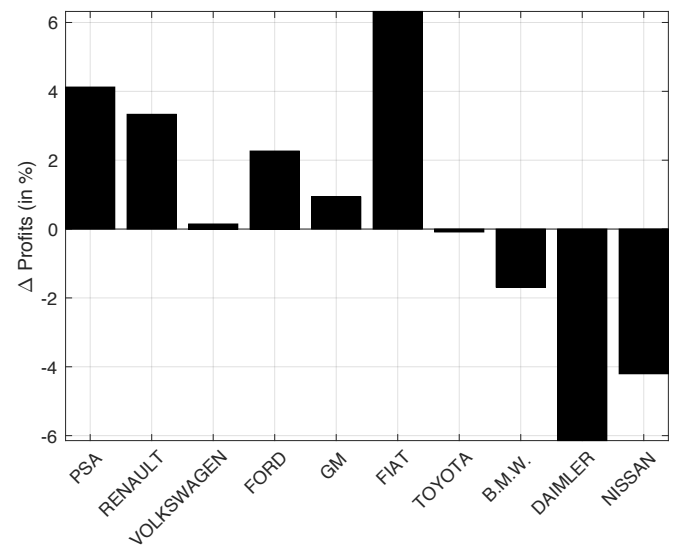

(a) Top 10 car manufacturers

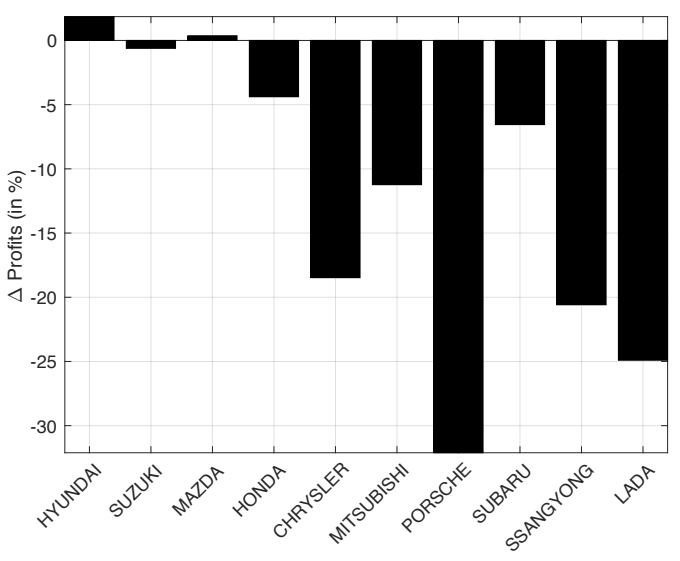

(b) Top 11-19 car manufacturers

\begin{tabular}{|c|c|c|c|c|c|c|c|}
\hline \multicolumn{2}{|c|}{ Group } & 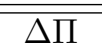 & $\bar{\Delta} \% \Pi$ & \multicolumn{2}{|c|}{ Group } & $\Delta \Pi$ & $\Delta \% \Pi$ \\
\hline 1 & PSA & 97.5 & 4.12 & 11 & HYUNDAI & 2.26 & 1.85 \\
\hline 2 & RENAULT & 60 & 3.33 & 12 & SUZUKI & -0.691 & -0.617 \\
\hline 3 & VOLKSWAGEN & 1.26 & 0.147 & 13 & MAZDA & 0.2 & 0.367 \\
\hline 4 & FORD & 10 & 2.27 & 14 & HONDA & -1.94 & -4.39 \\
\hline 5 & GM & 3.14 & 0.933 & 15 & CHRYSLER & -4.9 & -18.5 \\
\hline 6 & FIAT & 20.2 & 6.32 & 16 & MITSUBISHI & -1.25 & -11.2 \\
\hline 7 & TOYOTA & -0.285 & -0.085 & 17 & PORSCHE & -2.86 & -32.1 \\
\hline 8 & B.M.W. & -4.34 & -1.69 & 18 & SUBARU & -0.245 & -6.55 \\
\hline 9 & DAIMLER & -13.5 & -6.14 & 19 & SSANGYONG & -0.619 & -20.6 \\
\hline 10 & NISSAN & -6.94 & -4.2 & 20 & LADA & -0.026 & -24.9 \\
\hline
\end{tabular}

Note: “ $\Delta \Pi$ " represents profit variations in millions of euros, and " $\Delta \% \Pi$ " represents profit variations in percentages of the profits without the feebate.

Heterogeneity in the emissions of local pollutants. I analyse the heterogeneity of the feebate's effects on the emissions of local pollutants. I do not analyse the distributional impacts on $\mathrm{CO}_{2}$ emissions since these emissions do not directly affect the air quality of individuals but rather have a global impact on the environment. Figure 5 in Appendix D.4 displays the distributions of the variations in average emissions for the four different air pollutants. Even though the feebate increases the emissions of $\mathrm{NO}_{\mathrm{X}}$ and $\mathrm{PM}$ and decreases the emissions of $\mathrm{HC}$ and $\mathrm{CO}$, the magnitudes are heterogeneous across municipalities. $\mathrm{HC}$ 
and $\mathrm{CO}$ emissions increase in some municipalities because of the feebate policy, but the increases are all lower than $0.24 \%$.

I investigate in more detail how the heterogeneity in the feebate's effect on emissions relates to the demographic characteristics of municipalities. I first examine the average variation in emissions by income decile. As Table 7 above shows, there are clear relations between the variations in emissions and income deciles. Variations in both $\mathrm{NO}_{\mathrm{X}}$ and $\mathrm{PM}$ increase with income, while variations in $\mathrm{CO}$ and $\mathrm{HC}$ emissions decrease. Emissions of $\mathrm{CO}$ even increase in the lowest income decile while reducing in the other income deciles. The feebate appears to be progressive for $\mathrm{NO}_{\mathrm{X}}$ and $\mathrm{PM}$ but regressive for $\mathrm{CO}$ and $\mathrm{HC}$. Provided that $\mathrm{NO}_{\mathrm{X}}$ and $\mathrm{PM}$ are more harmful and costly than $\mathrm{HC}$ and $\mathrm{CO}$ for individuals, I can conclude that the feebate induces redistribution from rich to poor municipalities. The largest variations in $\mathrm{NO}_{\mathrm{X}}$ and $\mathrm{PM}$ by income decile are $1.3 \%$ and $0.8 \%$, respectively. These figures are far below the maximum variation levels, indicating that some heterogeneity remains within the highest income deciles.

Next, I compute the average variation in emissions levels by municipality size. A clear pattern emerges once again: the most significant decreases in $\mathrm{CO}$ and $\mathrm{HC}$ emissions and the largest increases in $\mathrm{NO}_{\mathrm{X}}$ and $\mathrm{PM}$ emissions occur in urban areas. In the Paris area, the feebate causes a rise of $1.1 \mathrm{mg} / \mathrm{km}$ in average emissions of $\mathrm{NO}_{\mathrm{X}}$, while in cities with fewer than 20,000 inhabitants, the increase is lower than $0.41 \mathrm{mg} / \mathrm{km}$. Similarly, the increase in PM emissions is around $0.3 \%$ in municipalities with fewer than 20,000 inhabitants, but the rise is almost twice as large in the Paris area $(+0.58 \%)$. Given that the levels of $\mathrm{NO}_{\mathrm{X}}$ and $\mathrm{PM}$ emissions constitute a critical issue in large cities, the feebate's unintended effect on these emissions raises serious concerns.

Finally, I turn to the heterogeneity in the variation of emissions according to the initial emissions levels. In the previous section, I find that the total cost of local pollutants increases by at most $14 \%$ when using heterogeneous social costs that increase with average initial car emissions or average air emissions concentrations (see Table 26 in Appendix D.3). This low value indicates that the emissions do not increase too much where they are initially high. But it may nevertheless hide some differences across pollutants and municipalities that I investigate here. In the left panel of Figure 2, I plot the variations in average emissions in percentage terms as a function of the initial emissions levels (i.e. average emissions of car purchases in the absence of the feebate) using local polynomial regressions. These graphs reveal that emissions of all the four pollutants increase most where they are initially the lowest. This is because the feebate causes an increase in average emissions of $\mathrm{NO}_{\mathrm{X}}$ and $\mathrm{PM}$ in urban and wealthy municipalities, which initially have low average emissions of $\mathrm{NO}_{\mathrm{X}}$ and PM. Similarly, the feebate decreases the emissions of $\mathrm{CO}$ and $\mathrm{HC}$ where they are initially higher, again in urban and wealthy municipalities. These municipalities typically have a lower share of diesel cars, explaining this pattern. The feebate, therefore, achieves some redistribution regarding emissions of local pollutants from the high-emissions municipalities to the low-emissions municipalities.

I obtain rather different results for the heterogeneity across air emissions concentration levels. A city's air emissions concentration relates to many factors on top of car fleet composition: traffic intensity, manufacturing activities and probably weather conditions that 
are more or less favourable to the dispersion of air particles. I obtain negative correlations between air emissions concentrations and average car emissions across municipalities (between -0.30 of -0.05 depending on the pollutant). The second panel of Figure 2 suggests that all emissions increase most where they are medium or high, indicating a negative indirect effect of the feebate policy on air quality. It is particularly the case of $\mathrm{NO}_{\mathrm{X}}$ emissions, which increase the most where $\mathrm{NO}_{2}$ emissions are highest, i.e., in dense and rich municipalities and the Paris area. I find slightly less heterogeneity in the variation in PM, CO and $\mathrm{HC}$ emissions, but the emissions tend to rise most where air concentrations are medium or high. In Appendix D.4, I provide the same graphs with variations in emissions in levels (Figure 6). I also show the detailed figures for the average change in emissions by emission deciles (Table 30) and analyse where diesel shares increase most (Figure 7).

Figure 2: Emissions variation in percentage terms as a function of emissions levels
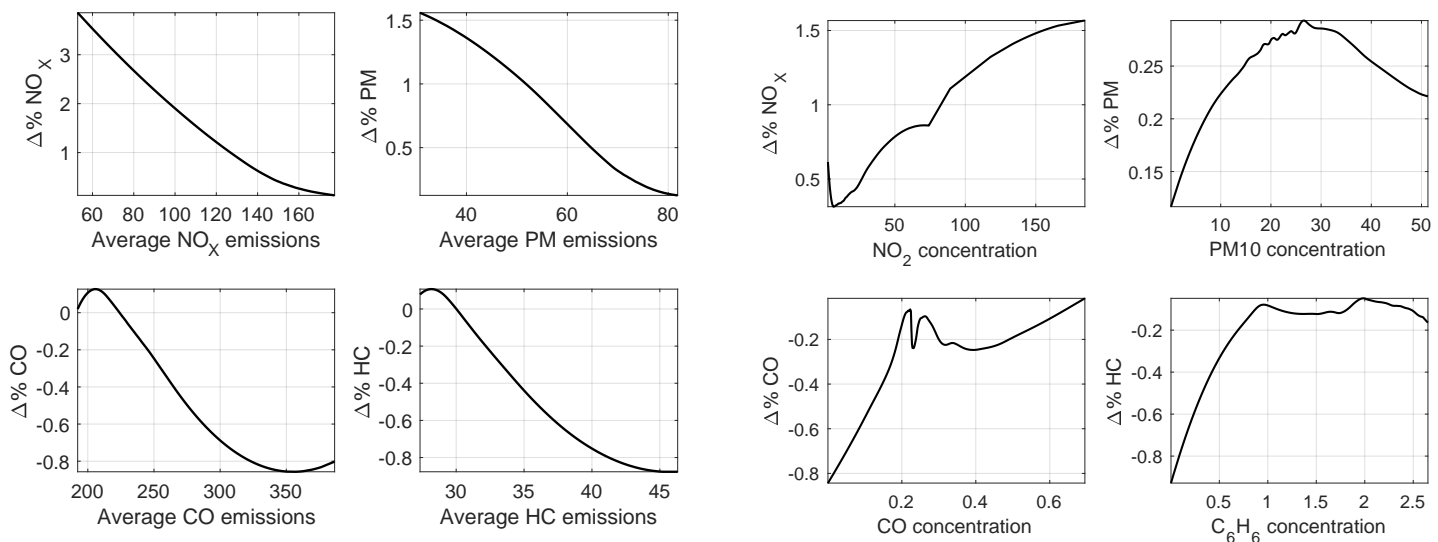

(a) Average car emissions

(b) Average air emissions concentrations

Note: Local polynomial regressions using second-order polynomials. Average car emissions are in mg/km except $P M$ emissions are in $\mathrm{mg} / 10 \mathrm{~km}$. Concentrations of $\mathrm{NO}_{2}, P M 10$ and $\mathrm{C}_{6} \mathrm{H}_{6}$ are in $\mu \mathrm{g} / \mathrm{m}^{3}$. Concentrations of $C O$ are in $\mathrm{mg} / \mathrm{m}^{3}$.

\subsection{Performance of the feebate scheme}

I assess the performance of the actual feebate scheme in terms of redistribution across households and the limitation of emissions of local pollutants and the diesel car share. I investigate alternative feebate schemes that achieve the same average $\mathrm{CO}_{2}$ emissions at the same budget as that of the current policy. Since there is an infinite number of possible thresholds, fees and rebates that generate these two outcomes, I restrict my attention to linear feebate schemes with differentiated slopes. These linear feebate schemes are defined by three parameters: the pivot point, the rebate slope and the fee slope. This restriction is necessary because I have two outcomes to match: average $\mathrm{CO}_{2}$ emissions and the pecuniary cost of the policy. Therefore, for a given pivot point, the marginal tax and rebate rates are pinned down by matching these two outcomes to those of the current feebate. I consider three classes of feebate schemes that differ in their applicability. The first feebate class applies uniformly to all cars. The second penalises diesel cars by preventing them from receiving rebates. The third disadvantages diesel cars by dividing their rebates by two while doubling 
their taxes. Formally, the feebate schemes of the three classes are given by:

$$
\begin{aligned}
\lambda_{j}^{(1)}= & r \times\left(e_{j}-\bar{e}\right) \mathbb{1}\left(e_{j} \leq \bar{e}\right)+t \times\left(e_{j}-\bar{e}\right) \mathbb{1}\left(e_{j} \geq \bar{e}\right) \\
\lambda_{j}^{(2)}= & r \times\left(e_{j}-\bar{e}\right) \mathbb{1}\left(e_{j} \leq \bar{e}\right) \mathbb{1}(\text { fuel }=\text { gasoline })+t \times\left(e_{j}-\bar{e}\right) \mathbb{1}\left(e_{j} \geq \bar{e}\right) \\
\lambda_{j}^{(3)}= & \frac{r}{2} \times\left(e_{j}-\bar{e}\right) \mathbb{1}\left(e_{j} \leq \bar{e}\right)+\frac{r}{2} \times\left(e_{j}-\bar{e}\right) \mathbb{1}\left(e_{j} \leq \bar{e}\right) \mathbb{1}(\text { fuel = gasoline }) \\
& +t \times\left(e_{j}-\bar{e}\right) \mathbb{1}\left(e_{j} \geq \bar{e}\right)+t \times\left(e_{j}-\bar{e}\right) \mathbb{1}\left(e_{j} \geq \bar{e}\right) \mathbb{1}(\text { fuel }=\text { diesel }),
\end{aligned}
$$

where $\lambda_{j}$ represents the rebate (fee) associated with car model $j, e_{j}$ represents the $\mathrm{CO}_{2}$ emissions of the car, and $\bar{e}$ is the pivot point that separates the positive from the negative feebates. $r$ (respectively $t$ ) is the marginal rebate (tax) rate for each unit of $\mathrm{CO}_{2}$ emissions below (above) the pivot point.

I compare the current feebate scheme to the optimal schemes for several different outcomes and several different objective functions. I use consumer surplus, national manufacturers' profits, emissions of local pollutants and diesel car share as outcomes. I consider four objective functions that put different weights for each municipality's outcome in the global objective: weights that are simply proportional to the population size; weights that are proportional to the population size and favour municipalities with low initial outcomes; a Rawlsian weighting scheme that puts all weight on the most disadvantaged municipality; and a weighting system that takes into account only the difference between the best and the worst outcomes as a measure of inequality. The different outcomes, objectives and corresponding formalised objective functions are summarised in Table 31 of Appendix D.5.

In practice, I solve for the optimal feebate scheme associated with a given objective function and outcome by performing a grid search. For each value of the pivot point, I solve for the slope parameters $r$ and $t$ such that average $\mathrm{CO}_{2}$ emissions and the budget are the same as under the actual feebate. Then, I select the optimal one for the defined objective function and outcome among all these feebate schemes associated with the same $\mathrm{CO}_{2}$ emissions and budget outcomes. I jointly solve the feebate's slope parameters and the new market equilibrium (optimal prices and market shares). I provide details on the strategy developed to reduce the computation time in Appendix D.5.

Table 8 displays the potential gains from replacing the 2008 feebate scheme with an optimal alternative feebate (optimal for a defined outcome and objective function). I provide in parentheses the parameters of this optimal feebate: the pivot point (in $\mathrm{g} / \mathrm{km}$ ), the tax rate and the rebate rate (both in $€$ per $\mathrm{g} / \mathrm{km}$ ). For the consumer surplus outcome, the first three columns suggest that the actual feebate performs very well for consumer surplus maximisation. The best linear feebates with diesel penalisation have lower performance than the actual feebate to maximise the simple weighted average surplus. The uniform feebates provide positive but negligible gains, below $0.1 \%$, relative to the existing feebate scheme. In contrast, inequalities across individuals could be reduced: the current feebate scheme achieves between 88.3 and $89.3 \%$ of the best potential redistribution outcome, depending on the feebate scheme class. The optimal feebates for inequality reduction have the highest pivot points, impose high taxes (between $€ 506$ and $€ 885 \mathrm{per} \mathrm{g} / \mathrm{km}$ ) on few car models and provide low rebates for almost all cars (the rebate rates are between $€ 2$ and $€ 8$ per g/ $\mathrm{km}$ ).

There is also little room to increase French profits: they could be improved by at most $0.5 \%$ 
with a uniform feebate. Such a feebate scheme has a very low pivot point, giving few but significant rebates and taxing almost all car models. The potential gains are even lower when the objective is to improve the weighted average profits (the weights are inversely proportional to the manufacturers' market shares, giving Renault more importance than PSA). There are significant potential gains from reducing the profit difference between Renault and PSA using the feebates with the lowest pivot points, very high rebates for two car models and taxes on all other models. These are clearly very different from the feebate schemes that improve the French car manufacturers' profits, indicating that the reduction of inequalities comes at the expense of overall profit losses.

The average emissions of $\mathrm{NO}_{\mathrm{X}}$ and $\mathrm{PM}$ could be further limited. The potential gains are equal to $2.6 \%$ for the average $\mathrm{NO}_{\mathrm{X}}$ emissions and $3.5 \%$ for PM emissions using uniform feebate schemes. Still, these gains are multiplied by 1.5 to 1.6 with diesel-penalizing feebate schemes. The different emissions weights do not qualitatively change the results, and the emissions concentration weights imply slightly larger potential $\mathrm{NO}_{\mathrm{X}}$ and $\mathrm{PM}$ emissions reductions than the average car emissions weights. The emissions are most limited using feebates with relatively low pivot points (111 to $115 \mathrm{~g} / \mathrm{km}$ ), taxing approximately $98 \%$ of the car models. There is one exception for the second class of feebate scheme, which achieves the largest limitation of $\mathrm{NO}_{\mathrm{X}}$ emissions with a pivot point equal to 148 and relatively homogeneous tax and rebate rates $(€ 20 \mathrm{~g} / \mathrm{km}$ for the tax rate and $€ 61 \mathrm{~g} / \mathrm{km}$ for the rebate rate). The potential gains in limiting the simple weighted average emissions of $\mathrm{CO}$ and $\mathrm{HC}$ are much more modest. They are below $1 \%$ for both pollutants and the two types of weights under uniform feebates. The gains are even smaller or disappear with diesel-penalizing feebates. Diesel-penalizing feebate schemes indeed discourage the purchase of diesel cars, which have low $\mathrm{CO}$ and $\mathrm{HC}$ emissions.

If the objective is to reduce emissions in the municipalities where they are highest, the potential gains are heterogeneous across feebate schemes and pollutants. The potential gains are the most extensive for $\mathrm{HC}$ emissions under feebates that provide zero rebates to diesel cars (17.5\%). Such improvements are also relatively significant for CO emissions under uniform feebates $\left(11.5 \%\right.$ ) but are very small for $\mathrm{NO}_{\mathrm{X}}$ and PM emissions (at most 1.1\% and 1.3\%, respectively). There are potential gains in terms of inequality reduction for all pollutants. For instance, the current feebate achieves $42 \%$ of the maximum decrease in the difference between the lowest and highest levels of $\mathrm{HC}$ emissions. The performance is better for $\mathrm{NO}_{\mathrm{X}}$ and PM emissions, for which the current feebate scheme achieves approximately $75 \%$ and $65 \%$ of the potential optimal inequality reductions, respectively. The feebate schemes that decrease inequalities are the same for most pollutants: the pivot points are minimum (89 or $105 \mathrm{~g} / \mathrm{km}$ ), the tax rates are low (€8 or $€ 13$ ), and the rebate rates are very high. Such a feebate scheme is, in contrast, never optimal for improving consumer surplus, indicating that the reduction in emissions inequality would come at the cost of a decrease in consumer surplus.

Unsurprisingly, the results for the share of diesel closely follow those for the reduction of $\mathrm{NO}_{\mathrm{X}}$ and PM emissions. Some feebate schemes can reduce the percentage of diesel cars, with potential improvements between 3 and $5 \%$ of the optimal outcome. As expected, the gains are more significant with diesel-penalizing feebate schemes, particularly those that grant no rebates to diesel cars. These particular feebate parameters are not too different from the 
actual parameters (a pivot point of 148 to $150 \mathrm{~g} / \mathrm{km}$ versus a neutral zone between 130 and $160 \mathrm{~g} / \mathrm{km}$ for the actual feebate), except that the actual feebate does not discriminate by fuel type. In summary, the optimal feebates are heterogeneous across outcomes and objectives, revealing that a regulator would have arbitrage between the different objectives and outcomes to select the optimal regulation.

\section{Conclusion}

In this paper, I quantify both the direct and indirect effects of the feebate policy and find that it increases global welfare. Consumers are worse off when they are taxed to subsidise the policy cost, but their loss is more than offset by an increase in the profits of French manufacturers. With a uniform tax rate, the feebate appears to favour the middle-income class, while it is progressive with a tax that is proportional to income. The policy decreases average $\mathrm{CO}_{2}$ emissions by $2.2 \mathrm{~g} / \mathrm{km}$ but increases average emissions of $\mathrm{NO}_{\mathrm{X}}$ and PM, the most hazardous air pollutants. Emissions of local pollutants increase most where they are initially lowest, namely, in rich and dense municipalities, achieving more redistribution from rich to modest individuals. These rich and urban municipalities are those where air emissions concentrations are highest, revealing a pervasive effect of the feebate. Finally, the implemented feebate scheme achieves almost all of the maximum potential consumer surplus and French car manufacturer profits. The inequalities across individuals and French car manufacturers could be reduced, but this would come at the cost of global welfare losses. Alternative feebate schemes could further limit $\mathrm{NO}_{\mathrm{X}}$ and PM emissions, especially using diesel-penalising ones. However, such diesel-penalising feebates would increase emissions of $\mathrm{CO}$ and $\mathrm{HC}$ and decrease consumer surplus, indicating trade-offs across pollutants and objectives. An optimal feebate scheme design would require specifying the regulator's objective and the weights associated with each outcome, which I leave for future research. 
Table 8: Potential gains from optimal linear feebates (in \% of the optimal outcomes)

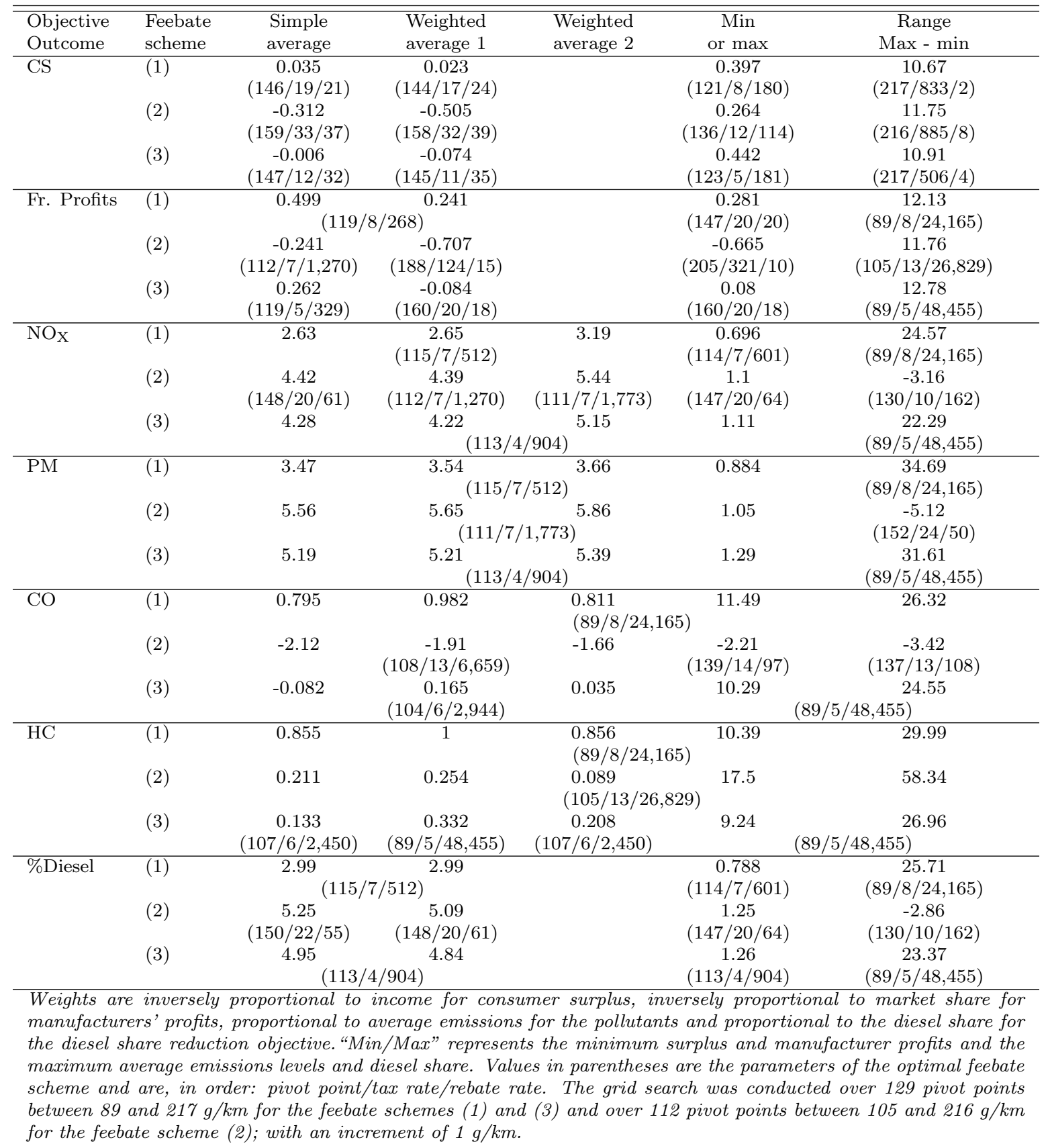




\section{References}

Adamou, A., Clerides, S., and Zachariadis, T. (2014). Welfare implications of car feebates: A simulation analysis. The Economic Journal, 124(578):F420-F443.

ADEME (2012-2015). Émissions de $\mathrm{CO}_{2}$ et de polluants des véhicules commercialisés en France. data.gouv.fr. Source: https://www. data.gouv.fr/fr/datasets/ emissions-de-co2-et-de-polluants-des-vehicules-commercialises-enfrancel, last accessed: 1 July 2021.

Allcott, H. and Kessler, J. B. (2019). The welfare effects of nudges: A case study of energy use social comparisons. American Economic Journal: Applied Economics, 11(1):236-76.

Ambec, S. and Coria, J. (2013). Prices vs quantities with multiple pollutants. Journal of Environmental Economics and Management, 66(1):123-140.

Anderson, S. P., De Palma, A., and Kreider, B. (2001). Tax incidence in differentiated product oligopoly. Journal of Public Economics, 81(2):173-192.

ATMO (2010-2019). Les données open data des AASQA. Atmo France. See https: // atmofrance. org/les-donnees/, last accessed: 1 July 2021.

Ballard, C. L., Shoven, J. B., and Whalley, J. (1985). General equilibrium computations of the marginal welfare costs of taxes in the United States. The American Economic Review, $75(1): 128-138$.

Bento, A., Freedman, M., and Lang, C. (2015). Who benefits from environmental regulation? Evidence from the Clean Air Act Amendments. Review of Economics and Statistics, 97(3):610-622.

Bento, A., Goulder, L., Jacobsen, M., and von Haefen, R. (2009). Distributional and efficiency impacts of increased US gasoline taxes. The American Economic Review, 99(3):pp. 667-699.

Berry, S., Levinsohn, J., and Pakes, A. (1995). Automobile prices in market equilibrium. Econometrica, 63:841-890.

Berry, S., Levinsohn, J., and Pakes, A. (2004). Differentiated products demand systems from a combination of micro and macro data: The new car market. Journal of political Economy, 112(1):68-105.

Bonnet, C. and Réquillart, V. (2013). Tax incidence with strategic firms in the soft drink market. Journal of Public Economics, 106:77-88.

Borenstein, S. and Davis, L. (2016). The distributional effects of US clean energy tax credits. Tax Policy and the Economy, 30(1):191-234.

CCFA (2003-2008). Fichier d'immatriculations de voitures neuves. Comité des Constructeurs Français d'Automobiles. See https: // ccfa. fr/. 
CGDD (2013). Évaluation économique du dispositif d'écopastille sur la période 2008-2012. Études 8 documents, 84.

Chen, J., Esteban, S., and Shum, M. (2008). Demand and supply estimation biases due to omission of durability. Journal of Econometrics, 147(2):247-257.

Chen, J., Esteban, S., and Shum, M. (2013). When do secondary markets harm firms? American Economic Review, 103(7):2911-34.

Crawford, G. S., Shcherbakov, O., and Shum, M. (2019). Quality overprovision in cable television markets. American Economic Review, 109(3):956-95.

Davis, L. W. and Knittel, C. R. (2019). Are fuel economy standards regressive? Journal of the Association of Environmental and Resource Economists, 6(S1):S37-S63.

DG MOVE (2014). Update of the handbook on external costs of transport. Report for the European Commission.

D'Haultfœuille, X., Durrmeyer, I., and Février, P. (2016). Disentangling sources of vehicle emissions reduction in France: 2003-2008. International Journal of Industrial Organization, 47:186-229.

D'Haultfœuille, X., Durrmeyer, I., and Février, P. (2019). Automobile prices in market equilibrium with unobserved price discrimination. The Review of Economic Studies, 86(5):1973-1998.

D'Haultfœuille, X., Givord, P., and Boutin, X. (2014). The environmental effect of green taxation: the case of the French bonus/malus. The Economic Journal, 124(578):F444F480.

Durrmeyer, I. and Samano, M. (2018). To rebate or not to rebate: Fuel economy standards versus feebates. The Economic Journal, 128(616):3076-3116.

EEA (2012-2018). Air quality time series. European Environment Agency. See https:// www. eea. europa. eu/data-and-maps/data/aqereporting-8, last accessed: 1 July 2021.

Feger, F., Pavanini, N., and Radulescu, D. (2020). Welfare and redistribution in residential electricity markets with solar power.

Gavazza, A., Lizzeri, A., and Roketskiy, N. (2014). A quantitative analysis of the used-car market. American Economic Review, 104(11):3668-3700.

Goldberg, P. (1998). The effects of the corporate average fuel efficiency standards in the US. The Journal of Industrial Economics, 46(1):1-33.

Griffith, R., Nesheim, L., and O'Connell, M. (2018). Income effects and the welfare consequences of tax in differentiated product oligopoly. Quantitative Economics, 9(1):305341. 
Gruenspecht, H. K. (1982). Differentiated regulation: The case of auto emissions standards. The American Economic Review, 72(2):328-331.

Holland, S., Mansur, E., Muller, N., and Yates, A. (2016). Are there environmental benefits from driving electric vehicles? The importance of local factors. American Economic Review, 106(12):3700-3729.

Holland, S. P., Mansur, E. T., Muller, N. Z., and Yates, A. J. (2019). Distributional effects of air pollution from electric vehicle adoption. Journal of the Association of Environmental and Resource Economists, 6(S1):S65-S94.

Huse, C. (2012). Fast and furious (and dirty): How asymmetric regulation may hinder environmental policy.

INSEE (2003-2008). Bases de données de niveau communal. Institut National the la statistique et des études économiques. Source: https://www. insee. fr/fr/ statistiques? debut=0\&geo=TOUTES_COMMUNE-1, last accessed: 1 July 2021.

Jacobsen, M. (2013). Evaluating US fuel economy standards in a model with producer and household heterogeneity. American Economic Journal: Economic Policy, 5(2):148-87.

Jacobsen, M. and Van Benthem, A. (2015). Vehicle scrappage and gasoline policy. American Economic Review, 105(3):1312-38.

Klier, T. and Linn, J. (2012). New-vehicle characteristics and the cost of the corporate average fuel economy standard. The RAND Journal of Economics, 43(1):186-213.

Levinson, A. (2019). Energy efficiency standards are more regressive than energy taxes: Theory and evidence. Journal of the Association of Environmental and Resource Economists, 6(S1):S7-S36.

Linn, J. (2019). Interactions between climate and local air pollution policies: The case of european passenger cars. Journal of the Association of Environmental and Resource Economists, 6(4):709-740.

Nurski, L. and Verboven, F. (2016). Exclusive dealing as a barrier to entry? Evidence from automobiles. The Review of Economic Studies, 83(3):1156-1188.

Opendatasoft (2016). Correspondance entre les codes postaux et codes INSEE des communes Françaises. data.gouv.fr. https: //www. data.gouv. fr/fr/datasets/ correspondance-entre-les-codes-postaux-et-codes-insee-des-communesfrancaises/\#_, last accessed: 1 July 2021.

Petrin, A. (2002). Quantifying the benefits of new products: The case of the minivan. Journal of Political Economy, 110(4):705-729.

Reguant, M. (2019). The efficiency and sectoral distributional impacts of large-scale renewable energy policies. Journal of the Association of Environmental and Resource Economists, 6(S1):S129-S168. 
Reynaert, M. and Sallee, J. M. (2021). Who benefits when firms game corrective policies? American Economic Journal: Economic Policy, 13(1):372-412.

Small, K. A. and Rosen, H. S. (1981). Applied welfare economics with discrete choice models. Econometrica: Journal of the Econometric Society, pages 105-130.

UK Vehicle Certification Agency (2000-2018). Car fuel data, $\mathrm{CO}_{2}$ and vehicle tax tools. UK Vehicle Certification Agency. Source: https:// carfueldata. vehiclecertification-agency.gov. uk/downloads/archive. aspx, last accessed: 1 July 2021.

West, S. (2004). Distributional effects of alternative vehicle pollution control policies. Journal of public Economics, 88(3):735-757. 


\section{A Predicting emissions}

\section{A.1 Data and reduced form equation for local pollutant emissions}

Here, I provide details on the data and the reduced form model used to predict emissions of local pollutants for car models in 2008. The first dataset comes from the French Energy Agency (ADEME) and provides information on the emissions levels for all car models sold in France from 2012 to 2015. ${ }^{15}$ The second dataset comes from the UK Vehicle Certification Agency and provides the emissions levels for the car models sold in the UK over the period 2000-2018. In the two datasets, the emissions levels of $\mathrm{NO}_{\mathrm{X}}, \mathrm{PM}, \mathrm{CO}$ and $\mathrm{HC}$, are measured with driving cycle tests. The ADEME dataset contains information on the main car characteristics: fuel type, body style, horsepower, weight and $\mathrm{CO}_{2}$ emissions. The UK data, in contrast, provide much less information: fuel type, $\mathrm{CO}_{2}$ emissions and cylinder capacity. I use a simple model to predict the values of the emissions of local pollutants for CCFA car models sold in 2008 based on the observable car characteristics and estimated from the combination of the ADEME and UK data. First, I exclude car models (i.e., model names) that are not in the CCFA dataset. The combination of the ADEME and UK samples provides 48,908 observations. The ADEME data account for $27.2 \%$ of the final sample, while the UK data account for $72.8 \%$. Unfortunately, emissions are not reported for all pollutants, so the regressions use fewer than the total number of observations.

I regress the emissions on the main car characteristics: horsepower, weight, $\mathrm{CO}_{2}$ emissions, and body style. I allow these characteristics to have differentiated effects depending on the type of fuel. I include fuel-specific year fixed effects, except for PM emissions, since I do not observe PM emissions for gasoline cars in the UK data. I also use the emissions standards of all pollutants as controls; these regressors capture trade-offs between the different emissions. I provide details on Euro emissions standards by year and fuel type in Table 9 below. I introduce a sample dummy (UK or ADEME) and model name fixed effects. To predict emissions for the car models that are not present in the ADEME or UK dataset, I use the average of the model fixed effects by segment. I estimate a model fixed effect for $73 \%$ to $89 \%$ of the car models in the CCFA dataset, depending on the pollutant.

I estimate the prediction models for $\mathrm{CO}, \mathrm{NO}_{\mathrm{X}}, \mathrm{PM}$, and $\mathrm{HC}$ separately because the missing values are not uniform across pollutants. I also estimate the same reduced-form equation for $\mathrm{CO}_{2}$ emissions and test the external validity of the prediction model by comparing the observed and predicted values. The parameter estimates are displayed in Table 10. Overall, the observable car characteristics explain significant percentages of the variance in emissions, and the $\mathrm{R}^{2}$ are between 0.511 (for $\mathrm{CO}$ ) and 0.955 (for $\mathrm{NO}_{\mathrm{X}}$ ).

\footnotetext{
${ }^{15}$ The data are not available before 2012, and ADEME stopped releasing publicly such data after 2015 .
} 
Table 9: Emissions standards under Euro 2-Euro 6

\begin{tabular}{llccccc}
\hline \hline & & Euro 2 & Euro 3 & Euro 4 & Euro 5 & Euro 6 \\
$(1997-2000)$ & $(2001-2005)$ & $(2006-2010)$ & $(2011-2014)$ & $(2015-2018)$ \\
\hline Diesel & $\mathrm{NO}_{\mathrm{X}}$ & - & 500 & 250 & 180 & 80 \\
& $\mathrm{PM}$ & 800 & 500 & 250 & 50 & 45 \\
& $\mathrm{CO}$ & 1000 & 640 & 500 & 500 & 500 \\
& $\mathrm{HC}+\mathrm{NO}_{\mathrm{X}}$ & 700 & 560 & 300 & 230 & 170 \\
& $\mathrm{HC}$ (inferred) & & 60 & 50 & 50 & 90 \\
\hline Gasoline & $\mathrm{NO}$ & - & 150 & 80 & 60 & 60 \\
& $\mathrm{PM}$ & - & - & - & 50 & 45 \\
& $\mathrm{CO}$ & 2,200 & 2,200 & 1,000 & 1,000 & 1,000 \\
& $\mathrm{HC}$ & - & 200 & 100 & 100 & 100 \\
\hline
\end{tabular}

Note: All emissions are in $\mathrm{mg} / \mathrm{km}$, except $P M$, in $\mathrm{mg} / 10 \mathrm{~km}$. For diesel cars, HC is not regulated per se, but there is a limit on the total emissions of $H C$ and $N O_{X}$. I infer a hypothetical norm of HC from the difference between the norm on $H C+N O_{X}$ and $N_{X}$. Under Euro 5, the PM emissions standard for gasoline cars applies to vehicles with direct injection engines only. Since I cannot distinguish which vehicles have such engines, I consider all gasoline cars are subject to this standard.

The effects of car characteristics depend on the fuel type and the pollutant. Horsepower is positively correlated with emissions of most of the pollutants for both fuel types (except for $\mathrm{PM}$ and $\mathrm{CO}$ for gasoline engines). At the same time, weight is negatively related to emissions (except for PM and diesel cars). The correlation between emissions of local pollutants and $\mathrm{CO}_{2}$ emissions is heterogeneous across pollutants and fuel types. While there is a negative association between $\mathrm{CO}_{2}$ emissions and $\mathrm{CO}$ and PM emissions for diesel cars, I obtain positive correlations for the other pollutants and engine types. The body types (wagon and convertible) have less explanatory power. Both wagon and convertible are significant for $\mathrm{NO}_{\mathrm{X}}$ and diesel vehicles, while for $\mathrm{CO}$ and $\mathrm{HC}$, only the variable convertible interacted with gasoline is significant. The high correlation that exists between car attributes probably explains these differences. Finally, the parameters of the diesel dummies indicate that diesel cars emit on average more $\mathrm{NO}_{\mathrm{X}}, \mathrm{PM}$ and $\mathrm{CO}$ but less $\mathrm{HC}$ than gasoline cars. The coefficients of emissions standards are significant. The emissions standards of the dependent pollutant always positively affect emissions, while the standards for the other pollutants have different signs. For instance, the standard for $\mathrm{NO}_{\mathrm{X}}$ is negatively correlated with $\mathrm{PM}, \mathrm{CO}$ and $\mathrm{HC}$ but positively correlated with $\mathrm{CO}_{2}$. The standard for $\mathrm{HC}$ is negatively associated with $\mathrm{NO}_{\mathrm{X}}, \mathrm{PM}$ and $\mathrm{CO}_{2}$, reflecting the trade-off among pollutants. Time trends are also negative and appear differentiated by the type of fuel. They are also steeper for diesel cars than for gasoline cars for $\mathrm{NO}_{\mathrm{X}}$ and $\mathrm{CO}$. 
Table 10: Regression of emissions of local pollutants on car characteristics

\begin{tabular}{|c|c|c|c|c|c|}
\hline & $\mathrm{NO}_{\mathrm{X}}$ & $\mathrm{PM}$ & $\mathrm{CO}$ & $\mathrm{HC}$ & $\mathrm{CO}_{2}$ \\
\hline Horsepower $\times$ Gasoline & $\begin{array}{l}0.21^{* *} \\
(0.069)\end{array}$ & $\begin{array}{l}-0.32 \\
(0.32)\end{array}$ & $\begin{array}{l}-2.8^{* *} \\
(0.46)\end{array}$ & $\begin{array}{l}0.018 \\
(0.041)\end{array}$ & ${ }_{(0.055)}^{2.3}{ }^{* *}$ \\
\hline Horsepower $\times$ Diesel & $\begin{array}{l}0.27 \\
(0.17)\end{array}$ & ${ }_{(0.63)}{ }^{*}$ & $\begin{array}{l}10.3^{* *} \\
(1.1)\end{array}$ & $\begin{array}{l}0.36^{* *} \\
(0.1)\end{array}$ & $\begin{array}{l}0.42^{* *} \\
(0.13)\end{array}$ \\
\hline Weight $\times$ Gasoline & $\begin{array}{l}-0.72^{* *} \\
(0.17)\end{array}$ & $\begin{array}{c}-0.82 \\
(1.2)\end{array}$ & $\begin{array}{c}-0.95 \\
(1.1)\end{array}$ & $\begin{array}{l}-0.24^{*} \\
(0.097)\end{array}$ & $\begin{array}{l}-3.9^{* *} \\
(0.13)\end{array}$ \\
\hline Weight $\times$ Diesel & $\begin{array}{l}-0.53^{* *} \\
(0.18)\end{array}$ & $\begin{array}{l}4.3^{* *} \\
(0.82)^{*}\end{array}$ & $\begin{array}{l}-8.6^{* *} \\
(1.2)\end{array}$ & $\begin{array}{l}-0.34^{* *} \\
(0.1)\end{array}$ & $\begin{array}{l}-2.1^{* *} \\
(0.14)\end{array}$ \\
\hline $\mathrm{CO}_{2} \times$ Gasoline & $\begin{array}{l}0.05 \\
(0.006)\end{array}$ & $\stackrel{0.22}{0}_{(0.092)}^{*}$ & $\begin{array}{l}0.62 \\
(0.038)\end{array}$ & $\begin{array}{l}0.05 \\
(0.003)\end{array}$ & \\
\hline $\mathrm{CO}_{2} \times$ Diesel & $\begin{array}{l}0.12 \\
(0.009)\end{array}$ & $\begin{array}{l}-0.42^{* *} \\
(0.033)\end{array}$ & ${ }^{-0.2^{* *}}$ & $\begin{array}{l}0.024^{* *} \\
(0.005)\end{array}$ & \\
\hline Wagon $\times$ Gasoline & $\begin{array}{l}0.86 \\
(1.5)\end{array}$ & $\begin{array}{c}1 \\
(4.9)\end{array}$ & $\begin{array}{l}-8.7 \\
(9.9)\end{array}$ & $\begin{array}{c}0.5 \\
(0.88)\end{array}$ & $\begin{array}{l}5.4^{* *} \\
(1.2)\end{array}$ \\
\hline Wagon $\times$ Diesel & $\begin{array}{l}-2.5^{\dagger} \\
(1.4)\end{array}$ & $\begin{array}{l}-5.5 \\
(4.3)\end{array}$ & $\begin{array}{l}0.93 \\
(9.3)\end{array}$ & $\begin{array}{l}-0.97 \\
(0.83)\end{array}$ & $\begin{array}{l}0.33 \\
(1.1)\end{array}$ \\
\hline Convertible $\times$ Gasoline & $\begin{array}{l}0.91 \\
(1.4)\end{array}$ & $\begin{array}{l}1.5 \\
(4.4)\end{array}$ & $\begin{array}{c}-25.1^{* *} \\
(9.2)\end{array}$ & ${ }_{(0.82)}$ & $\begin{array}{l}-6^{* *} \\
(1.1)\end{array}$ \\
\hline Convertible $\times$ Diesel & $\begin{array}{l}-5.4^{* *} \\
(1.7)\end{array}$ & $\frac{0.042}{(5.5)}$ & $\begin{array}{c}-16.9 \\
(11.3)\end{array}$ & $\begin{array}{c}-0.13 \\
(1)\end{array}$ & $\begin{array}{l}-5.6^{* *} \\
(1.4)\end{array}$ \\
\hline Diesel & $\begin{array}{l}21.6^{* *} \\
(3.6)\end{array}$ & $\begin{array}{l}16.2 \\
(13.5)\end{array}$ & $\begin{array}{l}83.4^{* *} \\
(20.3)\end{array}$ & $-\underset{(2)}{22.3^{* *}}$ & $\begin{array}{l}-59.1^{* *} \\
(2.4)\end{array}$ \\
\hline Euro norm $\mathrm{NO}_{\mathrm{X}}$ & $\begin{array}{l}0.57^{* *} \\
(0.014)\end{array}$ & $\begin{array}{l}-0.19^{* *} \\
(0.018)\end{array}$ & $\begin{array}{l}-0.71^{* *} \\
(0.023)\end{array}$ & $\begin{array}{l}-0.052^{* *} \\
(0.006)\end{array}$ & $\begin{array}{l}0.021^{* *} \\
(0.003)\end{array}$ \\
\hline Euro norm PM & $\begin{array}{l}0.059 \text { ** } \\
(0.006)\end{array}$ & $\begin{array}{l}0.45^{* *} \\
(0.015)\end{array}$ & $\begin{array}{l}0.061^{* *} \\
(0.021)\end{array}$ & $\begin{array}{c}-0.012^{* *} \\
(0.003)\end{array}$ & $\begin{array}{l}0.02 \\
(0.003)\end{array}$ \\
\hline Euro norm CO & $\begin{array}{l}0.027^{* *} \\
(0.002)\end{array}$ & $\begin{array}{l}0.069^{* *} \\
(0.005)\end{array}$ & $\begin{array}{l}0.13^{* *} \\
(0.005)\end{array}$ & $\begin{array}{l}0.014^{* *} \\
(0.001)\end{array}$ & $\begin{array}{l}-0.002^{* *} \\
(0.0006)\end{array}$ \\
\hline Euro norm HC & $\begin{array}{l}-0.63^{* *} \\
(0.022)\end{array}$ & $\begin{array}{l}-0.6^{* *} \\
(0.074)\end{array}$ & $\begin{array}{l}0.95^{* *} \\
(0.039)\end{array}$ & $\begin{array}{l}0.08^{* *} \\
(0.011)\end{array}$ & $\begin{array}{c}-0.031^{* *} \\
(0.005)\end{array}$ \\
\hline Intercept & $\begin{array}{l}8.9^{*} \\
(4.4)\end{array}$ & ${ }_{(19.1)}^{83^{* *}}$ & $\underbrace{272.3^{* *}}_{(27.6)}$ & $\begin{array}{l}46.2^{* *} \\
(2.5)\end{array}$ & ${ }_{(3.2)}^{201.9^{* *}}$ \\
\hline Trend $\times$ Gasoline & $\begin{array}{c}-0.032 \\
(0.089)\end{array}$ & $\begin{array}{l}-4.8^{* *} \\
(0.43)\end{array}$ & $\begin{array}{l}-5.9^{* *} \\
(0.53)\end{array}$ & ${ }^{-1.4^{* *}}$ & $\begin{array}{l}-3.9^{* *} \\
(0.062)\end{array}$ \\
\hline Trend $\times$ Diesel & $\begin{array}{l}-0.43^{* *} \\
(0.14)\end{array}$ & $\begin{array}{l}-4.8^{* *} \\
(0.43)\end{array}$ & $\begin{array}{l}-9^{* *} \\
(0.87)\end{array}$ & $\begin{array}{c}-0.087 \\
(0.084)\end{array}$ & $\begin{array}{l}-2^{* *} \\
(0.11)\end{array}$ \\
\hline No. observations & 42,767 & 13,847 & 48,646 & 44,066 & 48,908 \\
\hline $\mathrm{R}^{2}$ & 0.955 & 0.849 & 0.511 & 0.697 & 0.862 \\
\hline
\end{tabular}

Note: $\mathrm{NO}_{X}, \mathrm{CO}$ and $\mathrm{HC}$ are in $\mathrm{mg} / \mathrm{km}, \mathrm{PM}$ is in $\mathrm{mg} / 10 \mathrm{~km}$, and $\mathrm{CO}_{2}$ is in $\mathrm{g} / \mathrm{km}$. All the regressions include model name and fuel-specific year fixed effects. For parsimony, I present the average fuelspecific time trends only. The year fixed effects are constrained to be identical across fuel types for $P M$. Observations are weighted by the inverse of the number of versions of the model name in the year in the sample (UK or ADEME). Significance levels: ${ }^{\dagger}: 10 \%,{ }^{*}: 5 \%,{ }^{* *}: 1 \%$.

\section{A.2 Predicted emissions}

Table 11 presents the observed and predicted emissions in France and the UK. Overall the predictions are in line with the observed emissions levels by fuel type. Predicted emissions levels in 2008 are higher than the observed average in 2012-2015, except for HC and CO and only for diesel cars. The $\mathrm{HC}$ and $\mathrm{CO}$ average predicted values are nevertheless very close to the 2008 average for the UK, which is reassuring. Finally, I find that the model predicts levels of $\mathrm{CO}_{2}$ emissions that are very close to the observed emissions: the predicted averages are $2.7 \%$ and $2.1 \%$ higher than the observed emissions for gasoline and diesel cars, 
respectively.

Table 11: Average emissions of pollutants by fuel type

\begin{tabular}{|c|c|c|c|c|c|c|}
\hline & & \multicolumn{2}{|c|}{$2012-2015$} & \multicolumn{3}{|c|}{2008} \\
\hline & & $\begin{array}{c}\mathrm{FR} \\
\text { (obs.) }\end{array}$ & $\begin{array}{c}\text { UK } \\
\text { (obs.) }\end{array}$ & $\begin{array}{c}\text { FR } \\
\text { (pred.) }\end{array}$ & $\begin{array}{c}\mathrm{FR} \\
\text { (obs.) }\end{array}$ & $\begin{array}{c}\text { UK } \\
\text { (obs.) }\end{array}$ \\
\hline \multirow[t]{5}{*}{ Gasoline } & $\mathrm{NO}_{\mathrm{x}}$ & 22.94 & 24.12 & 24.4 & & 24.61 \\
\hline & PM & 18.08 & & 24.21 & & \\
\hline & $\mathrm{CO}$ & 382 & 373 & 413 & & 406 \\
\hline & $\mathrm{HC}$ & 41.92 & 42.1 & 49.32 & & 48.44 \\
\hline & $\mathrm{CO}_{2}$ & 167.6 & 166 & 190.6 & 185.6 & 208 \\
\hline \multirow[t]{5}{*}{ Diesel } & $\mathrm{NO}_{\mathrm{x}}$ & 134.9 & 132.4 & 198.3 & & 197.7 \\
\hline & PM & 12.02 & 27.58 & 90.03 & & 108.5 \\
\hline & $\mathrm{CO}$ & 231.6 & 224.3 & 155.8 & & 147.4 \\
\hline & $\mathrm{HC}$ & 26.62 & 25.84 & 23.03 & & 22.11 \\
\hline & $\mathrm{CO}_{2}$ & 140.5 & 142.5 & 166.3 & 162.9 & 172.7 \\
\hline
\end{tabular}

Table 12 below presents the correlation between the levels of emission of the different pollutants. The correlation matrix shows that the local pollutants are highly correlated with each other. There are two groups of pollutants: $\mathrm{NO}_{\mathrm{X}}$ and PM, with a correlation coefficient of 0.71 , and $\mathrm{CO}$ and $\mathrm{HC}$, with a correlation coefficient of 0.86 . However, the pollutants of the two groups are negatively and highly correlated: the correlation coefficients between $\mathrm{NO}_{\mathrm{X}}$ and $\mathrm{CO}$ and $\mathrm{HC}$ are -0.86 and -0.9 , respectively. These correlations are primarily driven by the fuel type, as we observe much weaker and different correlation signs across pollutants within fuel types.

Table 12: Correlations between the observed emissions of $\mathrm{CO}_{2}$ and predicted emissions of $\mathrm{CO}, \mathrm{NO}_{\mathrm{X}}, \mathrm{HC}$ and $\mathrm{PM}$ in 2008

\begin{tabular}{|c|c|c|c|c|c|c|c|c|c|c|c|c|}
\hline & \multicolumn{4}{|c|}{ All cars } & \multicolumn{4}{|c|}{ Gasoline } & \multicolumn{4}{|c|}{ 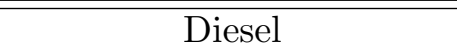 } \\
\hline & $\mathrm{NO}_{\mathrm{X}}$ & $\mathrm{PM}$ & $\mathrm{CO}$ & $\mathrm{HC}$ & $\mathrm{NO}_{\mathrm{X}}$ & $\mathrm{PM}$ & $\mathrm{CO}$ & $\mathrm{HC}$ & $\mathrm{NO}_{\mathrm{X}}$ & $\mathrm{PM}$ & $\mathrm{CO}$ & $\mathrm{HC}$ \\
\hline $\mathrm{CO}_{2}$ & -0.23 & -0.18 & 0.17 & 0.26 & 0.17 & 0.07 & -0.17 & 0.17 & 0.3 & -0.05 & -0.04 & -0.05 \\
\hline $\mathrm{NO}_{\mathrm{X}}$ & & 0.71 & -0.86 & -0.9 & & 0.07 & -0.03 & 0.45 & & 0.06 & 0.11 & 0.26 \\
\hline $\mathrm{PM}$ & & & -0.6 & -0.66 & & & 0.06 & 0.03 & & & 0.03 & -0.05 \\
\hline $\mathrm{CO}$ & & & & 0.86 & & & & 0.27 & & & & 0.47 \\
\hline
\end{tabular}

\section{A.3 Outside option emissions}

Because the feebate is likely to stimulate new car sales, I account for the environmental benefits of replacing old cars with newer ones. I need to estimate the emissions associated with the outside option. This option comprises heterogeneous underlying decisions such as 
keeping an old car, buying a car on the second-hand market and using public transport. According to the CCFA, 82.7\% of households owned a car in 2008, and the average car vintage was eight years old. Subtracting the share of new car owners, I find that $79.2 \%$ of those choosing the outside option are households that keep their old car, while $20.8 \%$ are households without a car. The households without a vehicle are assumed to have zero emissions. I predict the emissions of an average 8-year-old car by extrapolating fuel-specific time trends. I regress the emissions of car purchases on time trends over 2003-2007 for gasoline and diesel cars separately. ${ }^{16}$ I also predict the share of diesel in 2000 using the same strategy. Table 13 below shows the average emissions of an 8-year-old car by fuel type and the implied average emissions of the outside option. As expected, the average 8-year-old vehicle is much more polluting than a new car. The outside option $\mathrm{CO}_{2}$ and $\mathrm{NO}_{\mathrm{X}}$ emissions are nevertheless lower than those of an average new car in 2008 because the outside option includes non-drivers. This is not the case for PM: the outside option emissions are $60 \%$ higher than emissions from new vehicles in 2008.

Table 13: Average emissions from the outside option

\begin{tabular}{lccccc}
\hline \hline & $\mathrm{CO}_{2}$ & $\mathrm{NO}_{\mathrm{X}}$ & $\mathrm{PM}$ & $\mathrm{CO}$ & $\mathrm{HC}$ \\
\hline Gasoline, 8-year-old & 168.5 & 141.8 & 100.7 & 464.2 & 126 \\
Diesel, 8-year-old & 153.9 & 196 & 167 & 200.7 & 22.6 \\
Average 8-year-old car & 160 & 173.5 & 139.5 & 310.2 & 65.6 \\
Outside option & 126.7 & 137.4 & 110.4 & 245.6 & 51.9 \\
\hline Average car 2008 & 138.6 & 147.4 & 68.9 & 243.4 & 32.1 \\
\hline \hline Note: $\mathrm{CO}_{2}$ is in $\mathrm{g} / \mathrm{km}, \mathrm{NO}_{\mathrm{X}}, \mathrm{CO}$ and $\mathrm{HC}$ are in $\mathrm{mg} / \mathrm{km}, \mathrm{PM}$ is in $\mathrm{mg} / 10 \mathrm{~km}$.
\end{tabular}

\section{B Emissions concentrations}

I use data on average annual concentrations of $\mathrm{PM} 10, \mathrm{NO}_{2}, \mathrm{C}_{6} \mathrm{H}_{6}$ and $\mathrm{CO}$ from measurement stations over the period 2010-2019. The data are open-source, and the main source is the European Environment Agency (EEA), complemented with data from French regional air quality monitoring agencies (part of the ATMO network, see ATMO). The EEA dataset contains annual emissions concentrations for 598 measurement stations over 2012-2018. For each measurement station, I assign the municipality using the longitude and latitude coordinates. I supplement these data with the ATMO data provided by each regional agency to increase the period covered and the number of measurement stations. Finally, I merge the emissions concentrations with the dataset on household characteristics at the municipality level. The final sample covers 640 measurement stations with different coverage levels depending on the pollutant, as Table 14 shows. This table also presents descriptive statistics for the observed and predicted emissions concentrations. I predict the emissions concentrations from the observable characteristics of the municipalities. More precisely, I regress the logarithm of the concentrations on the median income and income squared, a trend and eight dummies for population density. I include the shares of households by household size and professional activity and county ("départements") fixed effects for PM10 and $\mathrm{NO}_{2}$.

\footnotetext{
${ }^{16}$ I exclude 2008 because the implementation of the feebate policy introduces a discontinuity in the trend.
} 
I do not include these controls for $\mathrm{C}_{6} \mathrm{H}_{6}$ and $\mathrm{CO}$ because there are too few observations (355 and 207, respectively). The parameter estimates of these regressions are presented in Table 15. The $\mathrm{R}^{2}$ of the regressions are relatively high for $\mathrm{NO}_{2}$ and PM10 (0.55 and 0.56, respectively), but they are lower for $\mathrm{C}_{6} \mathrm{H}_{6}$ and $\mathrm{CO}$ (0.21 and 0.26). Income and household sizes are proxies for the unobserved economic activity of the municipality, so their parameter estimates are not relevant to interpret. However, I expect more correlation between the population density and the professional activities and the emissions concentrations. I find that the share of executives has the highest positive correlation with the concentrations of PM10 and $\mathrm{NO}_{2}$. In contrast, the shares of farmers and manual labourers are negatively associated with emissions concentrations. The population density dummies are only significant for $\mathrm{NO}_{2}$, and they increase with population density, as expected. Finally, I obtain significant negative trends for all pollutants, reflecting an annual decrease by $2.8 \%$ to $4.9 \%$, depending on the pollutant.

Table 14: Observed and predicted concentration of emissions of pollutants

\begin{tabular}{|c|c|c|c|c|c|c|c|c|}
\hline & \multirow{2}{*}{$\begin{array}{c}\text { No. } \\
\text { municipalities }\end{array}$} & \multirow{2}{*}{$\begin{array}{c}\text { No. } \\
\text { stations }\end{array}$} & \multicolumn{3}{|c|}{ Observed } & \multicolumn{3}{|c|}{ Predicted } \\
\hline & & & Mean & Min & Max & Mean & Min & Max \\
\hline $\operatorname{PM} 10\left(\mu \mathrm{g} / \mathrm{m}^{3}\right)$ & 342 & 480 & 21.8 & 5.15 & 57.9 & 24.5 & 0.093 & 51.3 \\
\hline $\mathrm{NO}_{2}\left(\mu \mathrm{g} / \mathrm{m}^{3}\right)$ & 356 & 548 & 29.3 & 0.484 & 85.8 & 26.8 & 2.52 & 185 \\
\hline Benzene $\left(\mathrm{C}_{6} \mathrm{H}_{6}, \mu \mathrm{g} / \mathrm{m}^{3}\right)$ & 101 & 137 & 1.4 & 0.33 & 9.79 & 1.73 & 0.001 & 2.65 \\
\hline $\mathrm{CO}\left(\mathrm{mg} / \mathrm{m}^{3}\right)$ & 57 & 65 & 0.374 & 0.1 & 1.1 & 0.359 & 0 & 0.695 \\
\hline
\end{tabular}


Table 15: Parameter estimates of the regression of air emissions concentration on municipality characteristics

\begin{tabular}{|c|c|c|c|c|c|c|c|c|}
\hline & \multicolumn{2}{|c|}{ PM10 } & \multicolumn{2}{|c|}{$\mathrm{NO}_{2}$} & \multicolumn{2}{|c|}{$\mathrm{C}_{6} \mathrm{H}_{6}$} & \multicolumn{2}{|c|}{$\mathrm{CO}$} \\
\hline & Param. & Std. err. & Param. & Std. err. & Param. & Std. err. & Param. & Std. err. \\
\hline Income & $0.35^{\dagger}$ & 0.18 & $-0.75^{* *}$ & 0.23 & $3.4^{* *}$ & 0.92 & $2.4^{\dagger}$ & 1.4 \\
\hline Income $^{2}$ & $-0.22^{* *}$ & 0.044 & $0.12^{* *}$ & 0.039 & $-0.83^{* *}$ & 0.28 & -0.7 & 0.43 \\
\hline Couple & $0.62^{*}$ & 0.3 & -0.86 & 0.53 & & & & \\
\hline Family & $0.55^{* *}$ & 0.15 & $-0.69^{* *}$ & 0.24 & & & & \\
\hline Farmer & $-5.6^{* *}$ & 2 & -2 & 3.7 & & & & \\
\hline Entrepreneur & -0.35 & 0.99 & -2.8 & 1.7 & & & & \\
\hline Executive & $1.4^{* *}$ & 0.41 & $3.6^{* *}$ & 0.72 & & & & \\
\hline Intermediate & -0.053 & 0.49 & $1.7^{*}$ & 0.79 & & & & \\
\hline Employee & $-0.74^{\dagger}$ & 0.41 & $1.5^{*}$ & 0.67 & & & & \\
\hline Manual laborer & $-1.5^{* *}$ & 0.35 & -0.014 & 0.63 & & & & \\
\hline Retired & $-0.8^{* *}$ & 0.21 & 0.41 & 0.36 & & & & \\
\hline Trend & $-0.035^{* *}$ & 0.002 & $-0.028^{* *}$ & 0.003 & $-0.04^{* *}$ & 0.009 & $-0.048^{* *}$ & 0.014 \\
\hline $2,000-4,999$ & -0.013 & 0.08 & 0.19 & 0.14 & -0.78 & 0.94 & 0.15 & 3.2 \\
\hline $5,000-9,999$ & 0.05 & 0.073 & 0.17 & 0.15 & -0.47 & 0.96 & 0.95 & 3.3 \\
\hline $10,000-19,999$ & -0.079 & 0.073 & 0.078 & 0.14 & -0.59 & 0.93 & 0.22 & 3.2 \\
\hline $20,000-49,000$ & 0.023 & 0.068 & $0.25^{\dagger}$ & 0.13 & -0.57 & 0.92 & 0.48 & 3.2 \\
\hline $50,000-99,999$ & 0.035 & 0.068 & 0.19 & 0.13 & -0.42 & 0.91 & 0.5 & 3.2 \\
\hline $100,000-199,999$ & 0.042 & 0.069 & $0.28^{*}$ & 0.13 & -0.39 & 0.91 & 0.33 & 3.2 \\
\hline $200,000-2 \times 10^{6}$ & 0.073 & 0.07 & $0.38^{* *}$ & 0.14 & -0.35 & 0.91 & 0.78 & 3.2 \\
\hline Paris area & 0.094 & 0.11 & $1.4^{* *}$ & 0.23 & -0.14 & 0.91 & 1.1 & 3.2 \\
\hline Intercept & $3.1^{* *}$ & 0.24 & $3.5^{* *}$ & 0.41 & $-2.6^{*}$ & 1.2 & -3.6 & 3.4 \\
\hline No. obs. & & 96 & & 01 & & 55 & & 07 \\
\hline $\mathrm{R}^{2}$ & & 661 & & 52 & & 214 & & 62 \\
\hline
\end{tabular}

Note: The reference levels are singles, the socio-professional category "other" and municipalities with less than 2,000 inhabitants. All emissions concentrations are in $\mu \mathrm{g} / \mathrm{m}^{3}$ except $C O$ is in $\mathrm{mg} / \mathrm{m}^{3}$. All regressions are weighted by the municipality population divided by the number of observations per municipality. Regressions for PM10 and $\mathrm{NO}_{2}$ include county ("département") fixed effects. Significance levels: ${ }^{\dagger}: 10 \%,{ }^{*}: 5 \%,{ }^{* *}: 1 \%$.

\section{Calibration of the social costs of emissions}

As explained in the main text, I assume that the social costs of emissions in a municipality are functions of the initial pollution levels in the municipality. I calibrate different cost functions by keeping constant the average national emissions cost. I match the weighted average cost of emissions, using the municipality population sizes as weights to the value obtained with the uniform costs suggested by the report of the DG MOVE (2014). Formally, I calibrate a cost parameter $\tau_{a}^{p}$ for pollutant $p$ and the type of area $a$ (rural, suburban or urban) such that:

$$
\sum_{m} \phi_{m} \tau_{a(m)}^{p} f\left(\tilde{e}_{m}^{p}\right)=\sum_{m} \phi_{m} v_{a(m)}^{p}
$$

where $\phi_{m}$ is the share of the households located in the municipality $m . f$ is the function I calibrate (linear, quadratic or discontinuous). The function argument $\tilde{e}_{m}^{p}$ is the proxy for pollution level (the initial average car emissions, the average estimated air emissions concentrations or the population density). Finally, $v_{a(m)}^{p}$ is the uniform cost of pollutant $p$ suggested by the report of the DG MOVE (2014). It is indexed by $a(m)$, the type of 
area of the municipality, to account for heterogeneous costs of PM emissions across rural, suburban and urban areas. Since multiple combinations of emissions cost parameters satisfy this equation, I further impose $\tau_{a}^{p}$ to be identical across types of areas for $\mathrm{NO}_{\mathrm{X}}$ and $\mathrm{HC}$. For PM, I preserve the proportionality in the emissions costs suggested by the report of the DG MOVE (2014).

These different functional forms imply important heterogeneity in emissions costs across municipalities, as suggested in Table 16 below. The large ranges in air emissions concentrations, as Table 14 reveals, mechanically imply large heterogeneity in emissions costs under the linear and quadratic specifications. The population density is very heterogeneous throughout the country; this implies large ranges for emissions costs with a maximum of around $€ 7$ million for a ton of PM under the quadratic specification. Under discontinuous cost functions, a fraction of municipalities have zero emissions costs, and this fraction is heterogeneous across pollutants and specifications. $50 \%$ of the population lives in $3.5 \%$ of the municipalities; this implies that $96.5 \%$ of the municipalities have zero emissions cost for all pollutants under the discontinuous specifications using the population density. Under the other specifications, there is also important heterogeneity across pollutants and specifications. When I use average car emissions, $11 \%$ of municipalities have a positive $\mathrm{NO}_{\mathrm{X}}$ emissions cost; this percentage is equal to $77 \%$ when I use average emissions concentrations. I obtain the same pattern for PM emissions: $23 \%$ municipalities have a positive cost when I use car emissions versus $77 \%$ when I rely on air emissions concentrations). But I find the reverse for HC emissions: $81 \%$ of municipalities have a positive cost when I use car emissions, while only $23 \%$ do when I use air emissions concentrations. These 12 different specifications provide various cost estimates that I later use to check how much the total emissions cost increases when I account for potentially increasing returns to scale in emissions costs. 
Table 16: Heterogeneity in municipality emissions costs

\begin{tabular}{|c|c|c|c|c|c|c|c|c|c|}
\hline & \multicolumn{3}{|c|}{ Cost of $\mathrm{NO}_{\mathrm{X}}$} & \multicolumn{3}{|c|}{ Cost of PM } & \multicolumn{3}{|c|}{ Cost of $\mathrm{HC}$} \\
\hline \multirow[t]{2}{*}{ Uniform } & \multicolumn{3}{|c|}{13,052} & \multicolumn{3}{|c|}{$33,303 / 64,555 / 211,795^{*}$} & \multicolumn{3}{|c|}{1,695} \\
\hline & Min & $\operatorname{Max}$ & $\begin{array}{l}\text { Std. } \\
\text { dev. }\end{array}$ & Min & Max & $\begin{array}{l}\text { Std. } \\
\text { dev. }\end{array}$ & Min & Max & $\begin{array}{l}\text { Std. } \\
\text { dev. }\end{array}$ \\
\hline \multicolumn{10}{|c|}{ Function of average car emissions } \\
\hline Linear & 4,720 & 15,873 & 816 & 15,498 & 260,264 & 36,631 & 1,433 & 2,428 & 73 \\
\hline Quadratic & 1,690 & 19,115 & 1,609 & 7,122 & 315,822 & 36,703 & 1,205 & 3,461 & 145 \\
\hline Disc-unif. & 0 & 26,067 & 10,957 & 0 & 627,750 & 76,770 & 0 & 3,386 & 1,428 \\
\hline Disc-linear & 0 & 29,673 & 11,045 & 0 & 699,272 & 76,951 & 0 & 4,636 & 1,399 \\
\hline \multicolumn{10}{|c|}{ Function of average air emissions concentrations } \\
\hline Linear & 1,225 & 89,899 & 3,370 & 115 & 402,820 & 39,637 & 1.4 & 2,599 & 461 \\
\hline Quadratic & 59 & 315,965 & 5,858 & 0.4 & 715,853 & 42,411 & 0 & 3,685 & 947 \\
\hline Disc-unif. & 0 & 26,095 & 8,189 & 0 & 317,469 & 58,353 & 0 & 3,389 & 1,335 \\
\hline Disc-linear & 0 & 119,350 & 5,944 & 0 & 536,899 & 55,831 & 0 & 4,226 & 1,504 \\
\hline \multicolumn{10}{|c|}{ Function of population density } \\
\hline Linear & 1 & 240,429 & 4,718 & 1.5 & $2,237,765$ & 42,422 & 0.1 & 31,223 & 613 \\
\hline Quadratic & 0 & 849,083 & 8,274 & 0 & $7,040,416$ & 68,371 & 0 & 110,266 & 1,075 \\
\hline Disc-unif. & 0 & 26,092 & 4,794 & 0 & 292,099 & 41,951 & 0 & 3,388 & 623 \\
\hline Disc-linear & 0 & 249,949 & 4,915 & 0 & $2,277,366$ & 43,156 & 0 & 32,460 & 638 \\
\hline
\end{tabular}

Note: in $€ /$ ton of emissions. * : costs for PM in rural/suburban/urban areas.

\section{Additional Tables and Figures}

\section{D.1 Descriptive statistics}

Tables 17 and 18 present the results of the descriptive regressions to empirically investigate how car manufacturers reacted to the feebate policy in 2008. Table 17 estimates the passthrough rate of the feebate to buyers. The parameter estimate suggests that $57.6 \%$ of the rebate or fee was passed through to buyers on average. Table 18 investigates whether French car manufacturers anticipated the feebate scheme and modified the $\mathrm{CO}_{2}$ emission levels to maximise rebates. The coefficient of interest is the interaction between the French manufacturer dummy and the year 2008. If the coefficient was negative and significant, it could indicate that French manufacturers anticipated the policy. The parameter is not significant and positive, and this finding is robust to allowing the interaction coefficient to be car manufacturer-specific. In addition, these regressions indicate that the French car manufacturers typically produce cars with much lower $\mathrm{CO}_{2}$ emissions than their foreign competitors. The coefficient of the French dummy implies that French car manufacturers produce cars with $\mathrm{CO}_{2}$ emissions that are $23.2 \mathrm{~g} / \mathrm{km}$ lower than those produced by foreign car manufacturers. This suggests that French car manufacturers may benefit more from the feebate policy than foreign car manufacturers. 
Table 17: Regression of the net car price on the rebate/fee and controls

\begin{tabular}{lcc}
\hline \hline Price & Parameter & Std. error \\
\hline Rebate & $-0.576^{* *}$ & 0.122 \\
Fuel cost & $-234^{* *}$ & 67.9 \\
Horsepower & $1287^{* *}$ & 57.7 \\
Cylinder capacity & $168^{* *}$ & 29.9 \\
Weight & $1312^{* *}$ & 122 \\
Coupe/convertible & $2,594^{* *}$ & 228 \\
Station wagon & $218^{*}$ & 99.1 \\
Diesel & $1,073^{* *}$ & 324 \\
2004 & $-368^{* *}$ & 119 \\
2005 & $-438^{* *}$ & 146 \\
2006 & $-478^{* *}$ & 135 \\
2007 & $-566^{* *}$ & 136 \\
2008 & $-703^{* *}$ & 150 \\
\hline No. of observations & \multicolumn{2}{c}{5,028} \\
$\mathrm{R}^{2}$ & \multicolumn{2}{c}{0.979} \\
\hline \hline
\end{tabular}

Note: The regression includes car model fixed effects. The price and rebate are in $€$, the horsepower is the fiscal horsepower, the fuel cost is in $€ / 100 \mathrm{~km}$, the cylinder capacity is in $1,000 \mathrm{~cm}^{3}$, and the weight is in $100 \mathrm{~kg}$. The rebate is positive for a rebate and negative for a fee. Significance levels: ${ }^{\dagger}: 10 \%, *: 5 \%, * *: 1 \%$.

Table 18: Regression of $\mathrm{CO}_{2}$ emissions on year and car manufacturer origin dummies

\begin{tabular}{lcccc}
\hline \hline & Parameter & Std.err. & Parameter & Std.err. \\
\hline 2004 & -3.64 & 2.37 & -3.63 & 2.37 \\
2005 & $-6.17^{* *}$ & 2.34 & $-6.19^{* *}$ & 2.34 \\
2006 & $-7.53^{* *}$ & 2.33 & $-7.55^{* *}$ & 2.32 \\
2007 & $-10.51^{* *}$ & 2.3 & $-10.51^{* *}$ & 2.3 \\
2008 & $-18.33^{* *}$ & 2.39 & $-18.33^{* *}$ & 2.39 \\
French & $-23.22^{* *}$ & 1.9 & & \\
French $\times 2008$ & 6.58 & 4.25 & & \\
Intercept & $193.97^{* *}$ & 1.74 & $193.98^{* *}$ & 1.74 \\
Renault & & & $-19.04^{* *}$ & 2.96 \\
PSA & & & $-25.66^{* *}$ & 2.32 \\
Renault $\times 2008$ & & & 4.41 & 6.33 \\
PSA $\times 2008$ & & & 7.62 & 5.3 \\
\hline \hline
\end{tabular}

Note: $\mathrm{CO}_{2}$ emissions are in $\mathrm{g} / \mathrm{km}$. Significance levels: $\dagger: 10 \%, *: 5 \%, * *: 1 \%$.

Table 19 shows the average demographic characteristics for all municipalities and the sample of 3,000 municipalities used for the estimation. The sample is representative of the entire country. Urban and very urban areas are over-represented relative to rural areas, a direct consequence of drawing with weights proportional to the number of households. The 
sample of 3,000 municipalities shows significant variation in demographic characteristics, which is crucial for identifying heterogeneity parameters. For instance, the median income is between approximately $€ 6,000$ and $€ 44,000$. Income varies across municipalities and over time, while the other demographic characteristics are fixed over time. The frequencies of household sizes are heterogeneous in the sample, with variations from $7 \%$ to between $53 \%$ and $67 \%$.

Table 19: Descriptive statistics for the full sample and the sample of 3,000 municipalities

\begin{tabular}{|c|c|c|c|c|c|c|c|c|}
\hline \multirow{4}{*}{$\begin{array}{l}\text { No. of households } \\
\text { Income }\end{array}$} & \multicolumn{4}{|c|}{ Full sample } & \multicolumn{4}{|c|}{ Sample of 3,000 municipalities } \\
\hline & Mean & Std. dev. & Min & $\operatorname{Max}$ & Mean & Std. dev. & Min & $\operatorname{Max}$ \\
\hline & 18,347 & 30,547 & 15 & 194,661 & 20,378 & 31,373 & 49 & 173,887 \\
\hline & 17,200 & 3,918 & 5,601 & 50,696 & 17,334 & 4,010 & 6,411 & 43,849 \\
\hline \multicolumn{9}{|l|}{ Household size } \\
\hline Single & 0.35 & 0.11 & 0 & 0.75 & 0.36 & 0.11 & 0.091 & 0.67 \\
\hline Couple & 0.28 & 0.061 & 0 & 0.71 & 0.27 & 0.056 & 0.14 & 0.53 \\
\hline Family & 0.37 & 0.089 & 0.041 & 0.78 & 0.37 & 0.086 & 0.071 & 0.67 \\
\hline \multicolumn{9}{|c|}{ Professional activity } \\
\hline Farmer & 0.0095 & 0.021 & 0 & 0.52 & 0.0052 & 0.011 & 0 & 0.26 \\
\hline Entrepreneur & 0.033 & 0.015 & 0 & 0.39 & 0.031 & 0.012 & 0 & 0.2 \\
\hline Executive & 0.086 & 0.064 & 0 & 0.36 & 0.088 & 0.064 & 0 & 0.36 \\
\hline Intermediate & 0.14 & 0.038 & 0 & 0.41 & 0.14 & 0.034 & 0 & 0.31 \\
\hline Employee & 0.17 & 0.033 & 0 & 0.71 & 0.17 & 0.032 & 0 & 0.44 \\
\hline Manual laborer & 0.14 & 0.054 & 0 & 0.57 & 0.13 & 0.05 & 0 & 0.39 \\
\hline Retired & 0.26 & 0.074 & 0 & 0.76 & 0.26 & 0.07 & 0.053 & 0.65 \\
\hline Other activity & 0.17 & 0.05 & 0 & 0.57 & 0.18 & 0.045 & 0 & 0.41 \\
\hline \multicolumn{9}{|l|}{ Municipality size } \\
\hline Rural & 0.43 & 0.5 & 0 & 1 & 0.33 & 0.47 & 0 & 1 \\
\hline Urban & 0.19 & 0.39 & 0 & 1 & 0.22 & 0.41 & 0 & 1 \\
\hline Very urban & 0.38 & 0.49 & 0 & 1 & 0.45 & 0.5 & 0 & 1 \\
\hline
\end{tabular}

Note: The statistics are weighted by the number of households.

\section{D.2 Additional estimation results}

Table 20 provides the influence matrix for micro-moments and parameters of heterogeneity. This table reveals which moments are most crucial for parameter identification. Most of the time, the largest influence comes from moments constructed from the covariance between corresponding demographic and product characteristics. However, this is not the case for the parameter of income interacted with fuel cost, which is most influenced by the covariance between income and price. The parameter for urban area interacted with fuel cost is most influenced by the micro-moment involving the interaction between the dummy for urban area and fuel cost. 
Table 20: Influence matrix for heterogeneity parameters and micro-moments

\begin{tabular}{lcccccccc}
\hline \hline $\begin{array}{l}\text { Moment } \\
\text { parameter }\end{array}$ & $\begin{array}{c}\text { Income, } \\
\text { fuel cost }\end{array}$ & $\begin{array}{c}\text { Income, } \\
\text { price }\end{array}$ & $\begin{array}{c}\text { Urban, } \\
\text { fuel cost }\end{array}$ & $\begin{array}{c}\text { Urban, } \\
\text { weight }\end{array}$ & $\begin{array}{c}\text { W/o children, } \\
\text { cylinder }\end{array}$ & Income & Urban & Couple \\
\hline Income $\times$ fuel cost & -0.372 & 1.03 & 0.047 & -0.012 & 0.005 & 0.023 & -0.076 & 0.037 \\
Income $\times$ price & 1.01 & -3.49 & -0.111 & 0.026 & -0.009 & -0.048 & 0.245 & -0.097 \\
Urban $\times$ fuel cost & 0.078 & -0.082 & -0.541 & 0.312 & 0.021 & -0.413 & 0.236 & -0.28 \\
Urban $\times$ weight & -0.041 & 0.021 & 0.343 & -0.225 & -0.011 & 0.297 & -0.167 & 0.201 \\
W/o children $\times$ cylinder & -0.005 & -0.025 & 0.011 & 0.001 & -0.507 & 0.145 & -0.071 & 0.225 \\
\hline
\end{tabular}

In Table 21 below, I provide the estimated cost parameters. They all have the expected signs: it is more costly to produce powerful, fuel-efficient, heavy and high cylinder capacity cars.

Table 21: Additional estimation results

\begin{tabular}{|c|c|c|c|c|}
\hline & \multicolumn{2}{|c|}{ "Model w/o heterogeneity } & \multicolumn{2}{|c|}{ Model with heterogeneity } \\
\hline & Parameter & Std. err. & Parameter & Std. err. \\
\hline \multicolumn{5}{|l|}{ Marginal cost parameters } \\
\hline Intercept & $-1.24^{* *}$ & 0.053 & $-1.27^{* *}$ & 0.037 \\
\hline Horsepower & $0.052^{* *}$ & 0.003 & $0.049^{* *}$ & 0.003 \\
\hline Fuel consumption $(\mathrm{L} / 100 \mathrm{~km})$ & $-0.035^{* *}$ & 0.003 & $-0.023^{* *}$ & 0.003 \\
\hline Weight (100 kg) & $0.131^{* *}$ & 0.004 & $0.127^{* *}$ & 0.002 \\
\hline Cylinder capacity $\left(1,000 \mathrm{~cm}^{3}\right)$ & $0.005^{* *}$ & 0.002 & $0.005^{* *}$ & 0.002 \\
\hline
\end{tabular}

Note: Significance levels: $\dagger: 10 \%, *: 5 \%, * *: 1 \%$.

Figure 3 presents the distribution of the price sensitivity coefficient in the population. $98 \%$ of the population has a price sensitivity between -2.1 and -1.2 , while the distribution's mode is -1.55. The distribution has a noticeable tail of price-sensitive consumers since $60 \%$ of the population has a higher price sensitivity than the mode. 
Figure 3: Distribution of price sensitivities

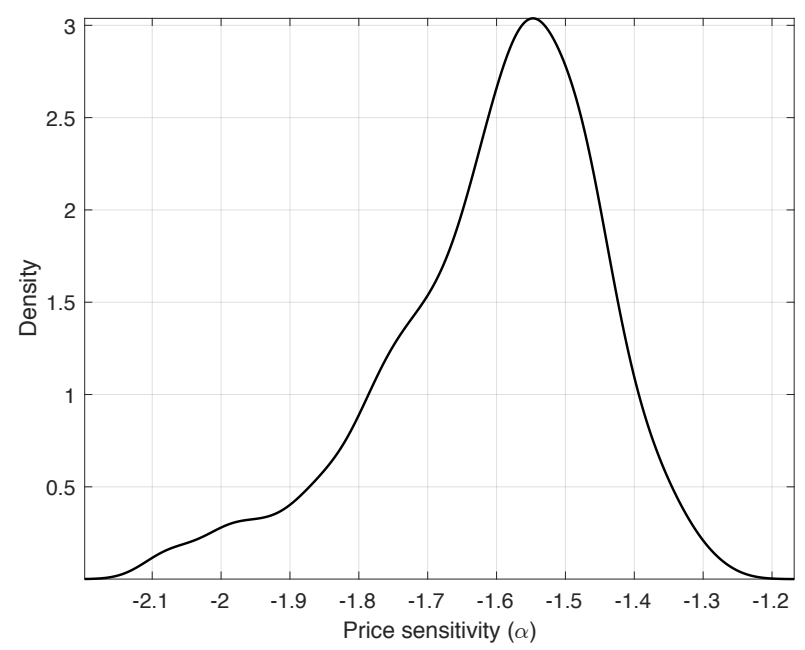

Note: The kernel estimator of the density of price sensitivities uses a Gaussian kernel for 31,588 municipalities in 2008 weighted by the number of households. The top and bottom $1 \%$ are trimmed.

The feebate introduction may create econometric issues related to relying on non-stationary car market share estimates. First, the policy was announced two months before its introduction, leaving room for consumers to bring forward or postpone their car purchases. It is possible that car sales only stabilise after a few months. I check the robustness of the estimated parameters to the exclusion of the first few months of each year. I also consider the effect of including December and January. Second, there may be a different anticipation effect associated with the feebate policy: individuals may expect car manufacturers to produce too many polluting cars relative to demand and expect sellers to get rid of their inventories at low prices towards the end of the year. I check the robustness to this type of anticipation effect by estimating the model using market shares calculated on a subset of months that exclude the last few months of the years (from September to December). Finally, I estimate the model without the year 2008.

All the estimation results are presented in Table 22 and reveal that the estimates are reasonably robust to the exclusion of the first or last few months. When I exclude 2008, the estimates present much less heterogeneity in fuel cost and price sensitivities. The parameter for heterogeneity in price sensitivity becomes not significantly different from zero. This could indicate a problem due to the non-stationarity of demand in 2008 or that the data have low identification power without 2008 because of less variation in car prices. Because the results remain very stable when I exclude the first or last months, I believe that the difference in parameter estimates reflects that including 2008 provides useful variation in prices to identify the heterogeneity parameters. I nevertheless use these parameters to check the robustness of the estimates of the policy effect on car emissions, car sales, car manufacturer profits and consumer surplus and find they are very similar. 
Table 22: Estimated demand parameters under alternative sample selections

\begin{tabular}{|c|c|c|c|c|c|c|c|c|c|}
\hline & (1) & $(2)$ & (3) & (4) & (5) & (6) & (7) & (8) & (9) \\
\hline Price & $\begin{array}{l}-0.677^{* *} \\
(0.074)\end{array}$ & $\begin{array}{l}-0.675^{* *} \\
(0.072)\end{array}$ & $\begin{array}{l}-0.693^{* *} \\
(0.074)\end{array}$ & $\begin{array}{l}-0.593^{* *} \\
(0.081)\end{array}$ & $\begin{array}{l}-0.566^{* *} \\
(0.084)\end{array}$ & $\begin{array}{l}-0.773^{* *} \\
(0.064)\end{array}$ & $\begin{array}{l}-0.813^{* *} \\
(0.064)\end{array}$ & $\begin{array}{l}-0.721^{* *} \\
(0.07)\end{array}$ & $\begin{array}{l}-1.57^{* *} \\
(0.035)\end{array}$ \\
\hline Horsepower & $\begin{array}{l}0.29 \\
(0.018)\end{array}$ & $\begin{array}{l}0.292 \\
(0.018)\end{array}$ & $\begin{array}{l}0.291 \\
(0.017)\end{array}$ & $\begin{array}{l}0.288^{* *} \\
(0.017)\end{array}$ & $\begin{array}{l}0.29 \\
(0.017)\end{array}$ & $\begin{array}{l}0.296 \\
(0.018)\end{array}$ & $\begin{array}{l}0.298 \text { ** } \\
(0.018)\end{array}$ & $\begin{array}{l}0.2966^{* *} \\
(0.018)\end{array}$ & $\begin{array}{l}0.297^{* *} \\
(0.02)\end{array}$ \\
\hline Fuel cost & $\begin{array}{l}-0.797^{* *} \\
(0.022)\end{array}$ & $\begin{array}{l}-0.804^{* *} \\
(0.022)\end{array}$ & $\begin{array}{l}-0.788^{* *} \\
(0.022)\end{array}$ & $\begin{array}{l}-0.799^{* *} \\
(0.022)\end{array}$ & $\begin{array}{l}-0.794^{* *} \\
(0.023)\end{array}$ & $\begin{array}{l}-0.805^{* *} \\
(0.021)\end{array}$ & $\begin{array}{l}-0.794^{* *} \\
(0.021)\end{array}$ & $\begin{array}{l}-0.811^{* *} \\
(0.022)\end{array}$ & $\begin{array}{l}-0.607^{* *} \\
(0.02)\end{array}$ \\
\hline Weight & $\begin{array}{l}0.349^{* *} \\
(0.015)\end{array}$ & $\begin{array}{l}0.347^{* *} \\
(0.015)\end{array}$ & $\begin{array}{l}0.344^{* *} \\
(0.015)\end{array}$ & $\begin{array}{l}0.3366^{* *} \\
(0.015)\end{array}$ & $\begin{array}{l}0.332^{* *} \\
(0.015)\end{array}$ & $\begin{array}{l}0.343^{* *} \\
(0.015)\end{array}$ & $\underbrace{0.34}_{(0.015)}$ & $\begin{array}{l}0.341 \\
(0.015)\end{array}$ & $\begin{array}{l}0.35 \\
(0.017)\end{array}$ \\
\hline Cylinder capacity & $\begin{array}{l}0.292^{* *} \\
(0.012)\end{array}$ & $\begin{array}{l}0.288^{* *} \\
(0.012)\end{array}$ & $\begin{array}{l}0.295^{* *} \\
(0.012)\end{array}$ & $\begin{array}{l}0.3022^{* *} \\
(0.012)\end{array}$ & $\begin{array}{l}0.3133^{* *} \\
(0.013)\end{array}$ & $\begin{array}{l}0.27 \\
(0.012)\end{array}$ & $\begin{array}{l}0.271 \text { ** } \\
(0.012)\end{array}$ & $\begin{array}{l}0.292 \text { ** } \\
(0.013)\end{array}$ & $\begin{array}{l}0.21 \\
(0.013)\end{array}$ \\
\hline Convertible & $\begin{array}{l}-0.079 \\
(0.085)\end{array}$ & $\begin{array}{l}-0.113 \\
(0.085)\end{array}$ & $\begin{array}{l}-0.072 \\
(0.086)\end{array}$ & $\begin{array}{l}-0.026 \\
(0.084)\end{array}$ & $\begin{array}{l}-0.009 \\
(0.082)\end{array}$ & $\begin{array}{c}-0.044 \\
(0.087)\end{array}$ & $\begin{array}{l}-0.059 \\
(0.087)\end{array}$ & $\begin{array}{l}-0.06 \\
(0.087)\end{array}$ & $\begin{array}{l}-0.033 \\
(0.098)\end{array}$ \\
\hline Wagon & $\begin{array}{l}-0.852^{* *} \\
(0.062)\end{array}$ & $\begin{array}{l}-0.849^{* *} \\
(0.062)\end{array}$ & $\begin{array}{l}-0.836^{* *} \\
(0.062)\end{array}$ & $\begin{array}{l}-0.81^{* *} \\
(0.061)\end{array}$ & $\begin{array}{l}-0.763^{* *} \\
(0.061)\end{array}$ & $\begin{array}{l}-0.864^{* *} \\
(0.062)\end{array}$ & $\begin{array}{l}-0.87^{* *} \\
(0.062)\end{array}$ & $\begin{array}{l}-0.866^{* *} \\
(0.062)\end{array}$ & $\begin{array}{l}-0.922^{* *} \\
(0.069)\end{array}$ \\
\hline Intercept & $\begin{array}{l}-8.51^{* *} \\
(0.233)\end{array}$ & $\begin{array}{l}-8.53^{* *} \\
(0.243)\end{array}$ & $\begin{array}{l}-8.45^{* *} \\
(0.231)\end{array}$ & $\begin{array}{l}-8.37^{* *} \\
(0.23)\end{array}$ & $\begin{array}{l}-8.3^{* *} \\
(0.228)\end{array}$ & $\begin{array}{l}-8.44^{* *} \\
(0.238)\end{array}$ & $\begin{array}{l}-8.39^{* *} \\
(0.239)\end{array}$ & $\begin{array}{l}-8.2^{* *} \\
(0.238)\end{array}$ & $\begin{array}{l}-8.79^{* *} \\
(0.258)\end{array}$ \\
\hline Income $\times$ fuel cost & $\begin{array}{l}0.227^{* *} \\
(0.01)\end{array}$ & $\begin{array}{l}0.229^{* *} \\
(0.01)\end{array}$ & $\begin{array}{l}0.224^{* *} \\
(0.01)\end{array}$ & $\begin{array}{l}0.236^{* *} \\
(0.011)\end{array}$ & $\begin{array}{l}0.236^{* *} \\
(0.011)\end{array}$ & $\begin{array}{l}0.222^{* *} \\
(0.009)\end{array}$ & $\begin{array}{l}0.215^{* *} \\
(0.009)\end{array}$ & $\begin{array}{l}0.228^{* *} \\
(0.01)\end{array}$ & $\begin{array}{l}0.111^{* *} \\
(0.006)\end{array}$ \\
\hline Income & $\begin{array}{l}-0.509^{* *} \\
(0.039)\end{array}$ & $\begin{array}{l}-0.509^{* *} \\
(0.038)\end{array}$ & $\begin{array}{l}-0.5^{* *} \\
(0.04)\end{array}$ & $\begin{array}{l}-0.554^{* *} \\
(0.043)\end{array}$ & $\begin{array}{l}-0.57^{* *} \\
(0.045)\end{array}$ & $\begin{array}{l}-0.454^{* *} \\
(0.034)\end{array}$ & $\begin{array}{l}-0.433^{* *} \\
(0.035)\end{array}$ & $\begin{array}{l}-0.484^{* *} \\
(0.037)\end{array}$ & $\begin{array}{c}0.009 \\
(0.019)\end{array}$ \\
\hline Urban $\times$ fuel cost & $\begin{array}{l}0.035^{* *} \\
(0.005)\end{array}$ & $\begin{array}{l}0.035^{* *} \\
(0.005)\end{array}$ & $\begin{array}{l}0.033^{* *} \\
(0.005)\end{array}$ & $\begin{array}{l}0.03 \\
(0.005)\end{array}$ & $\begin{array}{l}0.029^{* *} \\
(0.005)\end{array}$ & $\begin{array}{l}0.037 \\
(0.005)\end{array}$ & $\begin{array}{l}0.037^{* *} \\
(0.005)\end{array}$ & $\begin{array}{l}0.035^{* *} \\
(0.005)\end{array}$ & $\begin{array}{l}0.045 \text { ** } \\
(0.005)\end{array}$ \\
\hline Urban $\times$ weight & $\begin{array}{l}-0.034^{* *} \\
(0.003)\end{array}$ & $\begin{array}{l}-0.034^{* *} \\
(0.003)\end{array}$ & $\begin{array}{l}-0.033^{* *} \\
(0.003)\end{array}$ & $\begin{array}{l}-0.032^{* *} \\
(0.003)\end{array}$ & $\begin{array}{l}-0.032^{* *} \\
(0.003)\end{array}$ & $\begin{array}{l}-0.034^{* *} \\
(0.003)\end{array}$ & $\begin{array}{l}-0.032^{* *} \\
(0.003)\end{array}$ & $\begin{array}{l}-0.032^{* *} \\
(0.003)\end{array}$ & $\begin{array}{l}-0.034^{* *} \\
(0.003)\end{array}$ \\
\hline W/o. children $\times$ cylinder & $\begin{array}{l}-0.537^{* *} \\
(0.015)\end{array}$ & $\begin{array}{l}-0.534^{* *} \\
(0.015)\end{array}$ & $\begin{array}{l}-0.546^{* *} \\
(0.015)\end{array}$ & $\begin{array}{l}-0.56^{* *} \\
(0.016)\end{array}$ & $\begin{array}{l}-0.589^{* *} \\
(0.017)\end{array}$ & $\begin{array}{l}-0.484^{* *} \\
(0.013)\end{array}$ & $\begin{array}{l}-0.485^{* *} \\
(0.013)\end{array}$ & $\begin{array}{l}-0.528^{* *} \\
(0.015)\end{array}$ & $\begin{array}{l}-0.376^{* *} \\
(0.011)\end{array}$ \\
\hline No. observations & 5,028 & 5,187 & 4,974 & 4,906 & 4,839 & 5,027 & 4,919 & 4,919 & 4,064 \\
\hline
\end{tabular}

Note: (1): Main specification: December and January excluded, (2): all months, (3): December-February excluded, (4): DecemberMarch excluded, (5): December-April excluded, (6): November and December excluded, (7) October-December excluded, (8): September-

December excluded, and (9): December and January excluded, 2008 excluded. Significance levels: †: 10\%, *: 5\%, **: 1\%.

\section{D.3 Additional results on the aggregate feebate policy's effects}

Table 23 presents the difference between the observed and predicted outcomes in 2008 under the feebate policy. The observed outcomes are based on the market shares calculated using the registrations over February-November of the car models in my choice set (from the CCFA). The simulated outcomes rely on the equilibrium model, the parameters of preferences and the car marginal costs. I consider two car marginal costs that I obtain from (i) the entire sample of municipalities (benchmark outcomes) and (ii) the sample of 3,000 municipalities (alternative outcomes). First, the method to recover the car marginal costs has minimal impact on the predicted outcomes. Secondly, the predicted car sales and profits are very close to the observed sales and profits. There are minor budget cost differences of $€ 5.5$ and $€ 6.9$ million, which correspond to only $2.5 \%$ and $3.2 \%$ of the budget cost. 
Table 23: Difference between observed and predicted aggregate outcomes

\begin{tabular}{lccc}
\hline \hline & Observed & $\begin{array}{c}\text { Simulated } \\
\text { (benchmark) }\end{array}$ & $\begin{array}{c}\text { Simulated } \\
\text { (alternative) }\end{array}$ \\
\hline Total sales $(1,000$ units) & 1,216 & 1,223 & 1,215 \\
Share of diesel $(\%)$ & 71.92 & 70.97 & 71.11 \\
Profits French $(\mathrm{M} €$ ) & 4,354 & 4,322 & 4,289 \\
Profits all $(\mathrm{M} €$ ) & 7,610 & 7,645 & 7,598 \\
Budget cost $(\mathrm{M} €$ ) & -217.1 & -211.6 & -210.1 \\
\hline \hline
\end{tabular}

Note: "M€" stands for millions of euros. "Observed" profits are calculated using observed market shares and estimated margins. "Benchmark" outcomes are predicted from marginal costs obtained from the full sample of municipalities while "alternative" outcomes are based on the marginal costs estimated from the sample of 3,000 municipalities.

In Table 24 below, I provide the average pass-through rates for each class of $\mathrm{CO}_{2}$ emissions; all are close to $100 \%$. They are nevertheless heterogeneous across vehicle classes. The average pass-through rate is below $100 \%$ for class $\mathrm{C}+$, implying that car manufacturers absorb fractions of the rebates for this car category. For classes A and B, the prices decrease by more than the rebate amount on average. Class $\mathrm{E}+$ has the largest pass-through, reaching $104 \%$ of the fee. The overshifting of the tax reveals that the feebate softens competition for cars in this class. The feebate allows car manufacturers to increase their margins by $€ 8$ on average.

Table 24: Average feebate pass-through by emissions class

\begin{tabular}{lccc}
\hline \hline $\begin{array}{l}\text { Class } \\
\text { of emissions }\end{array}$ & $\begin{array}{c}\text { Fee } \\
(€)\end{array}$ & $\begin{array}{c}\Delta p \\
(€)\end{array}$ & $\begin{array}{c}\text { Pass-through } \\
\text { rate }(\%)\end{array}$ \\
\hline $\mathrm{A}$ & $-1,000$ & $-1,015$ & 101.52 \\
$\mathrm{~B}$ & -700 & -706.7 & 100.95 \\
$\mathrm{C}+$ & -200 & -198.4 & 99.18 \\
$\mathrm{C}-/ \mathrm{D}$ & 0 & 4.67 & \\
$\mathrm{E}+$ & 200 & 208.1 & 104.05 \\
$\mathrm{E}-$ & 750 & 768.3 & 102.44 \\
$\mathrm{~F}$ & 1,600 & 1,631 & 101.91 \\
$\mathrm{G}$ & 2,600 & 2,642 & 101.62 \\
\hline \hline $\begin{array}{l}\text { Note: } \\
\text { consumers. The pass-through rate is } \Delta p \text { divided by the fee }\end{array}$ \\
or rebate.
\end{tabular}

Table 25 presents the distribution of households according to car ownership status under and in the absence of the feebate policy depending on the assumption on the origin of extra car sales. Under the benchmark assumption, the proportion of non-motorised and old car-owning households is constant with and without the feebate. This implies that the fraction of old car owners decreases by 0.2 percentage points, and the fraction of nonmotorised households decreases by 0.1 percentage points because of the feebate. The share of households with an old car in the absence of the feebate policy is largest under the optimistic scenario $(66 \%)$ because the extra sales are assumed to be due to old car replacements. Under 
scenario (3), the share of households holding an old car is constant with and without the policy because the extra new car sales are supposed to be new drivers.

Table 25: Frequency of households according to their ownership status

\begin{tabular}{|c|c|c|c|c|}
\hline \multirow{3}{*}{ Scenario } & \multirow[t]{3}{*}{ Feebate } & \multicolumn{3}{|c|}{ No feebate } \\
\hline & & (1) & (2) & (3) \\
\hline & & Benchmark & Optimistic & Pessimistic \\
\hline New car & 16.9 & 16.6 & 16.6 & 16.6 \\
\hline No car & 17.3 & 17.4 & 17.4 & 17.6 \\
\hline Old car & 65.8 & 66 & 66 & 65.8 \\
\hline - diesel & 38.4 & 38.6 & 38.6 & 38.4 \\
\hline - gasoline & 27.3 & 27.4 & 27.4 & 27.3 \\
\hline
\end{tabular}

Note: in \%. (1): benchmark, (2): old car replacement, and (3): new drivers.

The total cost of emissions of local pollutants relies on estimates provided by the report of the DG MOVE (2014), which are uniform across locations except for PM emissions. Table 26 presents the monetary value of extra or avoided emissions of local pollutants depending on the assumption about the social costs of the emissions. Overall, the total costs of emissions are not so different from one specification to another, indicating that emissions do not increase too much where they are the costliest.

Table 26: Effects of the feebate policy on the cost of emissions of local pollutants

\begin{tabular}{|c|c|c|c|c|c|c|c|c|c|}
\hline & \multicolumn{3}{|c|}{ New cars } & \multicolumn{3}{|c|}{ Outside option } & \multicolumn{3}{|c|}{ Total } \\
\hline & $\mathrm{NO}_{\mathrm{X}}$ & $\mathrm{PM}$ & $\mathrm{HC}$ & $\mathrm{NO}_{\mathrm{X}}$ & $\mathrm{PM}$ & $\mathrm{HC}$ & cars & $\begin{array}{l}\text { Outside } \\
\text { option }\end{array}$ & $\begin{array}{c}\text { Net } \\
\text { balance }\end{array}$ \\
\hline Benchmark, uniform & 0.945 & 0.344 & 0.019 & -0.602 & -0.399 & -0.023 & 1.31 & -1.02 & 0.284 \\
\hline \multicolumn{10}{|l|}{ Function of average car emissions } \\
\hline Rob. 1: linear & 0.938 & 0.34 & 0.019 & -0.595 & -0.392 & -0.023 & 1.3 & -1.01 & 0.286 \\
\hline Rob. 2: quadratic & 0.932 & 0.337 & 0.019 & -0.59 & -0.386 & -0.023 & 1.29 & -0.999 & 0.289 \\
\hline Rob. 3: discontinuous & 0.932 & 0.328 & 0.019 & -0.576 & -0.355 & -0.024 & 1.28 & -0.956 & 0.323 \\
\hline Rob. 4: discontinuous \& linear & 0.93 & 0.327 & 0.019 & -0.575 & -0.353 & -0.024 & 1.28 & -0.952 & 0.324 \\
\hline \multicolumn{10}{|c|}{ Function of average air concentrations } \\
\hline Rob. 5: linear & 0.9 & 0.333 & 0.019 & -0.595 & -0.392 & -0.023 & 1.25 & -1.01 & 0.242 \\
\hline Rob. 6: quadratic & 0.813 & 0.322 & 0.02 & -0.59 & -0.386 & -0.023 & 1.16 & -0.999 & 0.156 \\
\hline Rob. 7: discontinuous & 0.915 & 0.324 & 0.02 & -0.576 & -0.355 & -0.024 & 1.26 & -0.956 & 0.304 \\
\hline $\begin{array}{l}\text { Rob. 8: discontinuous \& linear } \\
\text { Function of population density }\end{array}$ & 0.876 & 0.319 & 0.02 & -0.575 & -0.353 & -0.024 & 1.21 & -0.952 & 0.262 \\
\hline Rob. 9: linear & 0.854 & 0.306 & 0.018 & -0.594 & -0.392 & -0.023 & 1.18 & -1.01 & 0.169 \\
\hline Rob. 10: quadratic & 0.794 & 0.284 & 0.017 & -0.59 & -0.388 & -0.023 & 1.1 & -1 & 0.094 \\
\hline Rob. 11: discontinuous & 0.878 & 0.324 & 0.018 & -0.577 & -0.386 & -0.022 & 1.22 & -0.986 & 0.235 \\
\hline Rob. 12: discontinuous \& linear & 0.849 & 0.304 & 0.018 & -0.593 & -0.391 & -0.023 & 1.17 & -1.01 & 0.164 \\
\hline
\end{tabular}

Note: All costs are in millions of euros.

\section{D.4 Additional results on the distributional aspects of the feebate}

The role of preferences. The feebate's effect on individuals' surplus is related to the preference heterogeneity parameters through different channels. First, they determine the 
baseline level of consumer surplus, which mechanically affects the variation in consumer surplus in percentage. Consequently, the same increase in consumer surplus implies a larger relative gain when the consumer surplus level is small, i.e., when the average utility of holding a car is low. The price heterogeneity coefficient has a specific role because it appears in both the numerator and the denominator of the consumer surplus formula. By differentiating the consumer surplus function with respect to the price coefficient $\alpha_{m}$, I can show that consumer surplus always increases with $\alpha_{m}$ : the surplus associated with car purchase is high when the price sensitivity $\left(-\alpha_{m}\right)$ is low. My estimates suggest that the poorest households have lower price sensitivity and are associated with higher surplus levels than higher-income households. The other heterogeneity parameters positively impact consumer surplus if the sign of the parameter of heterogeneity multiplied by the car characteristic is positive, which is the case for income interacted with fuel cost and urban area interacted with fuel cost.

Understanding the effects of demographic characteristics on the variation in consumer surplus from the feebate is more complicated. Intuitively, we expect consumers to gain from the feebate if the cars consumers like become cheaper. For instance, we anticipate consumers with high fuel cost sensitivity (in poor municipalities) to gain more from the feebate than those who care less about fuel efficiency (in wealthy municipalities). The effect of preference heterogeneity is less straightforward to predict for other car characteristics not directly linked to the rebate or fee amount. Therefore, I empirically analyse each demographic characteristic's partial effect on the variation in consumer surplus in level and percentage. I fix all demographic characteristics to their average national values except the one that affects the parameter of heterogeneity of interest.

The results are provided in Table 27 below. First, income has two opposite effects on the consumer surplus and the effect of the feebate policy through its link to fuel cost and price sensitivities. Income decreases the gain from the feebate through fuel cost sensitivity, as predicted. Through the price coefficient, the income effect has a non-monotonic effect on welfare gains from the policy in levels but strictly raises the gains in relative terms. There is tension in the net income effect between its fuel cost sensitivity and price sensitivity channels. Richer consumers are more price-sensitive, so they gain more from the feebate, but these consumers do not care about fuel efficiency gains as much as low-income consumers. This is why the net income effect on the policy effect is non-monotonic in both absolute and relative terms.

The type of area is associated with different signs for the absolute variation in surplus and the relative variation. My results indicate that the average gain from the feebate is larger in urban than rural areas when analysing the partial role of the type of area through the preference for fuel cost. This is simply because urban areas are associated with a higher surplus of holding a car since, in relative terms, those in rural areas (who care more about fuel costs) gain more. The type of area has opposite effects through its link to the fuel cost and weight sensitivity parameters. On the one hand, urban individuals are less sensitive to fuel costs than those in rural areas, so they gain less from the feebate in relative terms. On the other hand, urban consumers care less about the car size, so they are less hurt by the feebate favouring small cars. This latter effect dominates since I obtain a higher relative gain in urban areas than in rural areas. However, in absolute terms, the gain is higher in rural areas than in urban areas, following the ranking for consumer surplus values. 
Finally, the valuation of cylinder capacity is lower for households without children, making their feebate gains larger than those of families with children. The variation in consumer surplus in percentage terms also increases with the share of households without children, even though the level of consumer surplus decreases with this variable. These are only partial effects of each demographic characteristic. While they provide intuitions about the feebate's impact at the individual level, given that the consumer surplus formula involves an exponential, there are interactions between the different parameters of preferences. The net effect of the feebate on individuals remains an empirical question.

Table 27: Effect of heterogeneity parameters on CS, $\triangle C S$ and $\triangle \% C S$

\begin{tabular}{lcccc}
\hline \hline & Parameter & CS & $\Delta$ CS & $\Delta \%$ CS \\
\hline Income $\times$ fuel cost & 0.227 & $\uparrow$ & $\downarrow$ & $\downarrow$ \\
Income $\times$ price & -0.509 & $\downarrow$ & $\uparrow$ then $\downarrow$ & $\uparrow$ \\
Net effect of income & & $\uparrow$ & $\uparrow$ then $\downarrow$ & $\uparrow$ then $\downarrow$ \\
Urban $\times$ fuel cost & 0.035 & $\uparrow$ & $\uparrow$ & $\downarrow$ \\
Urban $\times$ weight & -0.034 & $\downarrow$ & $\downarrow$ & $\uparrow$ \\
Net effect of urban & & $\downarrow$ & $\downarrow$ & $\uparrow$ \\
$\%$ Without children $\times$ cylinder & -0.537 & $\downarrow$ & $\uparrow$ then $\downarrow$ & $\uparrow$ \\
\hline \hline
\end{tabular}

Heterogeneity across households. The analysis by income decile hides significant heterogeneity in the effect of the policy for the highest income decile. The surplus variation increases until approximately $€ 29,000$ and then decreases. Individuals with incomes between $€ 18,000$ and $€ 38,000$ are estimated to gain from the feebate under a uniform tax. High-income individuals lose from the feebate regulation under both tax schemes. They lose more under the proportional tax because their tax payment is greater than the uniform tax value. I find a similar pattern for the distribution of the gains and losses in absolute terms. For the surplus variation in level terms and under the uniform tax scenario, the losses for the low-income categories are much lower, while under the proportional tax scenario, the surplus decreases slightly more sharply than it does when we consider variation in surplus in percentage terms. 
Figure 4: Average consumer surplus variation and income

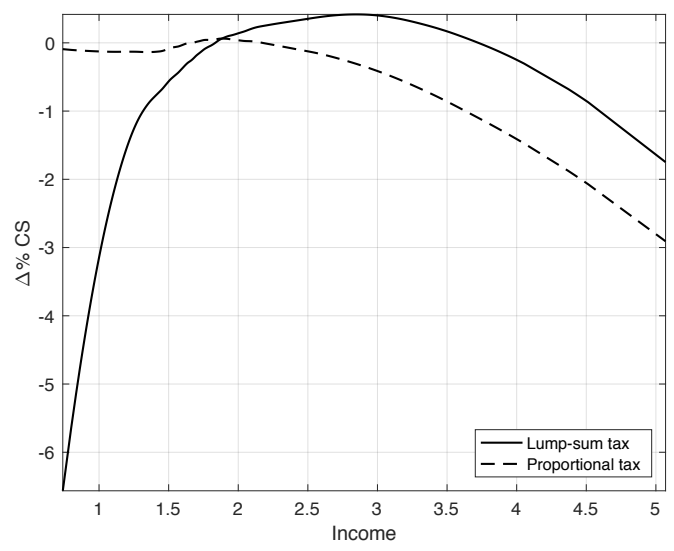

(a) Surplus variation in percentage terms

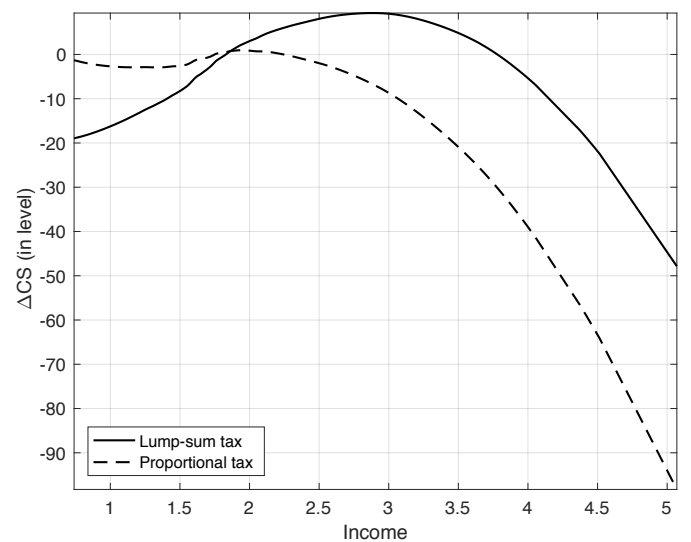

(b) Surplus variation in level terms Note: Income is in $€ 10,000$. Local polynomial regressions with $2^{\text {nd }}$ order polynomials.

In the main text, I provide the average surplus variation by income deciles. However, the income deciles are constructed from the distribution of the municipalities' median incomes. As a robustness check, I analyse the average surplus variation associated with the national income distribution deciles, using the data from the National Survey Institute in 2008 (see INSEE). I abstract from taxes to subsidise the cost of the policy for this robustness check. Because the utility parameters also depend on the type of area, I compute the variation in consumer surplus for each income decile for rural and urban areas separately. Lastly, because the preference for cylinder capacity depends on the household size, I set the household size to the national average, computed using the full sample of municipalities. The results presented in Table 28 reveal that the income deciles based on municipalities' median incomes imply an income distribution that is flatter than the true national income distribution. The third national income distribution decile is roughly equal to the eighth decile of my constructed income distribution. The results nevertheless confirm the bell-shaped relation between income and consumer surplus variation. By flattening the income distribution, the income decile that I consider hides that the top two income deciles are made worse off by the feebate policy. The variation in consumer surplus in percentage terms is close to that obtained when I use the municipalities' median income distribution deciles, except for the three highest income deciles, which display either much lower gains or losses. The average welfare loss reaches $€ 166$ for the highest income decile in urban areas. Still, this amount represents a decrease of only $2.3 \%$ of the surplus because the surplus base value is also large. The most significant gains in absolute terms are associated with the sixth income decile (between $€ 36,000$ and $€ 42,000$ ); they are between $€ 36.7$ and $€ 41.1$ (depending on the area). These figures are slightly higher than the average surplus increase for the top decile of my constructed income distribution. 
Table 28: Average consumer surplus variation by national income decile

\begin{tabular}{cccccc}
\hline \hline Income decile & \multicolumn{2}{c}{ Urban } & \multicolumn{2}{c}{ Rural } \\
& & level & $\%$ & level & $\%$ \\
\hline d1 & 13,830 & 19.5 & 2.55 & 22.2 & 2.45 \\
d2 & 17,810 & 23.6 & 2.88 & 26.8 & 2.79 \\
d3 & 21,780 & 28 & 3.05 & 31.6 & 2.98 \\
d4 & 26,110 & 32.7 & 3.03 & 36.7 & 2.99 \\
d5 & 30,720 & 36.5 & 2.73 & 40.8 & 2.74 \\
d6 & 35,980 & 36.7 & 2.07 & 41.1 & 2.12 \\
d7 & 42,010 & 25.4 & 1.01 & 29.6 & 1.1 \\
d8 & 50,010 & -19.4 & -0.49 & -15.1 & -0.37 \\
d9 & 63,950 & -165.8 & -2.3 & -159.7 & -2.19 \\
\hline \hline
\end{tabular}

Note: The second column provides the value of the income decile. "Level" represents variations of average surplus in levels (€), while "\%" represents variations in relative terms, using the consumer surplus value without a feebate as a reference.

I correlate the effects of the feebate with other demographic characteristics through descriptive regressions. I first regress the consumer surplus variation on the proportion of households in each household size category and each socio-professional category. I then use all demographic characteristics together. The results of the three specifications are displayed in Table 29. The correlation between welfare gains and household size in Specification (1) suggests that couples and families are associated with larger welfare gains than single individuals, in absolute terms. However, in relative terms, couples and then single people gain the most. This result occurs because single individuals are associated with a low surplus from buying a car; therefore, the welfare gains appear greater in relative terms. The positive gains for couples with children (families) in absolute terms are driven by their lower taste for cylinder capacity relative to single people and couples, making families less hurt when substituting for rebated cars with low cylinder capacities. Specification (2) correlates welfare benefits with the socioprofessional category. When I analyse the gains in absolute terms, the types of workers associated with the largest gains are intermediate professionals, entrepreneurs and manual labourers. Individuals in the high (executive) and medium socio-professional categories, such as farmers and employees, are in contrast associated with lower absolute gains. When we examine the gains in relative terms, the comparison across categories is very different: entrepreneurs, farmers, intermediate professionals and manual labourers have the lowest welfare gains, while executives' gains are almost comparable to gains of retired individuals. Finally, I find that household size has the same effect when using all demographics together, including income, income squared, and population density. Still, the influence of the socioprofessional category is smaller, as expected, since the professional activity is not directly linked to consumer preferences. The results show, as previously emphasised, a non-monotonic correlation between income and welfare benefits of consumers. I find significantly lower benefits in urban relative to rural municipalities (€1.3 less). However, in relative terms, the gains appear to be largest for individuals living in the densest cities $(+0.18 \%$ more than gains in rural municipalities). 
Table 29: Regression of average consumer surplus variation on demographic characteristics

\begin{tabular}{|c|c|c|c|c|c|c|c|c|c|c|c|c|}
\hline \multirow[b]{3}{*}{ Intercept } & \multicolumn{4}{|c|}{$(1)$} & \multicolumn{4}{|c|}{$(2)$} & \multicolumn{4}{|c|}{$(3)$} \\
\hline & \multicolumn{2}{|c|}{ level } & \multicolumn{2}{|c|}{$\%$} & \multicolumn{2}{|c|}{ level } & \multicolumn{2}{|c|}{$\%$} & \multicolumn{2}{|c|}{ level } & \multicolumn{2}{|c|}{$\%$} \\
\hline & $-8.63^{* *}$ & 0.85 & $6.19^{* *}$ & 0.05 & $6.12^{* *}$ & 1.94 & $7.97^{* *}$ & 0.16 & $-38.9^{* *}$ & 2.44 & $3.51^{* *}$ & 0.07 \\
\hline \%Couple & $4.29^{* *}$ & 0.28 & $0.08^{* *}$ & 0.01 & & & & & $4.71^{* *}$ & 0.28 & $0.1^{* *}$ & 0.01 \\
\hline$\%$ Family & $5.49^{* *}$ & 0.26 & $-1^{* *}$ & 0.01 & & & & & $4.42^{* *}$ & 0.31 & $-1.01^{* *}$ & 0.01 \\
\hline$\%$ Farmer & & & & & $2.02^{* *}$ & 0.5 & $-1.05^{* *}$ & 0.04 & -0.02 & 0.33 & $-0.02^{*}$ & 0.01 \\
\hline \%Entrepreneur & & & & & $8.02^{* *}$ & 0.78 & $-1.32^{* *}$ & 0.08 & 0.46 & 0.51 & 0.01 & 0.01 \\
\hline$\%$ Executive & & & & & $2.16^{* *}$ & 0.69 & $-0.15^{*}$ & 0.06 & $0.83^{*}$ & 0.4 & $0.03^{*}$ & 0.01 \\
\hline \%Intermediate & & & & & $8.79^{* *}$ & 0.55 & $-1.07^{* *}$ & 0.05 & $1.19^{* *}$ & 0.35 & $-0.03^{* *}$ & 0.01 \\
\hline \%Employee & & & & & 0.58 & 0.51 & $-0.68^{* *}$ & 0.04 & $1.42^{* *}$ & 0.28 & $0.04^{* *}$ & 0.01 \\
\hline \%Manual laborer & & & & & $4.43^{* *}$ & 0.33 & $-0.97^{* *}$ & 0.03 & $2.26^{* *}$ & 0.29 & $0.05^{* *}$ & 0.01 \\
\hline \%Other activity & & & & & $-3.65^{* *}$ & 0.59 & $-0.41^{* *}$ & 0.06 & 0.42 & 0.29 & -0.02 & 0.01 \\
\hline Income & & & & & & & & & $17^{* *}$ & 2.35 & $2.32^{* *}$ & 0.05 \\
\hline Income $^{2}$ & & & & & & & & & $-1.99^{* *}$ & 0.48 & $-0.5^{* *}$ & 0.01 \\
\hline Urban & & & & & & & & & $-1.34^{* *}$ & 0.22 & $0.14^{* *}$ & 0.01 \\
\hline Very urban & & & & & & & & & 0.52 & 0.33 & $0.18^{* *}$ & 0.01 \\
\hline
\end{tabular}

Note: The dependent variables are the average consumer surplus variation in both absolute terms and relative terms. Income is divided by $€ 10,000$. "\%" stands for the percentage of households in each category. Household sizes and professional activities are in 10\%. The reference category for household size is single, the reference category for the professional activity is retired, and the reference category for the size of the municipality is rural (less than 20,000 inhabitants). The regressions are weighted by the number of households in the municipalities in 2008. Significance levels: ${ }^{\dagger}: 10 \%,{ }^{*}: 5 \%,{ }^{* *}: 1 \%$.

Heterogeneity in emissions. I provide the distributions of the changes in emissions stemming from the feebate policy. These are the distributions over individuals since each municipality is weighted by the number of households. The different graphs presented in Figure 5 reveal substantial heterogeneity across pollutants as well as across municipalities. The average emissions of $\mathrm{NO}_{\mathrm{X}}$ and $\mathrm{PM}$ increase in all municipalities but with different intensities. Similarly, emissions of CO and HC decrease in the majority of the municipalities but increase in some, suggesting important heterogeneity.

Figure 5: Distribution of the variations in average emissions across municipalities
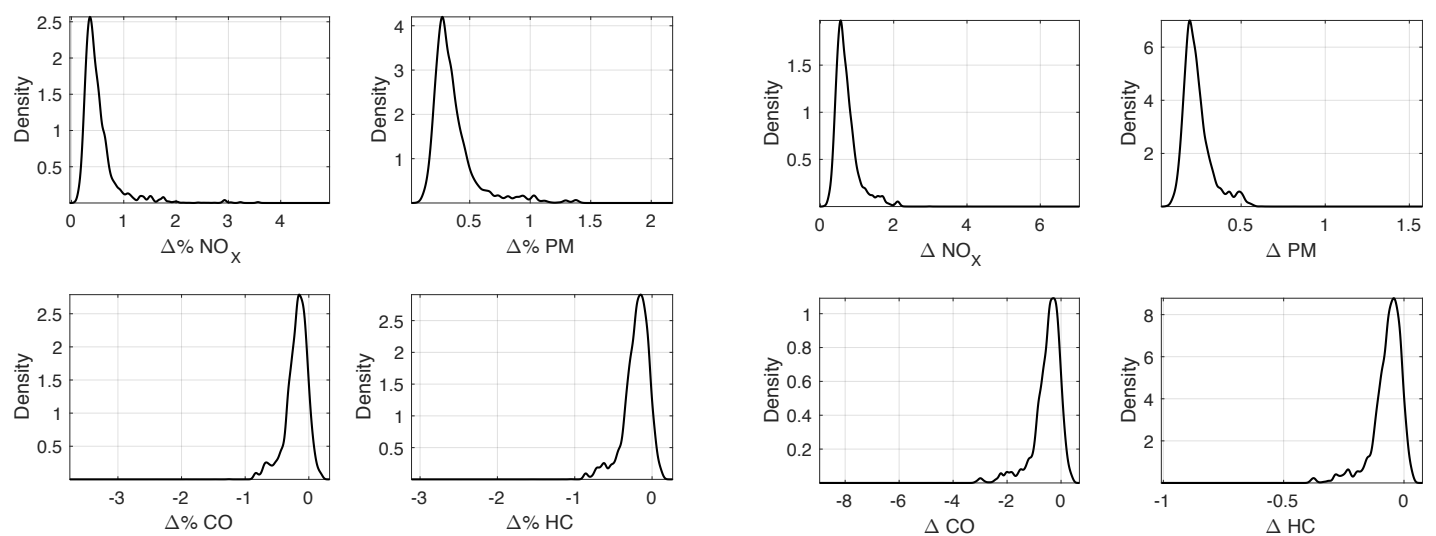

(a) In percentage terms
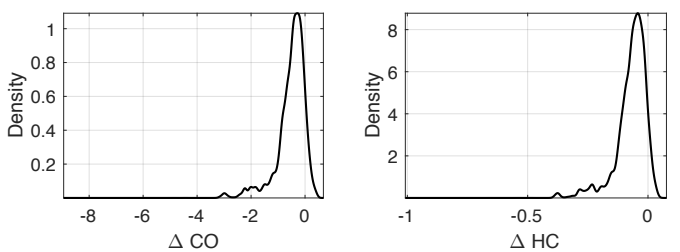

(b) In level terms

Note: The kernel estimators of the density of the variations of average pollutants use Gaussian kernels. I use the 31,588 municipalities weighted by the number of households.

As a robustness check, I analyse whether emissions increase most where they are initially highest, this time using variation in levels instead of in percentage terms. Figure 6 indicates that the relations between changes in levels and the initial emissions are very similar when 
analysing the variations in emissions in levels or percentage terms.

Figure 6: Emissions variations (in levels) as function of initial emissions levels
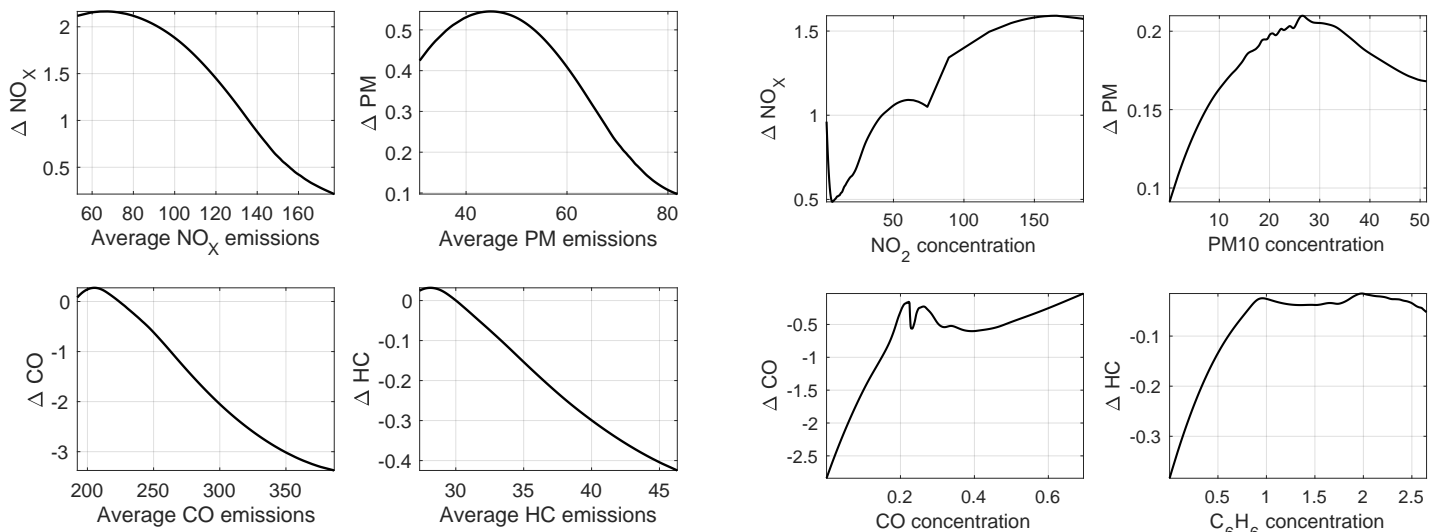

(a) Average car emissions
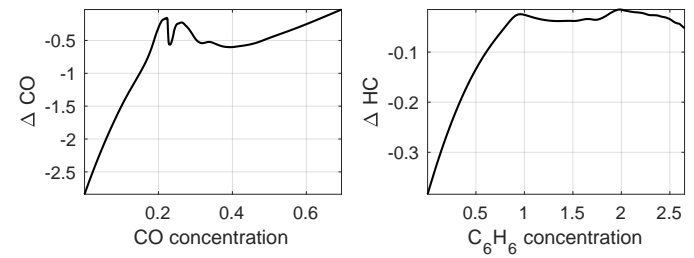

(b) Average air emissions concentrations

Note: Local polynomial regressions using second-order polynomials. Average car emissions are in $\mathrm{mg} / \mathrm{km}$, except $P M$ emissions are in $\mathrm{mg} / 10 \mathrm{~km}$. Concentrations of $\mathrm{NO}_{2}, P M 10$ and $\mathrm{C}_{6} \mathrm{H}_{6}$ are in $\mu \mathrm{g} / \mathrm{m}^{3}$. Concentrations of $C O$ are in $\mathrm{mg} / \mathrm{m}^{3}$.

I provide more detailed figures on the change of emissions by grouping municipalities according to their initial emissions and compute changes by emissions deciles. I consider emissions deciles calculated from average car emissions in 2008 in the absence of the feebate. I also analyse air emissions concentrations deciles which rely on the estimated average municipality air emissions concentrations. As before, I weight each municipality by the number of households to obtain the distribution of emissions across individuals. The results are consistent with the figures and confirm that emissions increase most where car emissions are initially lowest for $\mathrm{NO}_{\mathrm{X}}$ and $\mathrm{PM}$ while they decrease most where they are initially the highest for $\mathrm{CO}$ and $\mathrm{HC}$. However, when analysing the air emissions concentration deciles, $\mathrm{NO}_{\mathrm{X}}$ emissions increase most in municipalities with high $\mathrm{NO}_{2}$, while $\mathrm{CO}$ and $\mathrm{HC}$ emissions decrease least where they are initially high. For PM, there is minimal variation across emissions concentration deciles.

Figure 7 presents the variation of the diesel share as function of the initial diesel share of the municipality (represented by the percentage of diesel in 2008 in the absence of the feebate policy) both in level and relative terms. The two graphs consistently reveal that the diesel share increases most where it is initially the lowest: in urban and wealthy areas. The diesel share is estimated to increase by approximately $5 \%$ at the lowest level, while the increase is below $0.33 \%$ in places where the initial diesel share exceeds $80 \%$.

\section{D.5 Additional results on the feebate performance}

Table 31 summarises the different outcomes of interest and objective functions used to define optimal feebates. For the minimisation of average emissions, I rely on two different weights. The first weights are proportional to the average levels of car emissions in 2008 with the 
Table 30: Average emissions variation by emission and air concentration decile

\begin{tabular}{|c|c|c|c|c|c|c|c|c|}
\hline & \multicolumn{2}{|c|}{$\Delta \mathrm{NO}_{\mathrm{X}}$} & \multicolumn{2}{|c|}{$\Delta \mathrm{PM}$} & \multicolumn{2}{|c|}{$\Delta \mathrm{CO}$} & \multicolumn{2}{|c|}{$\Delta \mathrm{HC}$} \\
\hline & level & $\%$ & level & $\%$ & level & $\%$ & level & $\%$ \\
\hline \multicolumn{9}{|c|}{ Initial car emissions deciles } \\
\hline$\leq \mathrm{d} 1$ & 1.4 & 1.4 & 0.43 & 0.82 & 0.09 & 0.043 & 0.005 & 0.018 \\
\hline $\mathrm{d} 1-\mathrm{d} 2$ & 0.92 & 0.68 & 0.3 & 0.47 & -0.071 & -0.031 & -0.015 & -0.049 \\
\hline $\mathrm{d} 2-\mathrm{d} 3$ & 0.81 & 0.58 & 0.27 & 0.41 & -0.18 & -0.08 & -0.029 & -0.092 \\
\hline $\mathrm{d} 3-\mathrm{d} 4$ & 0.73 & 0.51 & 0.24 & 0.36 & -0.26 & -0.11 & -0.039 & -0.12 \\
\hline $\mathrm{d} 4-\mathrm{d} 5$ & 0.67 & 0.46 & 0.23 & 0.33 & -0.35 & -0.15 & -0.05 & -0.16 \\
\hline $\mathrm{d} 5-\mathrm{d} 6$ & 0.62 & 0.41 & 0.21 & 0.31 & -0.45 & -0.18 & -0.062 & -0.19 \\
\hline $\mathrm{d} 6-\mathrm{d} 7$ & 0.57 & 0.38 & 0.2 & 0.28 & -0.55 & -0.22 & -0.075 & -0.23 \\
\hline $\mathrm{d} 7-\mathrm{d} 8$ & 0.53 & 0.34 & 0.19 & 0.26 & -0.7 & -0.27 & -0.092 & -0.28 \\
\hline $\mathrm{d} 8-\mathrm{d} 9$ & 0.48 & 0.3 & 0.17 & 0.23 & -0.88 & -0.33 & -0.12 & -0.34 \\
\hline d9-d10 & 0.41 & 0.25 & 0.15 & 0.19 & -1.7 & -0.58 & -0.21 & -0.57 \\
\hline \multicolumn{9}{|c|}{ Air emissions concentrations deciles } \\
\hline$\leq \mathrm{d} 1$ & 0.6 & 0.41 & 0.25 & 0.43 & -0.83 & -0.29 & -0.072 & -0.19 \\
\hline $\mathrm{d} 1-\mathrm{d} 2$ & 0.58 & 0.38 & 0.23 & 0.35 & -0.21 & -0.085 & -0.066 & -0.19 \\
\hline $\mathrm{d} 2-\mathrm{d} 3$ & 0.61 & 0.41 & 0.23 & 0.34 & -0.41 & -0.15 & -0.062 & -0.18 \\
\hline $\mathrm{d} 3-\mathrm{d} 4$ & 0.63 & 0.43 & 0.24 & 0.35 & -0.42 & -0.16 & -0.076 & -0.22 \\
\hline $\mathrm{d} 4-\mathrm{d} 5$ & 0.67 & 0.46 & 0.24 & 0.37 & -0.63 & -0.23 & -0.073 & -0.22 \\
\hline $\mathrm{d} 5-\mathrm{d} 6$ & 0.63 & 0.43 & 0.24 & 0.35 & -0.47 & -0.18 & -0.091 & -0.27 \\
\hline $\mathrm{d} 6-\mathrm{d} 7$ & 0.75 & 0.54 & 0.24 & 0.35 & -0.75 & -0.28 & -0.1 & -0.3 \\
\hline $\mathrm{d} 7-\mathrm{d} 8$ & 0.81 & 0.6 & 0.24 & 0.37 & -0.56 & -0.22 & -0.052 & -0.16 \\
\hline $\mathrm{d} 8-\mathrm{d} 9$ & 0.82 & 0.61 & 0.24 & 0.36 & -0.45 & -0.18 & -0.05 & -0.15 \\
\hline $\mathrm{d} 9-\mathrm{d} 10$ & 1.1 & 0.99 & 0.25 & 0.39 & -0.38 & -0.15 & -0.044 & -0.14 \\
\hline
\end{tabular}

Note: "Level" represents variations in level terms (€), while "\%" represents variations in relative terms, using the value in the absence of feebate as a reference. Variations in level terms are in $\mathrm{mg} / \mathrm{km}$ for emissions of $\mathrm{NO}_{X}, \mathrm{CO}$ and $\mathrm{HC}$ and $\mathrm{mg} / 10 \mathrm{~km}$ for PM.

Figure \%: Variation in the diesel share and initial diesel share

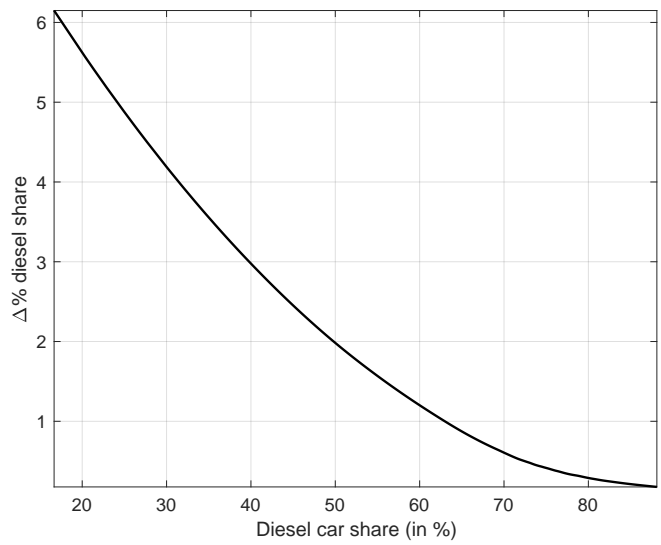

(a) In percentage terms

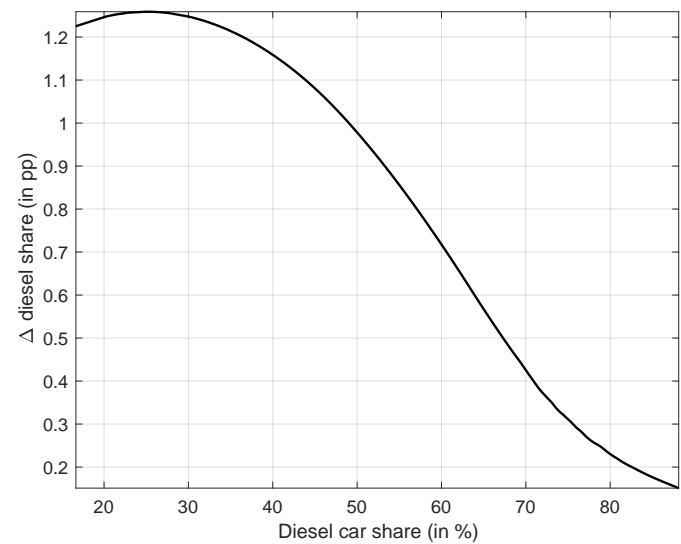

(b) In percentage points terms

Note: Local polynomial regressions using second-order polynomials. 
feebate, while the second weights are proportional to the estimated municipality average air emissions concentrations.

Table 31: Description of the objective functions and outcomes of interest

\begin{tabular}{lll}
\hline \hline Outcome & Objective & Function \\
\hline CS & Simple average & $\max _{\lambda_{j}} \sum_{m} \phi_{m} C S_{m}\left(\lambda_{1}, \ldots, \lambda_{J}\right)$ \\
CS & Weighted average & $\max _{\lambda_{j}} \sum_{m} \frac{\phi_{m}}{I_{m}} C S_{m}\left(\lambda_{1}, \ldots, \lambda_{J}\right)$ \\
CS & Min & $\max _{\lambda_{j}} \min _{m} C S_{m}\left(\lambda_{1}, \ldots, \lambda_{J}\right)$ \\
CS & Range & $\min _{\lambda_{j}}\left(\max _{m} C S_{m}\left(\lambda_{1}, \ldots, \lambda_{J}\right)-\min _{m} C S_{m}\left(\lambda_{1}, \ldots, \lambda_{J}\right)\right)$ \\
\hline French profits & Simple average & $\max _{\lambda_{j}} \sum_{f} \Pi_{f}\left(\lambda_{1}, \ldots, \lambda_{J}\right)$ \\
French profits & Weighted average & $\max _{\lambda_{j}} \sum_{f} \frac{1}{s_{f}} \Pi_{f}\left(\lambda_{1}, \ldots, \lambda_{J}\right)$ \\
French profits & Min & $\max _{\lambda_{j}} \min _{f} \Pi_{f}\left(\lambda_{1}, \ldots, \lambda_{J}\right)$ \\
French profits & Range & $\min _{\lambda_{j}}\left(\max _{f} \Pi_{f}\left(\lambda_{1}, \ldots, \lambda_{J}\right)-\min _{f} \Pi_{f}\left(\lambda_{1}, \ldots, \lambda_{J}\right)\right)$ \\
\hline Pollutant & Simple average & $\min _{\lambda_{j}} \sum_{m} \phi_{m} \eta_{m}\left(\lambda_{1}, \ldots, \lambda_{J}\right)$. \\
Pollutant & Weighted average 1 & $\min _{\lambda_{j}} \sum_{m} \tilde{\eta}_{m}^{1} \eta_{m}\left(\lambda_{1}, \ldots, \lambda_{J}\right)$ \\
Pollutant & Weighted average 2 & $\min _{\lambda_{j}} \sum_{m} \tilde{\eta}_{m}^{2} \eta_{m}\left(\lambda_{1}, \ldots, \lambda_{J}\right)$ \\
Pollutant & Max & $\min _{\lambda_{j}} \max _{m} \eta_{m}\left(\lambda_{1}, \ldots, \lambda_{J}\right)$ \\
Pollutant & Range & $\min _{\lambda_{j}}\left(\max _{m} \eta_{m}\left(\lambda_{1}, \ldots, \lambda_{J}\right)-\min _{m} \eta_{m}\left(\lambda_{1}, \ldots, \lambda_{J}\right)\right)$ \\
\hline \%Diesel & Simple average & $\min _{\lambda_{j}} \sum_{m} \phi_{m} d_{m}\left(\lambda_{1}, \ldots, \lambda_{J}\right)$ \\
\%Diesel & Weighted average & $\min _{\lambda_{j}} \sum_{m} \phi_{m} \bar{d}_{m} d_{m}\left(\lambda_{1}, \ldots, \lambda_{J}\right)$ \\
\%Diesel & Max & $\min _{\lambda_{j}} \max _{m} d_{m}\left(\lambda_{1}, \ldots, \lambda_{J}\right)$ \\
\%Diesel & Range & $\min _{\lambda_{j}}\left(\max _{m} d_{m}\left(\lambda_{1}, \ldots, \lambda_{J}\right)-\min _{m} d_{m}\left(\lambda_{1}, \ldots, \lambda_{J}\right)\right)$ \\
\hline \hline
\end{tabular}

Note: "CS" stands for consumer surplus. The consumer surplus weights are inversely proportional to the income $I_{m}$. The profit weights are inversely proportional to the market share of the car manufacturer $s_{f}$. Emission weights $\tilde{\eta}_{m}^{1}$ are proportional to the average emissions in 2008 with the feebate. Emission weights $\tilde{\eta}_{m}^{2}$ are proportional to the average air emissions concentrations. Diesel weights are proportional to the share of diesel in 2008 with the feebate $\bar{d}_{m}$.

The computation of the parameters of each feebate scheme requires solving a system of 966 non-linear equations (964 car prices plus the two feebate parameters). I reduce the computation time by improving several aspects. First, I rely on relevant initial values for the feebate parameters. These initial values are the solutions to a simplified problem that assumes that car manufacturers do not modify their prices and entirely pass through the feebate to consumers. To solve this simplified problem, I also start from relevant initial values, which are the solutions obtained for the representative sample of 3,000 municipalities. Finally, instead of performing a non-linear optimization over the 966 parameters, I use a nested algorithm. I optimize over the two feebate parameters only while solving the optimal prices inside the objective function using an iterative algorithm. This approach improves the computation time relative to performing the optimization over the prices and feebate parameters. I solve for 128 feebate schemes between 89 and $216 \mathrm{~g} / \mathrm{km}$ with an increment of one $\mathrm{g} / \mathrm{km} .{ }^{17} \mathrm{I}$ check the robustness of the results to the use of a finer grid on the representative sample of 3,000 municipalities. The results are displayed in Table 32 below. I do not find systematically larger potential gains with the finer grid, which assures me that the grid used is not too coarse.

\footnotetext{
${ }^{17}$ For the second feebate class, the grid is $[105,214] \mathrm{g} / \mathrm{km}$ because I cannot find solutions for pivot points outside of this range.
} 
Table 32: Potential gains from the optimal linear feebates (in \% of the optimal outcomes) for the sample of 3,000 municipalities

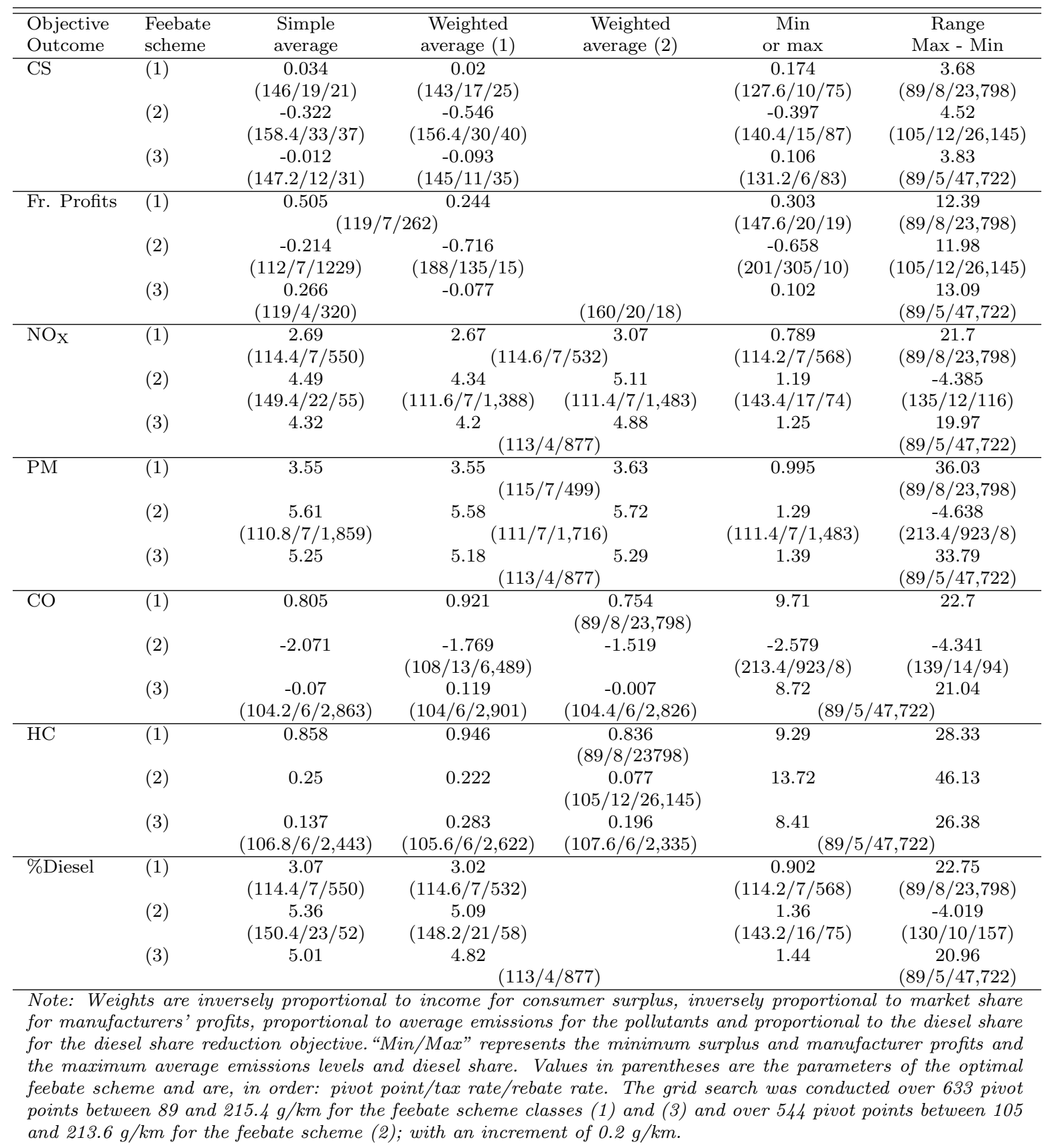

